University of Innsbruck

Working Papers in Economics and Statistics

The series is jointly edited and published by

- Department of Banking and Finance

- Department of Economics

- Department of Public Finance

- Department of Statistics

Contact address of the editor:

Faculty of Economics and Statistics

University of Innsbruck

Universitaetsstrasse 15

A-6020 Innsbruck

Austria

Tel: $\quad$ + 4351250796136

E-mail: Dean-EconStat@uibk.ac.at

The most recent version of all working papers can be downloaded at https://www.uibk.ac.at/fakultaeten/volkswirtschaft_und_statistik/forschung/wopec/

For a list of recent papers see the backpages of this paper. 


\title{
Economic Preferences and Personality Traits Among Finance Professionals and the General Population
}

\author{
Martin Holmén $^{\dagger} \quad$ Felix Holzmeister ${ }^{\ddagger}$ Michael Kirchler ${ }^{\S, \dagger}$ \\ Matthias Stefan $^{\S, *} \quad$ Erik Wengström ${ }^{\top}, \|$ \\ $\dagger$ University of Gothenburg, Department of Economics, Centre for Finance \\ ¥ University of Innsbruck, Department of Economics \\ $\S$ University of Innsbruck, Department of Banking and Finance \\ ฯ Lund University, Department of Economics \\ ॥ Hanken School of Economics, Department of Finance and Economics \\ *Corresponding author: matthias.stefan@uibk.ac.at
}

\begin{abstract}
Given their relevance for the financial well-being of many private investors and the economy as a whole, the behavior and personality traits of finance professionals have come under scrutiny. To better understand characteristics of the main protagonists of the finance industry, we run artefactual field experiments with finance professionals and a sample of the working population to investigate differences across industry-relevant economic preferences and personality traits. We report that finance professionals differ along several economic preferences and personality traits. However, we show that after adjusting for socio-economic characteristics many differences disappear and finance professionals only remain slightly more risk tolerant, less trustworthy, show a slightly increased level of psychopathy, and are more competitive than comparable participants. To shed light on the question why finance professionals differ from employees in other industries, we run an survey on experts with hiring experience to investigate whether they consider industry selection, self-selection, and imprinting by industry norms as explanatory for the observed subject pool differences. We find that experts conceive all three channels to be relevant, which is consistent with the assumption that the three channels are mutually correlated.
\end{abstract}

JEL: C93, G11, G41.

Keywords: Experimental finance, economic preferences, personality traits, finance professionals, general working population. 


\section{Introduction}

The finance industry is one of the biggest industries worldwide ${ }^{1}$ and bears systemic relevance and risk for the economy in general (Acharya et al., 2016). It is characterized by peculiar features: Financial products are typically complex (Brunnermeier and Oehmke, 2009; Inderst and Ottaviani, 2012a) and information asymmetries as well as conflicts of interest exist in financial markets (Cain et al., 2005; Inderst and Ottaviani, 2012b). This context makes room for severe problems, which can be aggravated by the fact that inferior decisions and advice by professionals are difficult to detect even ex post (Bluethgen et al., 2008) and, consequently, hard to monitor and prevent (Egan et al., 2019). In such an environment, the main protagonists-finance professionals - shape the finance industry with their personality traits and economic preferences, such as their altruism, risk-tolerance, honesty, and trustworthiness. These traits and preferences can be expected to determine professionals' behavior, which has direct consequences for both their clients and society as a whole. Thus, it is important to understand what kind of people work in the finance industry - even more so, given that the public perception has not been overall positive. As a consequence of the financial crisis of 2008 and subsequent scandals, such as the Libor manipulation, the public reputation of finance professionals took a nose dive. Many times the resulting public debate and negative press coverage have drawn an undifferentiated picture of finance professionals as being greedy and dishonest and substantially different from other occupational groups. ${ }^{2}$

In the scientific literature, most studies on finance professionals' behavior only focus on one particular behavioral bias or a single economic preference dimension, and they typically do not compare professionals' behavior to that of people from other industries or other groups in society. ${ }^{3}$ Moreover, many previous studies do not account for socio-economic background characteristics of finance professionals that could potentially explain part of the variation between finance professionals and other subject pools like students or the general population. With our study, we shed light on the economic preferences and personal characteristics of finance professionals by comparing a selection of industry-relevant economic preferences and personality traits between a

1 For instance, the share of the financial services industry of the gross domestic product in the United States was approximately 20\% in 2019 (Bureau of Economic Analysis, https://bit.ly/39c9rHW; retrieved November 25, 2020).

2 See, for instance, the mediocre ratings for the banking industry in the US during the last two decades: Gallup Business and Industry Ratings (2021). Moreover, following the financial crisis of 2008, the tone of press coverage became substantially more negative; see Picard et al. (2014). Since our study as been conducted in Sweden, it noteworthy that Sweden has also not been without scandals in the financial sector. For example, in 2020, one of the biggest banks, Swedbank, was found guilty and had to pay 4 billion SEK for money laundering in their Baltic subsidiaries. It was argued that the bank most likely suspected it but did not take appropriate actions (see Fulton et al., 2020, April 9, 2021). In 2010, one of the largest Swedish bank crashes ever happened when $H Q$ Bank was liquidated after it was found out that they were severely manipulating the values in the trading book in order to hide losses. (https://bit.ly/3r7G5SF, April 09, 2021).

3 To name but a few examples, see Glaser et al. (2005) and Pikulina et al. (2017) on overconfidence, Haigh and List (2005) on myopic loss aversion, Gilad and Kliger (2008) on risk priming, Kaustia et al. (2008) on anchoring, Cohn et al. (2014) on dishonesty, Kirchler et al. (2018) on social comparison, Holzmeister et al. (2020) on risk perception. For a recent overview of experiments with finance professionals, see Huber and König-Kersting (2022). 
sample of finance professionals and a randomly selected sample of the general working population (henceforth also referred to as "general population"). We contribute to the literature by providing a comprehensive picture of a multitude of characteristics to gain insights along which dimensions finance professionals differ from people employed in other industries.

In particular, we conducted a pre-registered artefactual field experiment, eliciting participants' risk preferences, distributional preferences, trustworthiness, dishonesty, and various personality traits. In total, 298 financial analysts ${ }^{4}$, investment advisors ${ }^{5}$, traders, fund-managers, and financial brokers, and 395 participants from a randomly selected sample of the Swedish working population - excluding finance professionals - participated in our study. Note that our sample of finance professionals is not representative for all people working in the finance industry, which would be an exceedingly heterogeneous group (Huber and König-Kersting, 2022). Rather, we deliberately chose the subset described above, as these people are at the core of financial decisionmaking or central for customers in the way they manage portfolios, provide analyses, and manage funds.

A multifaceted line of research has established that preference relations and personal traits tend to be systematically correlated with various demographic and socio-economic characteristics (see, e.g., Croson and Gneezy, 2009; Algan and Cahuc, 2010; Niederle and Vesterlund, 2011; Falk et al., 2018). Considering that the groups of finance professionals and the general working population are likely to differ systematically in socio-economic characteristics (e.g., due to self-selection into the industry or the selection of the industry itself), not adjusting for this potential source of heterogeneity may induce an omitted variable bias in estimating effects between subject pools: Differences in preferences and traits may be spuriously attributed to the variation in a subject pool indicator, although (part of) the variation may actually be due to systematic heterogeneity in socio-economic characteristics. By adjusting the differences between subject pools for the variability in potentially relevant socio-economic drivers (obtained from Statistiska centralbyrån ( $S C B$; Statistics Sweden), we can infer whether differences between the subject pools actually persist over and beyond the variation explained by participants' socio-economic background.

In order to examine preferences and personality traits that are relevant for financial decisionmaking, our experiment involved four incentivized tasks. In particular, we set up single choice lists (Eckel and Grossman, 2002) to assess participants' attitudes toward risk, losses, and skewness, and elicited distributional preferences (Kerschbamer, 2015), trustworthiness (Berg et al.,

\footnotetext{
4 "A financial analyst is responsible for a variety of research tasks in order to inform investment strategy and make investment decisions for their company or clients. This can include things like evaluating financial data, examining current events and market developments, examining an organization's financial statements, and creating financial models to predict future performance." Retrieved from CFA Institute, July 11, 2022

5 "Investment adviser means any person who, for compensation, engages in the business of advising others, either directly or through publications or writings, as to the value of securities or as to the advisability of investing in, purchasing, or selling securities, or who, for compensation and as part of a regular business, issues or promulgates analyses or reports concerning securities." Retrieved from Legal Information Institute, July 11, 2022.
} 
1995), and cheating behavior (Fischbacher and Föllmi-Heusi, 2013). In addition, we analyze individuals' personality traits, measured by means of the Big-5 personality test by Rammstedt and Oliver (2007), the Dark Triad inventory by Jonason and Webster (2010), and the sub-module of the Work and Family Orientation questionnaire focusing on competitiveness (Helmreich and Spence, 1978).

We find that the sample of finance professionals, as compared to participants from the general population, is significantly more risk tolerant, more selfish, less trustworthy, more competitive, and shows higher levels of narcissism, psychopathy, and Machiavellianism. These results suggest that finance professionals effectively differ from people employed in other industries - particularly in those characteristics that the general public is keen to pick up to sketch the dark side of the finance industry. This finding is in line with the assumption that the finance industry - in our case proxied by financial analysts, investment advisors, traders, fund-managers, and financial brokers - is indeed different to other industries. However, this argument leaves aside that finance professionals also differ from the general working population along several socio-economic dimensions.

A substantial part of the differences between finance professionals and the general population can actually be explained by the variation in participants' socio-economic characteristics. We observe that after adjusting the differences between subject pools for gender, age, income, and educational background, finance professionals tend to be only slightly more risk tolerant, remain less trustworthy, show a slightly increased level of psychopathy, and are still more competitive than comparable participants from other industries. While several differences entirely disappear when adjusting for socio-demographic characteristics, the effect sizes of those characteristics that remain statistically significant tend to be deflated. Thus, given the number of preferences and traits examined in our study, our results indicate that finance professionals and people employed in other industries with comparable socio-economic background are not that different after all.

Finally, we shed light on potential drivers (channels) of subject pool differences by running a preregistered expert survey. We recruited 205 experts from within the finance industry with hiring experience (i.e., human resource specialists and middle managers) to investigate whether they consider any of the three channels - industry selection, self-selection, or imprinting by industry norms - explanatory for behavioral patterns of the four experimental tasks showing significant subject pool differences (i.e., attitudes towards risk, trustworthiness, competitiveness, and psychopathy). We find that all three channels are considered to play at least some role for risk aversion, trustworthiness, and competitiveness. For psychopathy, only self-selection into the industry is perceived somewhat explanatory for subject pool differences. These findings indicate that experts do not conceive self-selection, industry-selection, and imprintment to be mutually exclusive concepts. The survey results are consistent with the assumption that the three channels are mutually correlated, presumably in a self-reinforcing manner. 


\section{Experimental Procedure}

We conducted an online experiment in Sweden in cooperation with Statistics Sweden $(S C B)$, who invited participants and provided a set of predefined variables from the registry for those participants who completed the experiment. The hard-copy invitations were distributed to a subset of highly skilled finance professionals $(F P)$ and a random sample of Sweden's general working population ( $G P$; excluding finance professionals). In particular, invitations were sent out to all (but only) finance professionals with $S C B$ 's job code classifications "2413" (financial analysts and advisers), "2414" (traders and fund managers), and "3311" (financial brokers). While the average age of both subject pools is almost identical $(F P=41.0, G P=41.2)$, the fraction of females $(F P=24.5 \%, G P=41.0 \%)$, the annual gross income (in Swedish Krona, SEK) $(F P=711,268, G P=396,878)$, and the fraction of participants without a university degree $(F P=8.1 \%, G P=28.1 \%)$ differ significantly $(p<0.001$ for all three comparisons $)$ between the two samples and reveal first industry-specific peculiarities of the finance sector. Further details and additional information on the recruitment, data collection, and experimental implementation are provided in Appendix A, where we report and discuss response rate analyses and self-selection effects. ${ }^{6}$

Once participants logged in to the software (programmed in oTree; Chen et al., 2016) using a personal identifier, they were presented with a detailed outline of the experiment and could continue once they provided informed consent. The experiment consisted of four parts which were presented to each participant in random order. The tasks on attitudes towards risk, losses, and skewness, the distributional preferences elicitation, the trust game, and the cheating task were incentiviced, as is common practice in experimental economics. The surveys on personality traits (i.e., the Big-5 and Dark Triad inventories, as well as the subscale of the Work and Family Orientation questionnaire on competitiveness) were unincentivized, as, again, is standard in the literature. At the end of the experiment, one of the incentivized measures was randomly selected for payout. Details of the experimental tasks, treatment variations, and payments are described in Section 3. For completing the online experiment, participants received a participation fee of 100 Swedish Krona (SEK). ${ }^{7}$ The experimental data was collected between January 7 and February 24, 2019. In total, 298 finance professionals and 395 people from the general population, working in other sectors, completed the experiment. The experiment was conducted in Swedish and

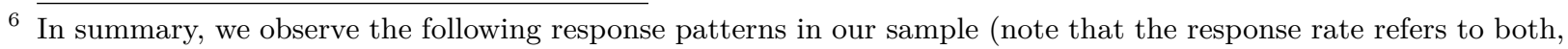
the experiment reported in this paper as well as the accompanying experiment reported in Holzmeister et al. (2022) and Stefan et al. (2022)): For the finance professionals sample, the response rate analysis shows that men responded to a greater extent than women, and that finance individuals in the age group 45-59 years responded to a slightly lesser extent than other ages. For the general population group, the response rate analysis shows similar patterns regarding gender and age. We further observe a difference between the three job codes within the finance professionals sample, where the response frequency was slightly lower (5\%) in the group of traders and portfolio managers (job code "2414") compared with analysts and advisers (code "2413") and brokers (code "3311") (6.4\%).

7 At the time of the experiment, the exchange rate between USD and SEK was about 1:9; the exchange rate between EUR and SEK was about 1:10.5. 
took on average 15 minutes to complete. The average payment to participants was 211.13 SEK $(\mathrm{sd}=51.92)$, which was approximately $\$ 23.50$ by the time the experiment ended. ${ }^{8}$ To ensure full privacy of the data collected during the experiment, payouts were handled by the third party survey firm Enkätfabriken.

In addition to the data collected in the online experiment, we obtained register data from $S C B$ for each participant who completed the experiment. In the analysis of the experimental results, we use part of the registry data as adjustment variables, in particular, participants' gender (binary indicator for female), age (in years), net income from major employment in 2017 (in thousand SEK's), and maximum education level (dichotomous indicators for high school education or less, university education smaller or equal to three years, and university education larger than three years). ${ }^{9}$

A detailed summary of participants demographics compared to the characteristics of the sample invited is presented in Table A1 in Appendix A. In particular, Table A1 reports the number of respondents and non-respondents per category of several socio-demographic characteristics, separated for both samples, as reported by $S C B$. Moreover, we report $\chi^{2}$-tests comparing whether participants in our samples differ significantly from those who have been invited by $S C B$ but did not participate in the experiment. We report self-selection effects into the experiment in terms of gender, age, country of birth, income, and education for the general population sample, and self-selection effects with respect to gender, age, and education for the finance professionals sample.

\section{Experiments and Results}

We address each of the five parts in our experiment separately. In particular, each subsection briefly motivates our research agenda, provides a concise description of the experimental implementation, relates our contribution to the previous literature, and discusses the main findings related to the particular part of our study. Each of the subsections is accompanied by a separate annex (see Appendices B-E), providing additional details on the experimental design and the definition of measures, descriptive results, as well as supporting and ancillary analyses.

The figures in the main text show the coefficient estimates of the dummy variable indicating the finance professionals subject pool in the corresponding regression models (which are presented in the accompanying tables in the appendices).

8 Extrapolating this number, the average hourly payout for the participants amounts to approximately $\$ 94$ at the time of the experiment. This amount is comparable to other studies with finance professionals (e.g., Haigh and List, 2005; Kirchler et al., 2018) and general population samples (e.g., Andersson et al., 2016).

9 Please note that we use only part of the available registry data. The main reasons is that for some of the registry data provided by $S C B$ we face substantial restrictions that are discussed in Appendix A. See Appendix A for further details on the register data. 
For the sake of interpretability, we report standardized effect sizes whenever suitable. We follow the Open Science Collaboration (2015) and Camerer et al. (2018) and determine standardized correlation coefficients $\left(r_{s}\right)$ and $95 \%$ confidence intervals (CIs) for key effects relevant to our research questions - in particular, the effects attributable to differences between the two subject pools. ${ }^{10}$ Standardized correlation coefficients allow us to provide a unified measure of the magnitude of an effect, which is independent of the scaling of the dependent variable and the statistical method used to determine the effect. As a rule of thumb, we follow the guidelines proposed by Cohen (1992) and refer to correlation coefficients with thresholds of 0.1, 0.3, and 0.5 as being indicative of small, medium, and large effects, respectively.

In an exploratory analysis, we present correlations between the different preferences and personality traits for the two subject pools in Table G1 in Appendix G. In general, we find qualitatively homogeneous correlational patterns within both samples. An additional exploratory analysis examines whether the various preferences and characteristics differ systematically between the three different job functions from which finance professionals were sampled; the results are tabulated and discussed in Appendix F.

\subsection{Attitudes towards Risk, Loss, and Skewness}

Since risk taking is at the core of financial decision-making (Nosić and Weber, 2010; Weber et al., 2013), the question whether finance professionals differ in their risk preferences from other populations arises naturally. The qualification for the finance profession might require a certain attitude towards risk, and the individual risk appetite might change with specific training and day-to-day experience in making risky decisions. Despite the regular exposure to risky decision environments, there is some evidence of higher myopic loss aversion (Haigh and List, 2005) and a more intuitive risky decision-making process (Gilad and Kliger, 2008) among finance professionals as compared to student participants. Moreover, existing evidence indicates that professionals' behavior can be explained by prospect theory (Gurevich et al., 2009; Abdellaoui et al., 2013), and that professionals - similar to laypeople - perceive risk as the likelihood of incurring losses rather than symmetric deviations from the expected return (Holzmeister et al., 2020). Since a mere focus on "risk-as-variance" might fall short of contributing to a better understanding of finance professionals" behavior in "risky" decision environments, we address attitudes towards a broad spectrum of characteristics that are intimately related to the concept of risk. We ask the following research question: Is there a difference in tolerance towards volatility, skewness, and losses between finance professionals and people from the general working population?

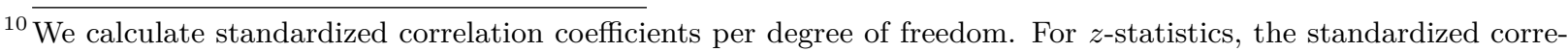
lation coefficient $r_{s}$ is given by $r_{s}=\tanh \left(z \cdot(n-3)^{-0.5}\right)$; for $t(d f)$-statistics, $r_{s}=\left(t^{2} \cdot\left(t^{2}+d f\right)^{-1}\right)^{0.5}$ is applied. The $95 \%$ confidence intervals around $r_{s}$ are determined by $r_{s} \pm \tan \left(\arctan ^{-1}\left(r_{s}\right)-\Phi^{-1}(0.975) \cdot(n-3)^{-0.5}\right)$, where $\Phi^{-1}(\cdot)$ denotes the inverse cumulative standard normal distribution function.
} 
Method. To answer this research question, we implemented a series of four single choice lists, based on Eckel and Grossman (2002). In particular, we varied the lotteries' prospective payoffs in such a way, that a single characteristic of the gambles was systematically varied while holding the other characteristics constant. In each of these four tasks, participants were presented with a menu of six lotteries, and were asked to indicate which of the prospects they prefer. In all four tasks, the lotteries were decreasing in their risk-adjusted expected return. To assess participants' attitudes towards risk, skewness, and losses, we varied two characteristics of the gambles - the skewness of lottery outcomes and the possibility to incur losses - using a factorial design.

Table 1: Parametrization of the four tasks used to elicit participants' attitudes towards risk, losses, and skewness. $S_{i}$ and $L_{i}$ are indicator functions for skewness and losses, respectively; e.g., $S_{1} L_{0}$ indicates the task with skewed lottery outcomes in the gain domain. $x_{1}, x_{2}$, and $x_{3}$ indicate the potential lottery outcomes in SEK. $E V, S D$, and $S K$ denote the lotteries' expected value, standard deviation, and skewness, respectively.

Task $S_{0} L_{0}$

\begin{tabular}{|c|c|c|c|c|}
\hline$x_{1}$ & $x_{2}$ & & & \\
\hline $50 \%$ & $50 \%$ & $E V$ & $S D$ & $S K$ \\
\hline 96.0 & 96.0 & 96.0 & 0.0 & \\
\hline 80.0 & 128.0 & 104.0 & 24.0 & 0.0 \\
\hline 64.0 & 160.0 & 112.0 & 48.0 & 0.0 \\
\hline 48.0 & 192.0 & 120.0 & 72.0 & 0.0 \\
\hline 32.0 & 224.0 & 128.0 & 96.0 & 0.0 \\
\hline 16.0 & 240.0 & 128.0 & 112.0 & 0.0 \\
\hline
\end{tabular}

Task $S_{0} L_{1}$

\begin{tabular}{|c|c|c|c|c|}
\hline$x_{1}$ & $x_{2}$ & & & \\
\hline $50 \%$ & $50 \%$ & $E V$ & $S D$ & $S K$ \\
\hline 16.0 & 16.0 & 16.0 & 0.0 & \\
\hline 0.0 & 48.0 & 24.0 & 24.0 & 0.0 \\
\hline-16.0 & 80.0 & 32.0 & 48.0 & 0.0 \\
\hline-32.0 & 112.0 & 40.0 & 72.0 & 0.0 \\
\hline-48.0 & 144.0 & 48.0 & 96.0 & 0.0 \\
\hline-64.0 & 160.0 & 48.0 & 112.0 & 0.0 \\
\hline
\end{tabular}

Task $S_{1} L_{0}$

\begin{tabular}{|c|c|c|c|c|c|}
\hline$x_{1}$ & $x_{2}$ & $x_{3}$ & & & \\
\hline $50 \%$ & $49 \%$ & $1 \%$ & $E V$ & $S D$ & $S K$ \\
\hline 96.0 & 96.0 & 96.0 & 96.0 & 0.0 & \\
\hline 82.1 & 123.9 & 223.0 & 104.0 & 24.0 & 1.1 \\
\hline 68.2 & 151.8 & 350.1 & 112.0 & 48.0 & 1.1 \\
\hline 54.2 & 179.8 & 477.1 & 120.0 & 72.0 & 1.1 \\
\hline 40.3 & 207.7 & 604.2 & 128.0 & 96.0 & 1.1 \\
\hline 26.4 & 220.4 & 684.0 & 128.0 & 111.5 & 1.1 \\
\hline
\end{tabular}

Task $S_{1} L_{1}$

\begin{tabular}{|c|c|c|c|c|c|}
\hline$x_{1}$ & $x_{2}$ & $x_{3}$ & & & \\
\hline $50 \%$ & $49 \%$ & $1 \%$ & $E V$ & $S D$ & $S K$ \\
\hline 16.0 & 16.0 & 16.0 & 16.0 & 0.0 & \\
\hline 2.1 & 43.9 & 143.0 & 24.0 & 24.0 & 1.1 \\
\hline-11.8 & 71.8 & 270.1 & 32.0 & 48.0 & 1.1 \\
\hline-25.8 & 99.8 & 397.1 & 40.0 & 72.0 & 1.1 \\
\hline-39.7 & 127.7 & 524.2 & 48.0 & 96.0 & 1.1 \\
\hline-53.6 & 140.4 & 604.0 & 48.0 & 111.5 & 1.1 \\
\hline
\end{tabular}

For the sake of denotation, we introduce the indicator functions $S_{i}$ and $L_{i}$ for skewness and losses, respectively. The parametrization of the four tasks is shown in Table 1 . While the lottery outcomes in the tasks $S_{0} L_{*}$ were symmetric, the outcomes were positively skewed in the tasks $S_{1} L_{*}$ (without altering their standard deviation). In the tasks $S_{*} L_{0}$, the minimum outcome was strictly positive, whereas a constant was subtracted from all payoffs in the tasks $S_{*} L_{1}$ (i.e., the prospects' standard deviation and skewness were unaffected). While a participant's lottery choice in $S_{0} L_{0}$, which only involves symmetric gambles in the non-negative domain, serves as a proxy of the decision-maker's risk tolerance, the other preference types are characterized by the difference in the lottery choices between tasks. For instance, $S_{0} L_{1}-S_{0} L_{0}$ captures the difference in choice behavior between the tasks $S_{0} L_{1}$ and $S_{0} L_{0}$ which is attributable to loss tolerance; 
likewise, $S_{1} L_{0}-S 0_{L} 0$ accounts for the difference in choice behavior attributable to attitudes towards skewness. ${ }^{11}$ Further details regarding the implementation, as well as descriptive and supplementary results are provided in Appendix B.

Results. Panel (a) of Figure 1 depicts the cumulative distributions of choices attributed to risk, skewness, and loss tolerance, separated for finance professionals $(F P)$ and the general population $(G P)$, respectively. While we report that finance professionals, on average, are significantly more risk tolerant than participants from the general population, we do not find evidence of systematic differences between the two samples with respect to attitudes towards skewness or losses (see the test statistics of Kolmogorov-Smirnov (KS) tests in panel (a) of Figure 1).

Turning to panels (b) and (c) of Figure 1, these effects can be examined in more detail: Panel (b) shows the differences in the average lottery choices between finance professionals and the general population sample for each of the four tasks eliciting attitudes towards risk, skewness, and losses. The coefficients represent the dichotomous variable indicating differences between the finance professionals subject pool and the general population estimated using ordinary least squares regressions summarized in Table B2 in Appendix B.

We find that the coefficient estimates of the dummy variable indicating the finance professionals sample turns out being significantly positive in each of the four tasks, in both models not including and models including adjustment variables. While the significant coefficient for task $S_{0} L_{0}$ immediately points towards a systematic difference in risk preferences (in the absence of skewness and losses), the coefficients for the tasks $S_{0} L_{1}, S_{1} L_{0}$, and $S_{1} L_{1}$ only indicate that finance professionals, on average, are also systematically more willing to take risk in decision environments that involve skewed payouts and/or potential losses.

To isolate differences in choice behavior attributable to skewness and loss tolerance between the subject pools, we illustrate the effect of the subject pool indicator variable on the differences in risky choices between tasks in panel (c) (see also the full regression results in panel (b) in Table B2 in Appendix B). In contrast to contributions by Haigh and List (2005) and Abdellaoui et al. (2013), we do not find evidence for systematic differences in participants' loss tolerance between subject pools, neither in decision environments without skewed outcomes $\left(S_{0} L_{1}-S_{0} L_{0}\right)$ nor in decision environments with skewed outcomes $\left(S_{1} L_{1}-S_{1} L_{0}\right) \cdot{ }^{12}$ Likewise, we do not find

\footnotetext{
${ }^{11}$ While our focus is on attitudes towards risk, skewness, and losses, the symmetric $2 \times 2$ variation across tasks also allows to assess attitudes towards skewness in a mixed domain (including losses) or towards losses given skewed gambles, respectively. However, we will only discuss these two types of attitudes parenthetically.

${ }^{12}$ Note that the discrepancy between our results and the findings reported by Haigh and List (2005) and Abdellaoui et al. (2013) could be due to various reasons. For instance, the results could be specific to the samples (Haigh and List (2005) recruited $n=54$ "professional futures and options pit traders from the Chicago Board of Trade;" Abdellaoui et al. (2013) recruited $n=46$ private bankers and fund managers from the US and Lebanon) and/or specific to the experimental design (Abdellaoui et al. (2013) used a bisection method where subjects had to select one of two presented prospects varying in the payouts and the probabilities; Haigh and List (2005) adopted the investment task of Gneezy and Potters (1997).
} 
(a)
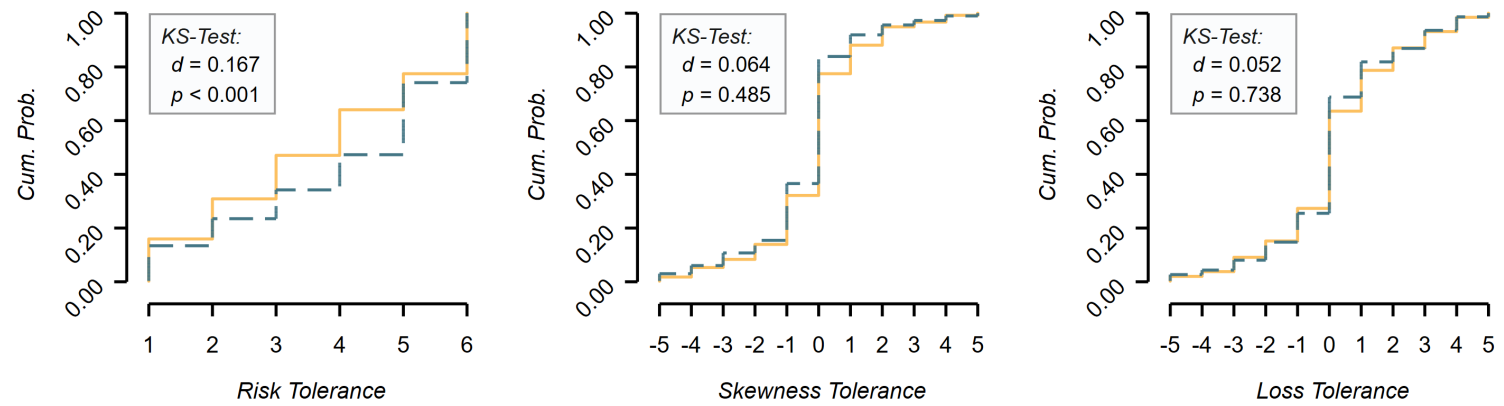

General Population $\quad-\quad$ - Finance Professionals

(b)

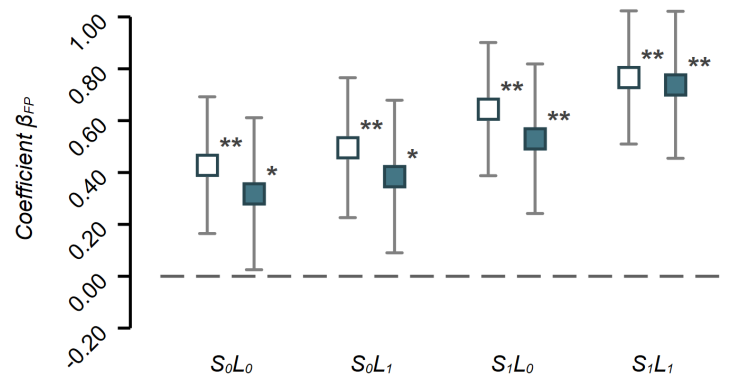

(c)

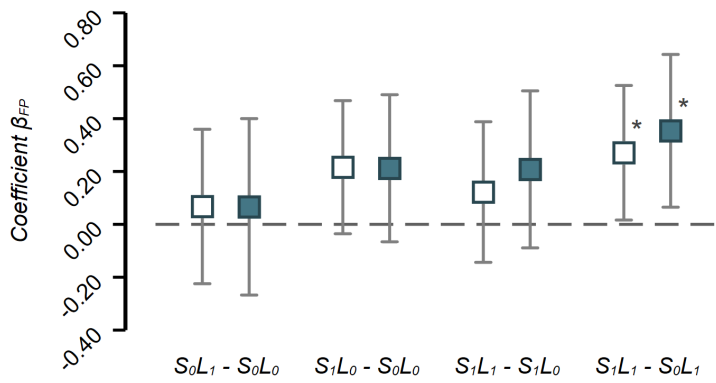

w/o Adjustments

w/ Adjustments

Figure 1: (a) Cumulative distributions of risk tolerance $\left(S_{0} L_{0}\right)$, skewness tolerance $\left(S_{1} L_{0}-S_{0} L_{0}\right)$, and loss tolerance $\left(S_{0} L_{1}-S_{0} L_{0}\right)$, separated for the general population and the finance professionals sample. Kolmogorov-Smirnov $(K S)$ tests are reported in boxes. $n_{G P}=395, n_{F P}=298$. (b) Coefficient plots for the dichotomous variable indicating the finance professionals subject pool in ordinary least squares regressions for each of the four tasks eliciting attitudes towards risk, skewness, and losses. $S_{i}$ and $L_{i}$ are indicator functions for skewness and losses, respectively; e.g., $S_{1} L_{0}$ indicates the task with skewed lottery outcomes in the gain domain. (c) Differences between coefficient estimates per task, i.e., estimates isolating the effects of attitudes towards losses and towards skewness, respectively. $S_{0} L_{1}-S_{0} L_{0}$, for instance, denotes the difference in choice behavior attributable to loss tolerance (in lotteries without skewed outcomes). Hollow markers in panels (b) and (c) show estimates from models without adjustments $(n=693)$; solid markers show estimates from models with adjustment variables $(n=688)$. Error bars indicate $95 \%$ confidence intervals based on robust standard errors. The regression estimates are summarized in Table B2 in Appendix B. ${ }^{*} p<0.05,{ }^{* *} p<0.005$.

evidence for differences in skewness tolerance between subject pools if the lottery payoffs are non-negative $\left(S_{1} L_{0}-S_{0} L_{0}\right)$. If the decision situation involves the possibility to incur losses, however, our data suggests that finance professionals are more skewness tolerant than laypeople, but the effect size is small $\left(r_{s}=0.079,95 \% \mathrm{CI}=[0.005,0.155]\right)$.

Thus, we can conclude that finance professionals, on average, tend to be systematically less risk averse. While the difference in risk-taking behavior between finance professionals and laypeople is in line with results reported in the literature (see, e.g., Kirchler et al., 2018, 2020; Stefan et al., 2022), it should be noted that the magnitude of the effect is rather small in our sample $\left(r_{s}=0.120,95 \% \mathrm{CI}=[0.046,0.198]\right)$. 


\subsection{Distributional Preferences}

For a long time, economic theory has assumed that economic decisions are only determined by the decision-maker's self-interest. The study of "social preferences" has become a focal point for a modified view on economic decision-making (see, e.g., Becker, 1974; Rabin, 1993). With regards to the finance industry, there seems to be a common perception of finance professionals being closer to the conceptualization of fully rational and selfish decision-makers. Yet, this view is not always supported by existing evidence on behavioral biases, for instance with regards to overconfidence (Deaves et al., 2010; Pikulina et al., 2017), anchoring (Kaustia et al., 2008), or framing (Roszkowski and Snelbecker, 1990). Moreover, existing experimental evidence suggests that distributional preferences are heterogeneous for various groups within a society (see, e.g., Fisman et al., 2015, 2017), and that economics students value efficiency more than equality compared to students in other fields and non-academics (Fehr et al., 2006). Since finance professionals have been trained in economic thinking, these findings might suggest that they are likely to differ from the rest of society in terms of distributional preferences. Furthermore, since finance professionals frequently act as "money doctors" (Gennaioli et al., 2015) —involving decisions about other people's money — distributional preferences can be of utmost importance. For instance, conflicts of interest in financial advise might be mediated by benevolent preferences towards the client, or rather be aggravated by purely selfish preferences (see, e.g., Angelova and Regner, 2013). Thus, we address the following yet unexplored research question: Is there a difference in distributional preferences between finance professionals and people from the general population?

Method. We elicit distributional preferences using the Equality Equivalence Test (EET) introduced by Kerschbamer (2015). The EET consists of two lists with five binary choices each-one in the domain of disadvantageous inequality ( $x$-list) and one in the domain of advantageous inequality ( $y$-list). In both lists, each outcome of the five binary choices specifies a payoff for both the decision-maker and a randomly matched counterpart, and participants are asked to indicate whether they prefer option "Left" or option "Right." For all items in both lists, option "Right" implies an equal payoff distribution, yielding 100 SEK for both participants. Outcomes associated with the option "Left" in the $x$-list increase from 60 SEK to 140 SEK (in steps of 20 SEK) for the decision-maker, whereas the matched counterpart receives a payment of 160 SEK (disadvantageous inequality). The five prospectus outcomes for the decision-maker in the $y$-list increase from 60 SEK to 140 SEK, but the counterpart receives a payment of 40 SEK instead (advantageous inequality). Based on a participant's switching points in the menu of binary choices in the two lists, the EET assigns one of nine archetypes of distributional preferences and a two-dimensional index of preference intensity, measured as the decision-makers' willingness-to-pay in case the second player is ahead or behind, respectively. The parametrization used in the experiment is summarized in Table 2. 
Table 2: Parametrization of the Equality Equivalence Test (EET). The table shows the monetary payoffs (in SEK) for the "active" player ( $m$, for "me") and the "inactive" player ( $o$, for "other") for the two choices "Left" and "Right," for both the $x$-list (disadvantageous inequality) and the $y$-list (advantageous inequality).

\begin{tabular}{|c|c|c|c|c|}
\hline \multicolumn{2}{|c|}{ "Left" } & & \multicolumn{2}{|c|}{ "Right" } \\
\hline$m$ & $o$ & & $m$ & $o$ \\
\hline 60 & 160 & 00 & 100 & 100 \\
\hline 80 & 160 & 00 & 100 & 100 \\
\hline 100 & 160 & 00 & 100 & 100 \\
\hline 120 & 160 & 00 & 100 & 100 \\
\hline 140 & 160 & $\circ \bigcirc$ & 100 & 100 \\
\hline
\end{tabular}

\begin{tabular}{|c|c|c|c|c|}
\hline \multicolumn{2}{|c|}{ "Left" } & & \multicolumn{2}{|c|}{ "Right" } \\
\hline$m$ & $o$ & & $m$ & $o$ \\
\hline 60 & 40 & 00 & 100 & 100 \\
\hline 80 & 40 & 00 & 100 & 100 \\
\hline 100 & 40 & 00 & 100 & 100 \\
\hline 120 & 40 & 00 & 100 & 100 \\
\hline 140 & 40 & 00 & 100 & 100 \\
\hline
\end{tabular}

Results. Panel (a) of Figure 2 shows the fractions of distributional preference types based on the EET, separated for the general population and the finance professionals sample. We find that the share of participants whose behavior can be characterized as selfish is higher among finance professionals as compared to the general population $\left(F P=36.6 \%, G P=26.8 \% ; r_{s}=0.104\right.$, $95 \% \mathrm{CI}=[0.030,0.181] ; p=0.006)$, and that the proportion of inequality averse types is lower among finance professionals $\left(F P=10.1 \%, G P=17.5 \% ; r_{s}=0.105,95 \% \mathrm{CI}=[0.030,0.182]\right.$; $p=0.006)$. We do not find evidence for systematic differences in the share of maximin $(F P=$ $\left.30.9 \%, G P=27.6 \% ; r_{s}=0.036,95 \% \mathrm{CI}=[-0.039,0.111] ; p=0.347\right)$ and purely altruistic types $\left(F P=15.4 \%, G P=13.2 \% ; r_{s}=0.032,95 \% \mathrm{CI}=[-0.042,0.107] ; p=0.396\right)$ between the two subject pools. With regards to more "exotic" archetypes, the shares of participants exhibiting equality aversion $\left(F P=2.0 \%, G P=5.1 \% ; r_{s}=0.079,95 \% \mathrm{CI}=[0.005,0.155] ; p=0.036\right)$ and kick-down preferences $\left(F P=0.7 \%, G P=2.8 \% ; r_{s}=0.077,95 \% \mathrm{CI}=[0.003,0.153] ; p=0.042\right)$ tend to be higher among the general population.

Above and beyond the delineation of distributional preference types, the EET allows characterizing the observed choice behavior in terms of participants' willingness-to-pay for an increase or decrease of the counterpart's material payoff in the domain of disadvantageous $\left(w t p^{d}\right)$ and advantageous inequality $\left(w t p^{a}\right)$, respectively. As such, $w t p^{d}\left(w t p^{a}\right)$ can be interpreted as the monetary amount a decision-maker is willing to give up in order to increase (if $w t p>0$ ) or decrease (if $w t p<0$ ) the other player's payoff by one unit in the domain of disadvantageous (advantageous) inequality.

Panel (b) of Figure 2 shows the coefficient estimates for the dichotomous variable indicating finance professionals in interval regressions for participants' willingness-to-pay in the domain of disadvantageous and advantageous inequality (as reported in Table C2 in Appendix C). With regards to the domain of advantageous inequality, we find that both subject pools tend to be benevolent towards their counterpart when they are ahead in terms of material payoffs. We do not find evidence for differences in participants' willingness-to-pay $\left(w t p^{a}\right)$ between subject 
(a)

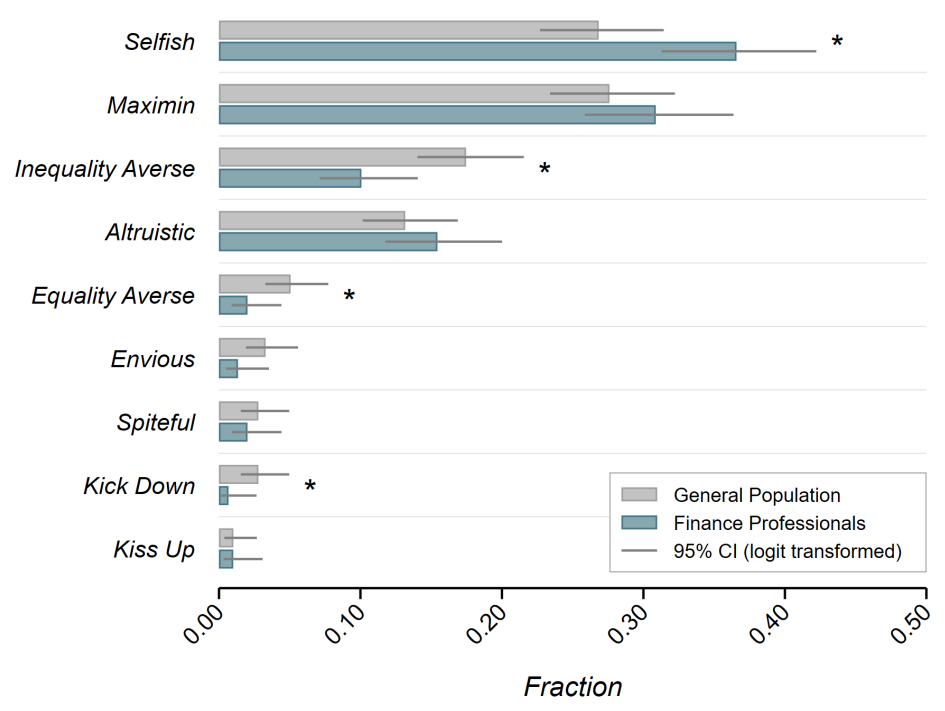

(b)

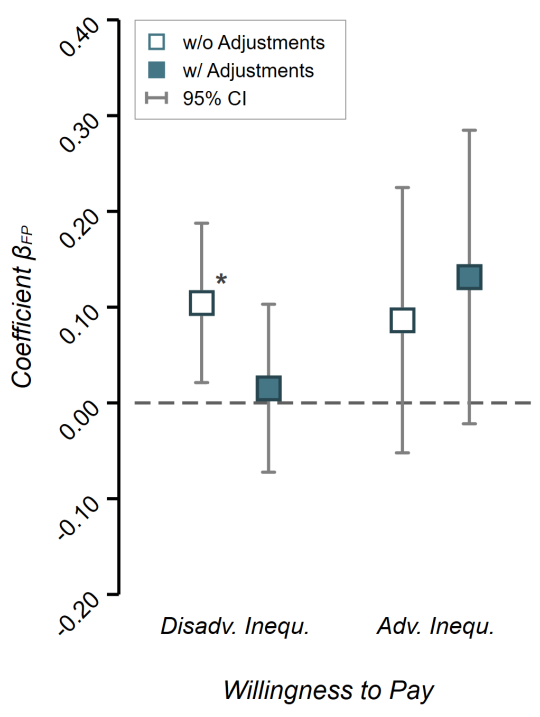

Figure 2: (a) Fractions of distributional preference archetypes based on the Equality Equivalence Test (EET). Error bars indicate logit-transformed 95\% confidence intervals; significance indicators are based on two-sample tests of proportion. $n_{G P}=395, n_{F P}=298$. (b) Coefficient plots for the dichotomous variable indicating the finance professionals subject pool in interval regressions for participants' willingness-topay in the domain of disadvantageous and advantageous inequality, respectively. Hollow markers show estimates from models without adjustments $(n=693)$; solid markers show estimates from models with adjustment variables $(n=688)$. Error bars indicate $95 \%$ confidence intervals based on robust standard errors. The regression estimates are provided in Table C2 in Appendix C. ${ }^{*} p<0.05,{ }^{* *} p<0.005$.

pools in this domain of inequality. Turning to participants' willingness-to-pay in the domain of disadvantageous inequality we find that finance professionals tend to have a slightly higher willingness-to-pay $\left(w t p^{d}\right)$ when they are behind in terms of material payoffs as compared to participants from the general population. This mirrors our earlier finding that financial professionals are less inclined to be inequality averse compared to participants from the general population. However, the magnitude of the effect is small $\left(r_{s}=0.093,95 \% \mathrm{CI}=[0.019,0.170] ; p=0.014\right)$ and the difference between subject pools vanishes if the model takes into account the heterogeneity in socio-demographic variables. ${ }^{13}$

\subsection{Trust and Trustworthiness}

Large sectors of the financial industry build on the foundation of trust (Zingales, 2015). For instance, financial advisory services call for clients' trust in the consultant (Gurun et al., 2018; Burke and Hung, 2019) — not least due to information asymmetries, implying that clients cannot even assess the quality of the advice provided (Dulleck and Kerschbamer, 2006; Balafoutas and Kerschbamer, 2020). Moreover, stock market participation has been shown to be conditional on

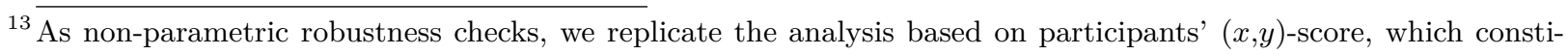
tutes an ordinal measure of distributional preferences and their intensities, using ordered logistic regressions (see panel (b) in Table C2 in Appendix C). It is reassuring that our results are qualitatively robust to the non-parametric measure. 
individuals' trust in the finance sector (Guiso et al., 2008; Balloch et al., 2015; Georgarakos and Pasisi, 2015). While survey evidence indicates at best moderate levels of trust in the financial sector (Sapienza and Zingales, 2012; Holzmeister et al., 2022), we lack further evidence on prevalent trust in finance professionals, and whether the extent to which finance professionals are trusted is actually "justified." Particularly little is known about the latter, i.e., finance professionals' trustworthiness. ${ }^{14}$ A recent study by Gill et al. (2020) provides long-term causal evidence on lower levels of trustworthiness among college students who self-select into pursuing a career in the finance industry. These findings raise serious questions about the trustworthiness of finance professionals compared to the general population, thereby leading to the following research question: Is there a difference in trustworthiness between finance professionals and people from the general population?

Method. To examine trust and trustworthiness, we implement a standard investment game (Berg et al., 1995), ${ }^{15}$ where participants are assigned to the roles of either the trustor (first mover) or the trustee (second mover). Trustors are endowed with 100 SEK and can forward between 0 SEK and 100 SEK (in steps of 20 SEK) to the trustee, who receives three times the distributed amount. The trustee then decides how much of the tripled amount to return to the first mover (in steps of $20 \mathrm{SEK}$ ). We interpret the first-mover's behavior as indicating trust (in the trustee) and the second-mover's behavior as indicating trustworthiness (Brülhart and Usunier, 2012).

In our setting, finance professionals always were assigned the role of the trustee, whereas participants from the general population were assigned one of the two roles at random: With a probability of two-thirds, they were the first mover, and with a probability of one-third they were the second mover. To examine whether trust differs depending on whether the trustee is a participant from the general population or a finance professional, we assign first movers randomly into both conditions and tell them whether the matched player is a finance professional or a person from the general population. Since the matching of trustors and trustees was only implemented once all participants have finished the experiment, the second movers were required to decide strategically, i.e., they had to report how much they would return to the first mover conditional on each potentially received amount. We opted for the strategy method because the experiment was conducted online, not allowing for direct interaction between both roles. In case the trust game was chosen for payout, the payments for both roles were determined based on the

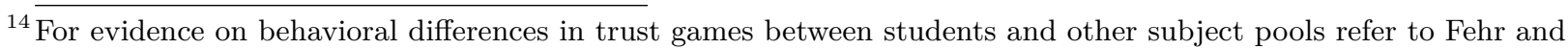
List (e.g., 2004) and Johnson and Mislin (2011).

${ }^{15}$ There has been a discussion of limitations of this investment game as a measure of trust. In particular, confounds, such as altruism (Cox, 2015) and betrayal aversion (Fehr, 2009), might dilute the observed behavior in trust games, while at the same time other aspects of trusting behavior might be neglected (Ben-Ner and Halldorsson, 2010; Ermisch et al., 2009). Since the investment game, arguably, remains the most popular experimental procedure to measure trust among researchers (Johnson and Mislin, 2011), we stick to this standard experiment, while we note cautiousness when it comes to interpreting the observed behavior. 
decision of the second mover, which was conditioned on the decision of the randomly matched first mover.

Results. On average, participants from the general population acting as first movers entrust $69.3 \%(s d=30.0 \% ; n=105)$ of their endowment to trustees from the general population and $66.2 \%(s d=31.1 \% ; n=200)$ to trustees from the finance professionals sample. The difference in the amounts sent to the second mover is not statistically significant between the two treatments (two-sample $t$-test: $\left.t(303)=0.846, p=0.3980 ; r_{s}=0.049,95 \% \mathrm{CI}=[-0.064,0.163]\right) .{ }^{16}$

With regards to the second movers' behavior, we find that finance professionals, on average, tend to be less trustworthy than participants from the general population, as they return systematically less at all amounts sent by the first mover (see panel (a) in Figure 3). In ordinary least squares regressions of the amount returned by trustee for each amount sent by the first mover, we show that the coefficient for the dichotomous variable indicating finance professionals turns out to be significantly negative, even after adjusting for the variation in socio-economic variables (see panel (b) in Figure 3 and the detailed regression results in Table D2 in Appendix D).

(a)

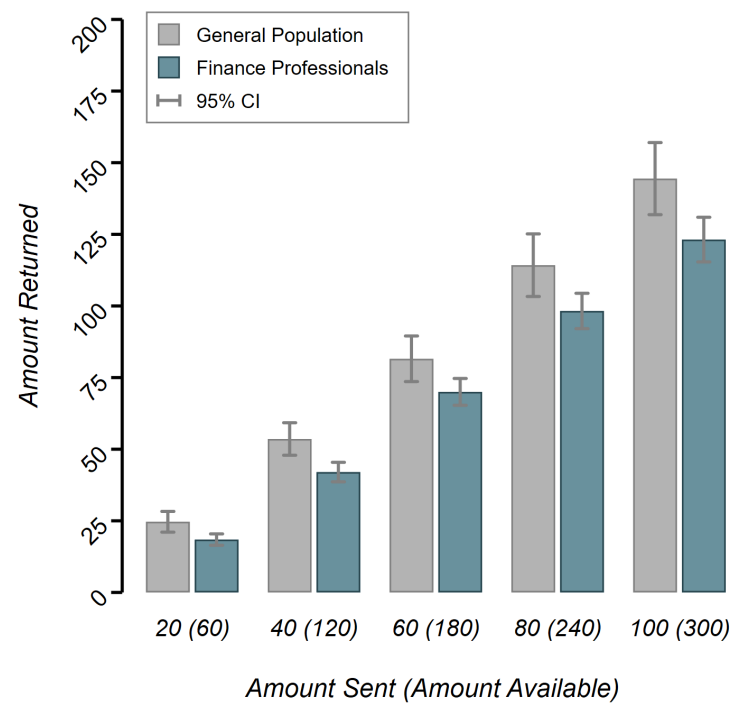

(b)

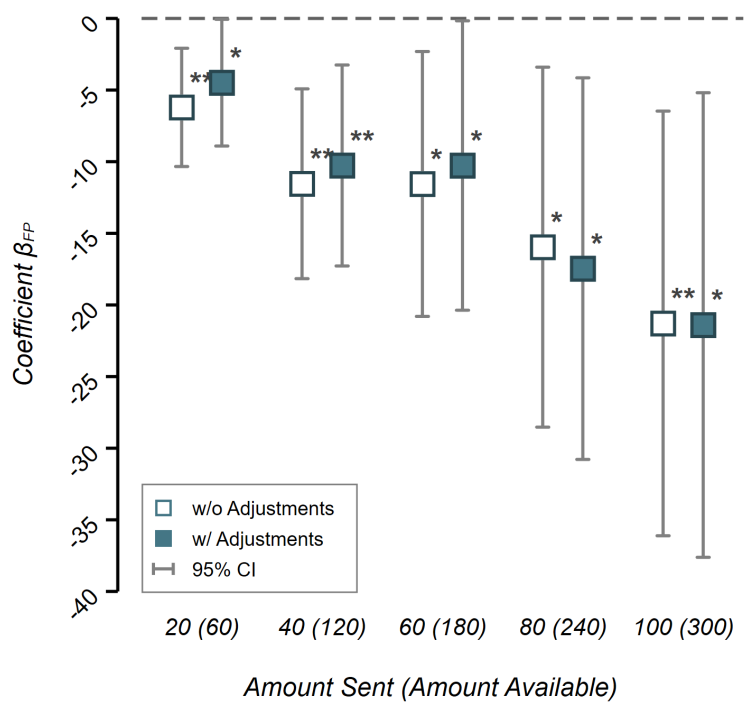

Figure 3: (a) Mean amount returned by second movers in the (strategy method) trust game conditional on each possible amount sent by the first mover, separated for the general population and finance professionals samples. (b) Coefficient plots for the dichotomous variable indicating the finance professionals subject pool in interval regressions for the amount returned by second movers in the trust game for each amount sent by the first mover (the tripled amount available is indicated in parentheses). Hollow markers show estimates from models without adjustments $(n=388)$; solid markers show estimates from models with adjustment variables $(n=387)$. Error bars indicate $95 \%$ confidence intervals based on robust standard errors. The estimates from the regressions are provided in Table D2 in Appendix D. ${ }^{*} p<0.05,{ }^{* *} p<0.005$.

Thus, our results suggest that finance professional reciprocate trust (measured by the amount sent to them by the first mover) systematically less than participants from the general pop-

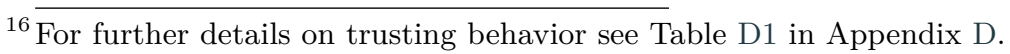


ulation. Importantly, this result prevails in comparable magnitude even when controlling for socio-economic background variables. This finding is in line with the results by Gill et al. (2020) and resonates with perceived mistrust towards protagonists of the financial industry that is regularly encountered (Sapienza and Zingales, 2012).

\subsection{Dishonesty behavior}

The question whether finance professionals tend to behave dishonestly has been widely studied and discussed, arguably not least due to a prevalent perception of misconduct among bank employees (Cohn et al., 2014; Zingales, 2015; Egan et al., 2019; Rahwan et al., 2019; Huber and Huber, 2020). In particular, the finding by Cohn et al. (2014) that finance professionals are more dishonest than others when being experimentally primed with their professional identity gained widespread attention. These results suggest that the culture prevailing in the banking industry leads to more dishonest behavior. More recently, these findings have been questioned (Rahwan et al., 2019), which has led to a discussion revolving around questions concerning the replicability and the method of priming (see, e.g., Vranka and Houdek, 2015; Cohn et al., 2019a). We add to this discussion by asking the following research question: Do finance professionals show a higher or lower tendency to exhibit dishonest behavior compared to people from the general population?

Method. To address this question, we experimentally examine dishonest behavior based on a design similar to Fischbacher and Föllmi-Heusi (2013): Participants throw three simulated dice (see, e.g., Kocher et al., 2018, for an application of the procedure using computer-simulated dice rolls) and report the sum of the observed pips (i.e., between 3 and 18). The participants' payoff is the sum of reported pips, multiplied by a factor of 10 SEK. Thus, participants have a financial incentive to report a higher number of pips than the actual number realized by the three dice. Since the actual outcome of the simulated die rolls is known to the experimenters, the task allows determining a measure of misreporting on the individual level.

Results. We find that $90.6 \%$ of the general population and $94.6 \%$ of the finance professionals sample report the realized number of pips truthfully. Only $5.5 \%(G P)$ and $3.7 \%(F P)$ over-report the number of pips, respectively, whereas comparably small fractions of participants under-report the actual number of pips ( $3.8 \%$ of $G P$ and $1.7 \%$ of $F P$ ). The general population sample, on average, reports 0.144 more pips than shown (one-sample $t$-test: $t(394)=1.785, p=0.075$; $\left.r_{s}=0.090,95 \% \mathrm{CI}=[-0.009,0.191]\right)$; finance professionals, on average, over-report by 0.104 pips (one-sample $t$-test: $t(297)=1.584, p=0.114 ; r_{s}=0.092,95 \% \mathrm{CI}=[-0.022,0.2091]$ ). Given that participants' reports do not significantly differ from the actual number of pips in 
both samples, it does not come at a surprise that the difference in misreporting between the two subject pools does not significantly differ from zero (independent samples $t$-test: $t(691)=0.369$, $\left.p=0.712 ; r_{s}=0.014,95 \% \mathrm{CI}=[-0.061,0.089]\right)$.

In general, we find only very little cheating - among both the general population and the finance professionals sample - in our experiment. While there are several results reported in the literature that indicate preferences for truth-telling or costs of dishonesty (see, e.g., Abeler et al., 2014, 2019), the virtual absence of dishonest behavior in our experiment appears to be striking. While we cannot provide a conclusive explanation for the absence of dishonest behavior, two potential reasons come to mind: First, there is evidence that potential observability of dishonest behavior can lead to less dishonest reporting (Abeler et al., 2019). However, we apply a similar procedure (using computer-simulated dice rolls) as, e.g., Kocher et al. (2018). Second, usually we expect participants of online surveys to provide truthful answers, so that a norm of honesty might prevail. Third, the modus operandi-i.e., the distribution of invitations by $S C B$ as the official statistical office and participants' awareness that register data provided by $S C B$ will be matched with the experimental data - might have influenced the overall level of dishonest behavior. More important for our research agenda is that we do not find differences in individual preferences for honesty between finance professionals and the general population in our experiment. However, if the experimental procedure influences the overall level of dishonesty, potential difference between subject pools might have become less salient. ${ }^{17}$

\subsection{Personality Traits}

As personal characteristics are an elusive concept, we confine our research on personality traits that are typically in focus of public debates: (i) socially undesirable characteristics (i.e., the "Dark Triad," measuring narcissism, psychopathy, and Machiavellianism), (ii) competitiveness, and (iii) the habitual patterns of personality traits (Zillig et al., 2002) as a whole (i.e., the Big-5: openness, conscientiousness, extraversion, agreeableness, and neuroticism). Despite the public interest in the question whether finance professionals differ systematically from people employed in other fields, only few scientific studies address certain aspects of personality characteristics of practitioners in finance. For instance, in two papers Kirchler et al. (2018) and Kirchler et al. (2020) report higher levels of competitiveness among finance professionals compared to students, academics, and the general population, but lower levels compared to professional athletes. The trait of psychopathy is particularly relevant for financial decision-making, since it explains misbehavior in taking risk on behalf of others (Jones, 2014) and gambling with money of someone

\footnotetext{
${ }^{17}$ Please note that we do not directly compare our findings to those reported in Cohn et al. (2014). The reason is that we do not examine the finance business culture and we can only provide little additional insight for this discussion, as our primary focus is on the comparison of individuals working in the finance industry and the general population. Thus, we have a different research question and a different methodological approach than Cohn et al. (2014).
} 
else (Jones, 2013). Furthermore, there is evidence on correlations between low neuroticism and high openness (as Big-5 personality traits) and risk taking (Lauriola and Levin, 2001) in general. Brown and Taylor (2014) report on the correlation between extraversion and openness and the levels of debt and assets held and Bucciol and Zarri (2017) show that agreeableness is negatively associated with stock holdings (see Bucciol and Zarri, 2017, for further evidence on the impact of personality traits beyond the Big-5). ${ }^{18}$

Thus, if personality traits of finance professionals systematically differ from the rest of the population, this might well have an influence on decisions made within the finance industry, in particular on behalf of clients. We therefore ask the following research question: Is there a difference in personality traits (i.e., Big-5, Dark Triad, and competitiveness) between finance professionals and people from the general population?

Method. We elicit the Big-5 personality traits (openness, conscientiousness, extraversion, agreeableness, and neuroticism) using the validated 10-item inventory introduced by Rammstedt and Oliver (2007). Moreover, we elicit the socially undesirable personality traits of narcissism, psychopathy, and Machiavellianism using the 12-item Dark Triad inventory by Jonason and Webster (2010). Finally, we run a 5-item questionnaire on competitiveness, based on the sub-module of the Work and Family Life Orientation (WOFO) questionnaire by Helmreich and Spence (1978). The scores for each trait are $z$-standardized across the pooled sample, implying a mean of zero and standard deviation of one for all measures of personality characteristics.

Results. Figure 4 summarizes the differences in the various personality characteristics between participants from the general population and the finance professionals sample (based on the results of ordinary least squares regressions of the various personality traits on a variable indicating the finance professionals sample, as well as the full models including adjustments for participants' socio-economic characteristics reported in Table E4 in Appendix E). As illustrated in panel (a) of Figure 4, we find that finance professionals tend to score higher on all three socially undesirable traits captured by the Dark Triad inventory: narcissism $\left(r_{s}=0.091\right.$, $95 \% \mathrm{CI}=[0.017,0.167])$, Machiavellianism $\left(r_{s}=0.106,95 \% \mathrm{CI}=[0.032,0.183]\right)$, and psychopathy $\left(r_{s}=0.182,95 \% \mathrm{CI}=[0.109,0.264]\right)$. Importantly, once we adjust the differences between the two subject pools for the variation in socio-economic characteristics, the effect sizes are attenuated: While the effects in narcissism and Machiavellianism scores are virtually set to zero, the difference in psychopathy is reduced by a third, but remains significant $\left(r_{s}=0.122\right.$, $95 \% \mathrm{CI}=[0.048,0.200])$.

\footnotetext{
${ }^{18}$ For similar findings on stock market participation using the Temperament and Character Inventory TCI instead of the Big-5 questionnaire, refer to Conlin et al. (2015).
} 
(a)

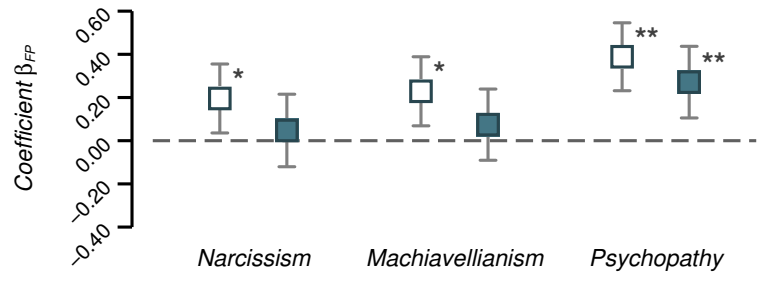

(c) (b)

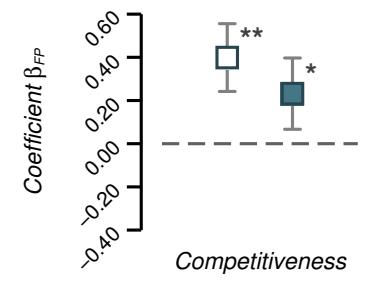

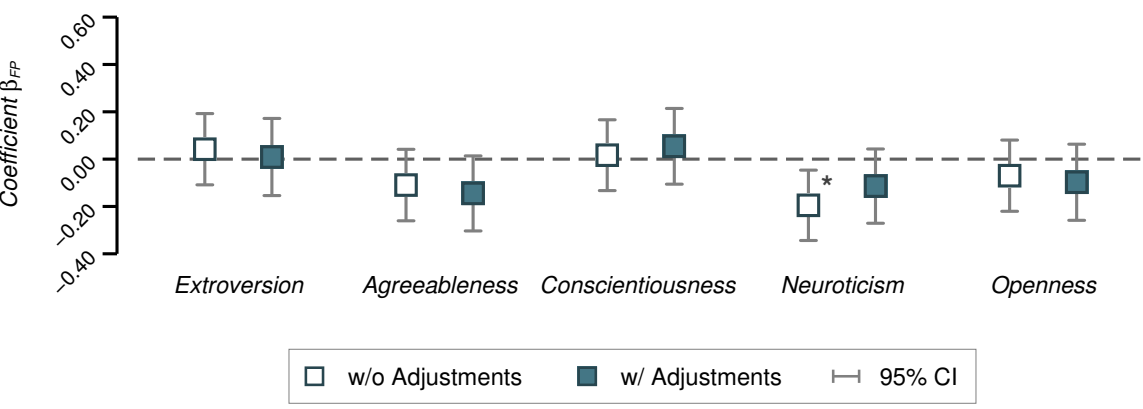

Figure 4: Coefficient plots for the personality traits elicited using (a) the Dark Triad inventory, (b) the competitiveness items from the Work and Family Orientation questionnaire (WOFO), and (c) the Big-5 inventory. All panels depict estimates for the dichotomous variable indicating the finance professionals subject pool in ordinary least squares regressions. Hollow markers show estimates from models without adjustment variables $(n=693)$; solid markers show estimates from models with adjustments $(n=688)$. Error bars indicate $95 \%$ confidence intervals based on robust standard errors. The estimates from the regressions are provided in Table E4 in Appendix E. * $p<0.05,{ }^{* *} p<0.005$.

As outlined in panel (b) of Figure 4, we find that finance professionals, on average, tend to be significantly more competitive than participants from the general population. While this effect is in line with previous findings (Kirchler et al., 2018, 2020), the magnitude of the effect is rather small $\left(r_{s}=0.187,95 \% \mathrm{CI}=[0.115,0.270]\right)$ in our sample, and nearly halved $\left(r_{s}=\right.$ $0.105,95 \% \mathrm{CI}=[0.031,0.182]$ ) by significant effects of gender, age, and income (see Table E4 in Appendix E for details).

Finally, as illustrated in panel (c) of Figure 4, we do not find evidence on systematic differences between subject pools in terms of personality traits addressed by the Big-5 personality test. The only exception is a difference in neuroticism scores, which is of small magnitude $\left(r_{s}=0.098\right.$, $95 \% \mathrm{CI}=[0.023,0.174])$ and only to be found in the model not adjusting for socio-economic characteristics. Once we control for participants' socio-economic background, the significant difference between subject pools is deflated.

Based on the analyses sketched above, we conclude that there is evidence for some differences between the two subject pools in our experiment. These differences are particularly pronounced before adding adjustment variables, pointing at sample characteristics of finance professionals. After adjusting for the socio-economic background, we report that finance professionals tend to 
score higher on the psychopathy scale - a personality trait associated with untruthfulness, selfishness, and being callous (see, e.g., Paulhus and Williams, 2002) - and tend to self-report being more competitive than participants from the general population. These results on competitiveness and psychopathy might emphasize the relevance of the question of a banking culture, as discussed above, and are consistent with a higher propensity of selfish behavior among professionals that we find in our experiment (see Section 3.2).

\section{Self-Selection, Industry Selection, or Imprintment?}

So far, we have shown that, without adjusting for participants' socio-economic characteristics, finance professionals are more risk-taking, more selfish, less inequality averse, show lower levels of trustworthiness and exhibit higher levels of narcissism, machiavellianism, psychopathy, and competitiveness. However, when controlling for differences in socio-economic adjustments, we find that most differences vanish and that the prevailing findings on risk-taking, trustworthiness, psychopathy, and competitiveness show lower effect sizes. For the remaining differences, however, the question about their origin arises. Can the differences between subject pools be explained by self-selection of professionals with certain characteristics into the industry, selection by the finance industry, and/or imprintment of industry norms (i.e., the assimilation to industry-specific norms and its specific culture)?

To shed light on this question, we apply the following approach: First, we run additional analyses investigating the role of demographic variables, in particular gender and age, on behavioral differences across subject pools. Second, we run a survey, eliciting experts' interpretation of our experimental findings. With this survey we analyze whether experts consider any of the three channels - industry selection, self-selection, or imprinting - explanatory for the experimentally observed subject pool differences. Finally, we discuss implications derived from the experimental findings and the survey responses of the experts in this section.

\subsection{Moderating Effects of Socio-Demographics}

To begin with, we analyze the role of demographic variables on behavioral differences between the two subject pools. We only consider age and gender as they are exogenous, whereas income and education are supposedly endogenous. In particular, we conduct ordinary least squares regressions of the particular trait on an indicator variable for the finance professionals subject pool $(F P)$ and the socio-economic adjustment variables (gender, age, income, and education), extended by the interaction term $F P \times$ age and $F P \times$ gender. Up front we would like to note that the analyses below are post-hoc and, accordingly, they should be interpreted with caution. In 
addition, analyzing interaction effects sacrifices statistical power; thus, significant results might be exaggerated and insignificant results should be interpreted with even greater care.

The results of our analysis treating age as a moderator (left panels in Figure 5) show that the interaction effect $F P \times$ age tends to narrow the difference between subject pools for all four characteristics. Yet, only the effect for competitiveness turns out being statistically significant: the effect of age on competitiveness differs between subject pools, as particularly young finance professionals are significantly more competitive than their non-finance counterparts.

Identifying why the gap narrows with age is difficult as the finding can be driven by self-selection in (and out) of the industry, selection by the industry itself, or imprinting of industry norms. Using age as a proxy implies that people are exposed to industry norms for many years, which could be an indirect measure of imprintment of industry norms. However, it can also be the case that the prevailing culture in the finance industry has changed over time. In addition, age could also indirectly measure that professionals with different personality traits and preferences entered the industry decades ago - potentially because of different industry norms or different prerequisites from the industry. Therefore, we are cautious in the interpretation of the role of age for preferences and personality traits.

Second, the finance industry is well-known for its imbalance in terms of gender (Adams and Kirchmaier, 2016; Niessen-Ruenzi and Ruenzi, 2019). If differences between subjects pools observed in the experiment should be due to (industry or self-) selection effects, one would expect these differences to be larger for males than for females. As can be seen in the right panels of Figure 5, the interaction effect $F P \times$ gender indeed tends to amplify the main effect (i.e., subject pool difference) for all four characteristics, although none of the coefficient estimates reaches statistical significance.

As for the analyses of the moderating effects of age, we are cautious in interpreting the moderating effects of gender. Gender can be considered as a coarse proxy for potential selection effects, either in terms of industry selection or self-selection into the industry. However, industry norms could - and probably will - interact with (industry and self-) selection, as purely male dominated industry norms and a low fraction of female professionals might be unattractive for females to enter the industry. Therefore, in this analysis we cannot cleanly separate the roles of the different channels of selection into the industry or industry norms.

\subsection{Expert Survey}

Procedure. To circumvent the identification problems outlined in the previous sub-section, we implemented a survey eliciting experts' interpretation of our experimental findings (pre-registered at https://osf.io/5akcp). We obtained contact details of a pre-selected sample of experts from 
a. Attitude towards risk

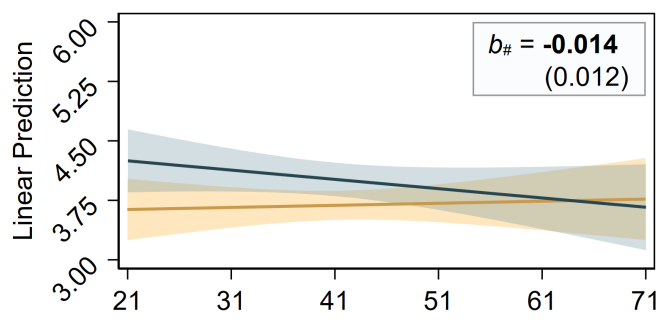

b. Trustworthiness

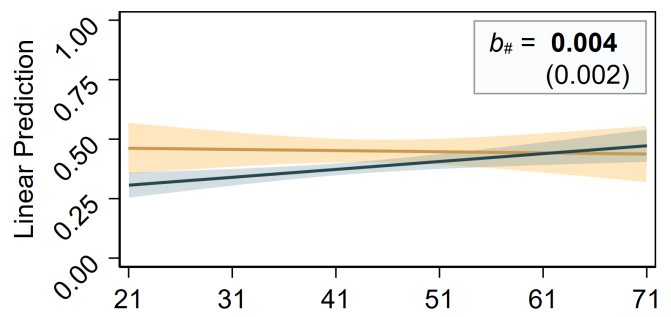

c. Competitiveness

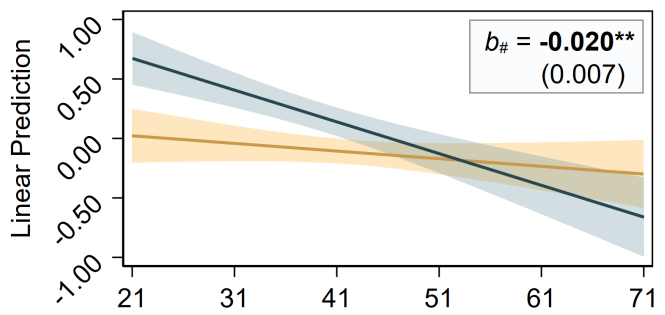

d. Psychopathy

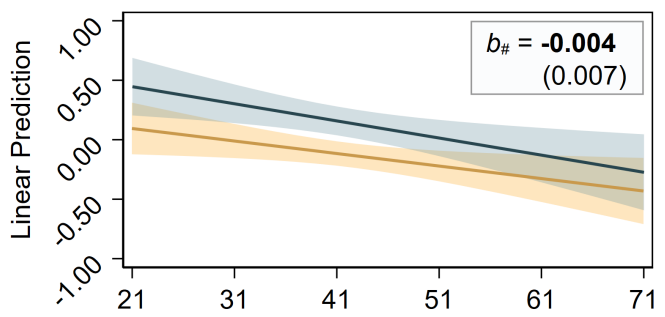

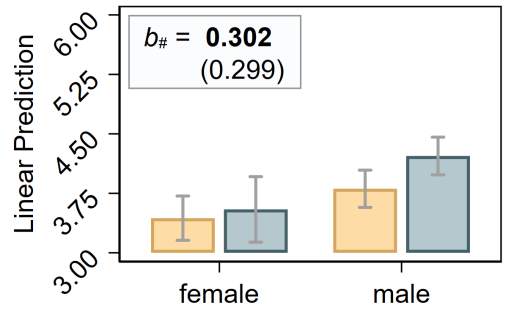
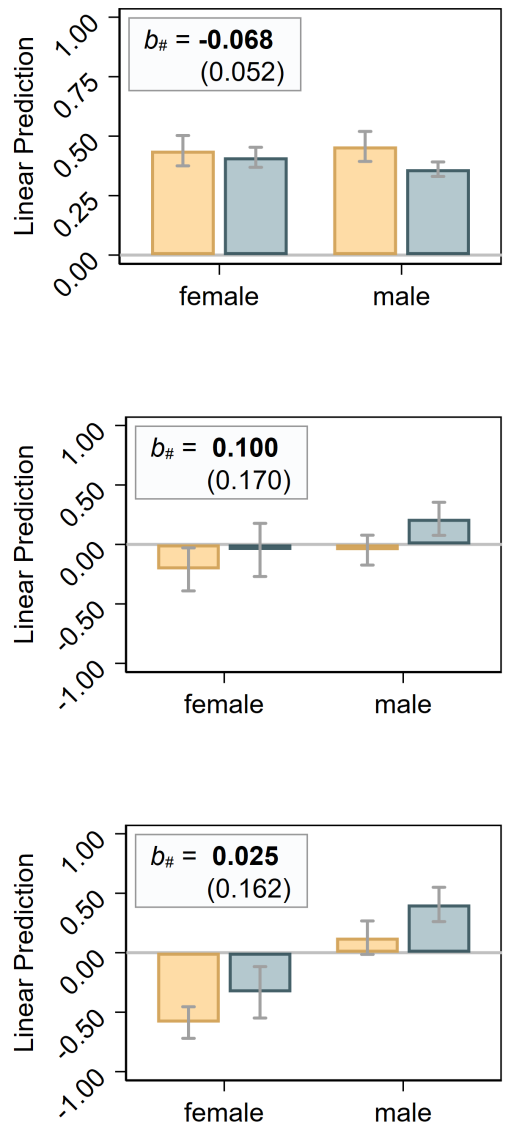

\section{- General Population _ _ Finance Professionals}

Figure 5: The figure plots linear predictions (and 95\% confidence intervals) for (a) attitudes towards risk, (b) trustworthiness, (c) competitiveness, and (d) psychopathy conditional on age (left panels) and gender (right panels), separated for finance professionals and the general population sample. Risk aversion enters in levels, competitiveness and psychopathy are standardized scores; trustworthiness enters as the average amount returned in percent across the five decisions in the strategy-method trust game (i.e., trustworthiness is percent-scaled). The predicted margins are based on ordinary least squares regressions of the particular trait on an indicator variable for the finance professionals subject pool $(F P)$ and the socio-economic adjustment variables (gender, age, income, and education), extended by the interaction term $F P$ $\times$ age (left panels) and $F P \times$ gender (right panels). $b_{\#}$ reported in the top of each panel presents the estimate of the interaction effect (with the corresponding standard error in parentheses). ${ }^{*} p<0.05,{ }^{* *} p<0.005 ; n=688$ in all regression models. 
within the finance industry from Statistic Sweden $(S C B)$. We targeted human resources specialists (job code "2423") and middle managers with personnel responsibility (job code "1612") within the financial services (industry code "64") and insurance industry (industry code "66"), respectively. In total, we contacted a random sample of 580 human resources specialists and 1,200 middle managers out of a total of 3,141 individuals that would have qualified as eligible participants. The contact details of this sample (postal addresses) obtained from $S C B$ were forwarded to the third-party survey company Enkätfabriken, who generated and merged participant identifiers and login codes with the contact details for each participant and sent out the questionnaire during May 2022. As per the a priori power calculations, we aimed for 199 completes. Following our pre-registered stopping rule, we closed the survey after having reached this number of participants, leaving us with 205 complete observations. For completing the online survey, one out of ten participants was randomly chosen and received SEK 990 for participation (provided as a gift card) via Enkätfabriken.

In the survey, participants were presented, in random order, with a description of the four tasks for which differences between financial professionals and the general population have been found after adjusting the effect for the variation in socioeconomic variables (i.e., attitudes towards risk, trustworthiness, competitiveness, and psychopathy). For each of these tasks, participants were provided with a short description of the findings with regards to differences between financial professionals and participants from other industries. ${ }^{19}$ The survey was approved by the Internal Review Board at the University of Innsbruck.

For each of the four presented results, survey respondents were asked to indicate to what extent each of three potential explanations would likely account for the differences observed in the experiment. The three explanations (channels) were the following: (i) industry selection ("Hiring decisions in the finance industry favor applicants with these characteristics."); (ii) self-selection ("People with these characteristics choose to work in the finance industry."); and (iii) imprinting ("The prevailing norms and culture in the financial industry over time influences the employees so that these characteristics become more common."). For each of the three items (i.e., channels), subjects had to state to what degree the statements were correct using the following Likert scale: 1 ("Completely incorrect"); 2 ("Incorrect"); 3 ("Somewhat incorrect"); 4 ("Somewhat correct"); 5 ("Correct"); 6 ("Completely correct"). The order of the three items was randomized on the participant level to counter potential order effects (but remained constant for each participant to avoid confusion among respondents). For screenshots of the survey, see the pre-registration

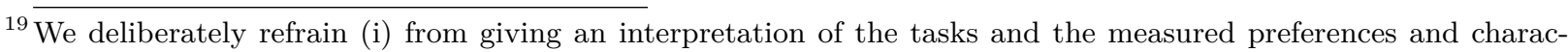
teristics (e.g., we did not use the word "psychopathy"), since the use of these terms may differ between everyday language and scientific use-cases; and (ii) from providing statistical details, in particular effect sizes, since survey participants might lack the statistical skills to correctly interpret them. Moreover, participants might vary in statistical skills so that we could not have ensured consistent interpretation of statistical information across survey respondents. For these reasons, we provided a qualitative statement of differences and described them as systematic, a term we explicitly explained in the introduction to the survey.
} 
at https://osf.io/ykv7e/

The goal of the expert survey is twofold: First, the survey responses allow analyzing whether or not experts with experience in hiring decisions in the finance industries consider any of the three channels (i.e., industry selection, self-selection, or imprinting) explanatory for the observed subject pool difference for each of the four tasks. Second, the survey allows to infer whether one particular channel is considered relatively more/less explanatory as compared to other channels for each of the four tasks.

Results. The mean survey responses, separated by the three channels, for the characteristics (i) attitudes towards risk, (ii) trustworthiness, (iii) competitiveness, and (iv) psychopathy are illustrated in Figure 6. All tests based on the expert survey, as far as not otherwise indicated, have been pre-registered at https://osf.io/5akcp.

In a first step, we examine whether or not experts consider any of the three channels explanatory for the observed differences between finance professionals and the general population sample. We do so, separately for each characteristic $\times$ channel-combination, by testing whether the mean level of agreement exceeds 3 ("somewhat incorrect") in a one-sided one-sample $t$-test, i.e., whether experts perceive a particular channel at least somewhat explanatory for the observed difference between subject pools in a particular task. Note that the statements were phrased as positive conjectures (e.g., "hiring decisions [..] favor applicants with these characteristics"). Choice options 3 ("somewhat incorrect") and 4 ("somewhat correct") divide the 6-point scale into domains of agreement and disagreement. Thus, we interpret any choice exceeding 3 ("somewhat correct") on the scale to be indicative that a particular channel is at least somewhat explanatory for the differences observed in the main experiment. As reported in Figure 6, all three channels are perceived to play at least some role for the observed differences between subject pools for risk aversion, trustworthiness, and competitiveness. For psychopathy, only self-selection is perceived somewhat explanatory, but not the industry-related channels of industry selection and imprintment.

In a second step, we investigate whether, for each of the four characteristics, any particular channel is considered relatively more or relatively less explanatory compared to other channels. For each task, we test whether responses differ systematically in pairwise comparisons of channels using (two-sided) paired-sample $t$-tests. The results are reported in Figure $6 .{ }^{20}$ For risk aversion and trustworthiness, the three pairwise comparisons between channels are significant at an $\alpha=0.5 \%$ level; for competitiveness, only the difference between self-selection and imprintment turns out to be significant $(p<0.05)$, but the practical relevance is likely negligible. Notably,

${ }^{20}$ Following our pre-analysis plan, we only test for differences in the relevance of channels if both channels (involved in a particular pairwise comparison) turn out to be statistically significant in the first analysis, i.e., if the means are significantly larger than 3 ("somewhat incorrect"). 
respondents' average agreement is highest for self-selection into the industry for all four characteristics; imprintment ranks second and industry-selection third in a horse race (except for competitiveness for which mean responses are approximately at par).

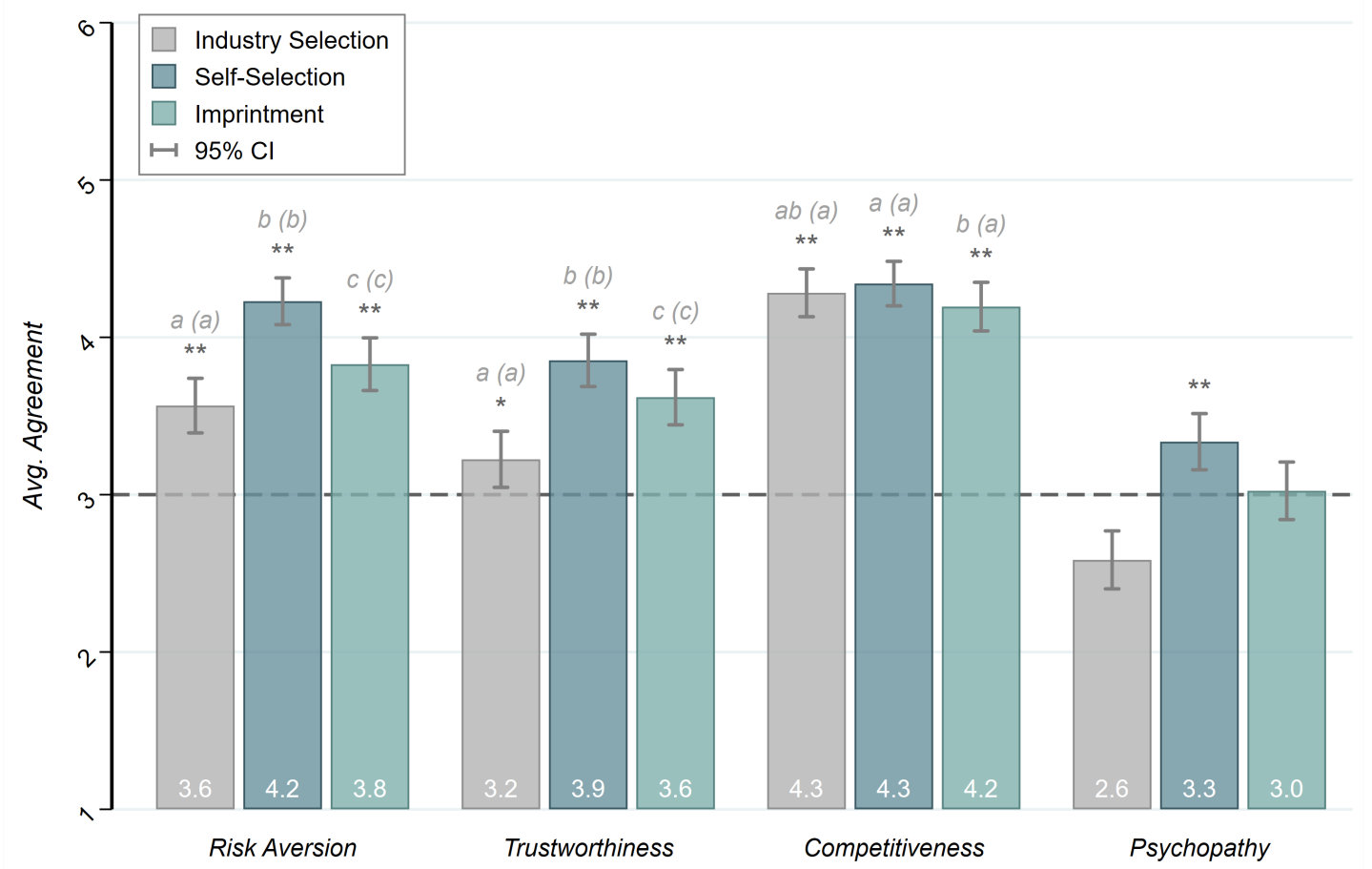

Figure 6: Average survey responses per channel (self-selection, industry selection, and imprintment) for (i) attitudes towards risk, (ii) trustworthiness, (iii) competitiveness, and (iv) psychopathy. Survey questions were answered on a scale from 1 to 6 . Error bars indicate $95 \%$ confidence intervals. Asterisks indicate statistical significance in one-tailed one-sample $t$-tests for $\mu_{0}=3$ per channel per preference/trait type; ${ }^{*} p<0.05$, ** $p<0.005 ; n=205$ in each test. Letters and letters in parentheses indicate significance groupings for pairwise comparisons between channels (that are statistically significantly larger than $\mu_{0}=3$ in the one-sided tests) based on two-tailed paired-sample $t$-tests for $p<0.05$ and $p<0.005$, respectively $(n=205$ in each test). That is, channels (per preference/trait type) with a common letter in the significance group label do not significantly differ in means.

\subsection{Discussion}

The survey results shed light on the question whether differences between subject pools are driven by self-selection, selection by the finance industry, or industry imprintment from the perspective of experts who have an inside view into the finance industry. As such, the survey responses reveal several observations that allow for a more multifaceted discussion of mechanisms potentially driving subject pool differences.

First, we observe that experts agree to a relatively large extent to the conjecture that differences between finance professionals and the general population are - at least partly - explained by the three channels, except for the difference in psychopathy. Conversely, respondents' endorsement of the three channels suggests that experts in the field would expect finance professionals to differ 
from the general population in various characteristics due to the implications of self-selection, industry-selection, and imprintment that shape the industry.

Second, experts' firm affirmation to all three channels indicate that they do not conceive selfselection, industry-selection, and imprintment to be mutually exclusive concepts: all three channels are considered relevant to explain the differences in attitudes towards risk, trustworthiness, and competitiveness, but not psychopathy, between finance professionals and the general population. As such, the survey results are consistent with the assumption that the three channels are mutually correlated, probably even in a self-reinforcing manner. For the sake of illustration, suppose that people on average hold the belief that the finance industry endorses certain types of behavioral characteristics, say competitiveness and preparedness to take risk. This belief will translate into the expectation that competitive and risk-loving applicants will have an edge in the industry's hiring processes, such that people will expect that the industry is indeed made up of competitive and risk-loving individuals. In turn, this expectation will presumably lead to a relative increase in applications from people who are willing to compete and take risks as compared to applications from less competitive and risk-taking candidates. As in the proverb "birds of a feather flock together," individuals tend to associate and bond with similar others - a concept referred to as homophily (see, e.g., Lazarsfeld and Merton, 1954; McPherson et al., 2001)—, which can be expected to influence people's choice of the industry ("inbreeding homophily"; see, e.g., McPherson et al., 2001; Currarini et al., 2016). Consequently, competition-seeking and risk-loving people will indeed be over-represented in the industry. The resulting proximity in terms of behavioral characteristics within the network could serve as a "breeding ground" for a self-enhancing business culture (see, e.g., Charness et al., 2019; Dimant, 2019). As employees tend to remain in the same industry for most of their working lives (Ellul et al., 2020), we can expect that they shape the industry (Gill et al., 2020). ${ }^{21}$ Managers with the mentioned riskpreference and competitiveness are expected to more likely hire similar peers (see, e.g., Guenzel and Malmendier, 2020). Eventually, any of the steps in this chain of reasoning would feed back into the loop and would give people a good reason to strengthen their prior belief about the industry. The anticipation that industry-selection, self-selection, and imprintment shape the industry could suffice to make industry-selection, self-selection, and imprintment a self-fulfilling prophecy.

Third, we observe that different channels are still perceived to be explanatory to a varying degree for the different characteristics. As illustrated in Figure 6, experts conceive self-selection to be most relevant among the three channels to explain the observed differences in preferences and characteristics. Yet, we call for care when comparing the relevance of channels in a horse race based on our survey results: since the sample of respondents in our survey consists of

${ }^{21}$ Our findings are consistent with those reported by Gill et al. (2020), since in our survey experts consider selfselection relevant for the findings on trustworthiness, while at the same time also see the importance of industry selection (and imprintment). 
human resource specialists and middle managers in the finance industry, they might be prone to motivated reasoning (see, e.g., Kunda, 1990), which would lead them to attribute differences in negatively connoted characteristics between finance professionals and the general population to self-selection rather than industry-related mechanisms (i.e., industry-selection or imprinting). Given this potential limitation, the observation that industry-selection is perceived to be at play for three out of four characteristics is even more remarkable, as it indicates that hiring decisions are not made to counteract the over-representation of employees that are more competitive, more risk-tolerant, or less trustworthy - despite the awareness of a lack of diversity in these characteristics.

\section{Conclusion}

With our study, we investigated differences in economic preferences and personality traits between a Swedish sample of finance professionals and a sample of the Swedish working population. In an online experiment, we assessed participants' attitudes toward risk, losses, and skewness, and elicited distributional preferences, trustworthiness, honesty, and personality characteristics, including the Big-5 personality traits, the Dark Triad, and competitiveness. The experimental data has been merged with registry data on socio-economic characteristics provided by Statistics Sweden, which allows for adjusting the effects of interest for the variability of background variables.

First, we find that finance professionals are indeed different from the "average working adults" employed in other industries, inasmuch as they are significantly less risk-averse, more selfish, less trustworthy, more competitive, and show higher levels of narcissism, psychopathy, and Machiavellianism. Second, we show that after adjusting for socio-economic background variables, finance professionals are not so different from a sample of the general population employed in other industries sharing a similar background: Finance professionals "only" tend to be slightly less risk averse, less trustworthy, show a slightly increased level of psychopathy, and are more competitive than comparable participants from other industries. All other differences vanish and the magnitude of the effects remaining statistically significant tends to be deflated.

We would like to mention two points for discussion: First, although our analysis accounts for the variation in a number of socio-economic characteristics, our adjustments are still limited (for reasons described in Appendix A). We cannot rule out that including additional information on participants' socio-economic background would not affect the observed (or not observed) differences between finance professionals and the general working population samples. However, it is noteworthy that already a small set of standard socio-economic characteristics entering our analysis as adjustment variables explains a substantial part of the differences between subject 
pools. In addition, self-selection into our experiment based on unobserved characteristics might affect our estimates (see Appendix A).

Second, our results provide hints where the differences in preferences and characteristics between finance professionals and the general working population stem from. Existing literature argues for both, selection effects (e.g., Gill et al., 2020) as well as an influence (imprinting) from the industry (e.g., Cohn et al., 2014). It is difficult to disentangle selection into the finance industry on behalf of the industry and on behalf of individuals' self-selection, as they are likely to be correlated with each other and with a prevailing industry culture. This raises the question about the distinction between selection and imprinting (industry culture norms). We therefore ran an experts survey with participants from the finance industry with hiring experience-human resource specialists and middle managers - , to investigate whether they consider any of three channels, i.e., industry selection, self-selection, or imprinting by industry norms, to be explanatory for the observed behavioral patterns. The results of the survey underline the idea that the three channels are mutually correlated: All three channels are perceived to play at least some role for the observed differences between subject pools for risk aversion, trustworthiness, and competitiveness.

For these reasons, we would like to call for caution when interpreting observed selection-effects as opposed to industry culture, because the latter can affect (self-)selection into the industry as well. This insight is also relevant when choosing where to set policy measures, because it shows that the selection of finance professionals into the industry might affect the peculiarities and culture of the finance industry, which, in turn, can lead to selection effects. Adams et al. (2016) survey the 2016 CFA membership and show that female CFA members are less tradition- and conformity-oriented than male members. This suggests that gender-related barriers discourage women from entering the finance industry. Those barriers could, for instance, involve inflexible and/or long working hours, disadvantaging women facing more obligations outside their profession (e.g., due to child care). In tandem with the findings in our expert survey, this highlights the possibility of mutual correlations between the channels industry selection, self-selection, and imprintment. This hints at possible policy measures, such as increasing the fraction of female professionals by changing the industry culture (e.g., flexible working hours, childcare facilities, mentoring programs). It can be expected that such measures would lead to increased self-selection of female professionals into the industry in the future. Further policy measures could already target increased university enrollment in relevant academic programs, as outlined by Adams and Kirchmaier (2016). If such interventions change the culture and in turn self-selection, in the long run we can also expect a transition in industry-selection and screening (Gill et al., 2020). Maybe this is also what Christine Lagarde (president of the European Central Bank) had in mind when she said: "As I have said many times, if it had been Lehman Sisters rather than Lehman Brothers, the world 
might well look a lot different today." ${ }^{22}$

\section{Acknowledgements}

We thank Sebastien Duchene, Cary Frydman, Christoph Huber, Steffen Huck (the editor), Rudolf Kerschbamer, Christian König-Kersting, Stefan Palan, and Julia Rose for very valuable comments on earlier versions of this paper. We particularly thank Fredrik Bergdahl and Ingrid Persson at Statistiska centralbyrain for the excellent collaboration on the project. Financial support from the Austrian Science Fund FWF (START-grant Y617-G11 and SFB F63), the Austrian National Bank (grant 17788), the Swedish Research Council (grant 2015-01713), and Formas (grant 2020-00199) is gratefully acknowledged. This study was ethically approved by the review boards at Statistiska centralbyrån (SCB; Statistics Sweden) and in Gothenburg (Sweden). The experimental software including all instructions, treatment variations, and the Swedish translations has been pre-registered at https://osf.io/ykv7e/. English demo versions of the experiment and all treatments are available via http://hea-2019-02-en.herokuapp.com.

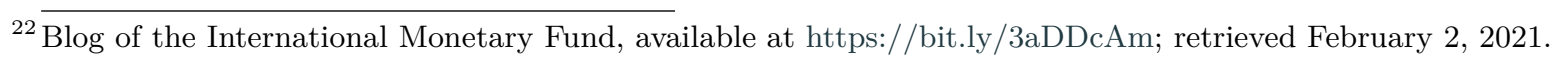




\section{References}

Abdellaoui, M., Bleichrodt, H., \& Kammoun, H. (2013). Do financial professionals behave according to prospect theory? An experimental study. Theory and Decision, 74, 411-429.

Abeler, J., Becker, A., \& Falk, A. (2014). Representative evidence on lying costs. Journal of Public Economics, 113, 96-104.

Abeler, J., Nosenzo, D., \& Raymon, C. (2019). Preferences for truth-telling. Econometrica, 87(4), $1115-1153$.

Acharya, V. V., Pedersen, L. H., Philippon, T., \& Richardson, M. (2016). Measuring systemic risk. The Review of Financial Studies, 30(1), 2-47.

Adams, R., Barber, B., \& Odean, T. (2016). Family, Values, and Women in Finance. SSRN Working Paper.

Adams, R. \& Kirchmaier, T. (2016). Women on Boards in Finance and STEM Industries. American Economic Review, 106(5), 277-281.

Algan, Y. \& Cahuc, P. (2010). Inherited trust and growth. American Economic Review, 100, 2060-2092.

Andersson, O., Holm, H. J., Tyran, J.-R., \& Wengström, E. (2016). Deciding for others reduces loss aversion. Management Science, 62(1), 29-36.

Angelova, V. \& Regner, T. (2013). Do voluntary payments to advisors improve the quality of financial advice? An experimental deception game. Journal of Economic Behavior and Organization, 93, 205-218.

Balafoutas, L. \& Kerschbamer, R. (2020). Credence goods in the literature: What the past fifteen years have taught us about fraud, incentives, and the role of institutions. Journal of Behavioral and Experimental Finance, 26, 100285.

Balloch, A., Nicolae, A., \& Philip, D. (2015). Stock market literacy, trust, and participation. Review of Finance, 19(5), 1925-1963.

Barlett, C. \& Barlett, N. (2015). The young and the restless: Examining the relationships between age, emerging adulthood variables, and the Dark Triad. Personality and Individual Differences, 86, 20-24.

Becker, A., Deckers, T., Dohmen, T., Falk, A., \& Kosse, F. (2012). The relationship between economic preferences and psychological personality measures. Annual Review of Economics, 4(1), 453-478.

Becker, G. S. (1974). A theory of social interactions. Journal of Political Economy, 82(6), 10631093.

Ben-Ner, A. \& Halldorsson, F. (2010). Trusting and trustworthiness: What are they, how to measure them, and what affects them. Journal of Economic Psychology, 31(1), 64-97.

Berg, J., Dickhaut, J., \& McCabe, K. (1995). Trust, reciprocity, and social history. Games and Economic Behavior, 10, 122-142.

Bluethgen, R., Meyer, S., \& Hackethal, A. (2008). High-Quality Financial Advice Wanted! Working Paper. 
Böhm, M., Metzger, D., \& Strömberg, P. (2018). Since you are so rich, you must be really smart: Talent and the finance wage premium. European Corporate Governance Institute - Finance Working Paper No. 553/2018.

Brown, S. \& Taylor, K. (2014). Household finances and the 'Big Five' personality traits. Journal of Economic Psychology, 45, 197-212.

Brülhart, M. \& Usunier, J.-C. (2012). Does the trust game measure trust? Economics Letters, $115(1), 20-23$.

Brunnermeier, M. \& Oehmke, M. (2009). Complexity in financial markets. Working Paper.

Bucciol, A. \& Zarri, L. (2017). Do personality traits influence investors' portfolios? Journal of Behavioral and Experimental Economics, 68, 1-12.

Burke, J. \& Hung, A. (2019). Trust and financial advice. Journal of Pension Economics and Finance, 1-18.

Cain, D., Loewenstein, G., \& Moore, D. (2005). The Dirt on Coming Clean: Perverse Effects of Disclosing Conflicts of Interest. The Journal of Legal Studies, 34, 1-25.

Camerer, C. F., Dreber, A., Holzmeister, F., Ho, T.-H., Huber, J., Johannesson, M., Kirchler, M., Nave, G., Nosek, B., Pfeiffer, T., Altmejd, A., Buttrick, N., Chan, T., Chen, Y., Forsell, E., Gampa, A., Heikensten, E., Hummer, L., Imai, T., Isaksson, S., Manfredi, D., Rose, J., Wagenmakers, E.-J., \& Wu, H. (2018). Evaluating the replicability of social science experiments in Nature and Science. Nature Human Behaviour, 2, 637-644.

Charness, G. \& Gneezy, U. (2012). Strong evidence for gender differences in risk taking. Journal of Economic Behavior and Organization, 83(1), 50-58.

Charness, G., Naef, M., \& Sontuoso, A. (2019). Opportunistic conformism. Journal of Economic Theory, 180, 100-134.

Charness, G. \& Rabin, M. (2002). Understanding social preferences with simple tests. The Quarterly Journal of Economics, 117(3), 817-869.

Chen, D. L., Schonger, M., \& Wickens, C. (2016). oTree - An open-source platform for laboratory, online, and field experiments. Journal of Behavioral and Experimental Finance, 9, 88-97.

Cohen, J. (1992). A power primer. Psychological Bulletin, 112(1), 155-159.

Cohen, J., Cohen, P., West, S. G., \& Aiken, L. S. (2003). Applied Multiple Regression/Correlation Analysis for the Behavioral Sciences. Third Edition. Mahwah, New Jersey: Lawrence Erlbaum Associates.

Cohn, A., Fehr, E., \& Marechal, M. (2014). Business culture and dishonesty in the banking industry. Nature, 516, 86-89.

Cohn, A., Fehr, E., \& Marechal, M. (2019a). Selective participation may undermine replication attempts. Nature, 575, E1-E2.

Cohn, A., Jessen, L., Klašnja, M., \& Smeets, P. (2019b). Why do the rich oppose redistribution? An experiment with America's top 5\%. Working Paper.

Conlin, A., Kyröläinen, P., Kaakinen, M., Järvelin, M.-R., Perttunen, J., \& Svento, R. (2015). Personality traits and stock market participation. Journal of Empirical Finance, 33, 34-50.

Cox, J. (2015). How to identify trust and reciprocity. Journal of Empirical Finance, 33, 34-50. 
Croson, R. \& Gneezy, U. (2009). Gender differences in preferences. Journal of Economic Literature, $47(2), 448-474$.

Currarini, S., Matheson, J., \& Vega-Redondo, F. (2016). A simple model of homophily in social networks. European Economic Review, 90, 18-39.

Deaves, R., Lüders, E., \& Schröder, M. (2010). The dynamics of overconfidence: Evidence from stock market forecasters. Journal of Economic Behavior and Organization, 75 (3), 402-412.

Dimant, E. (2019). Contagion of pro- and anti-social behavior among peers and the role of social proximity. Journal of Economic Psychology, 73(3), 66-88.

Dulleck, U. \& Kerschbamer, R. (2006). On doctors, mechanics, and computer specialists: The economics of credence goods. Journal of Economic Literature, 44(1), 5-42.

Eckel, C. C. \& Grossman, P. J. (2002). Sex differences and statistical stereotyping in attitudes toward financial risk. Evolution and Human Behavior, 23, 281-295.

Edin, P. \& Fredriksson, P. (2000). LINDA: Longitudinal individual data for Sweden. Working Paper.

Egan, M., Matvos, G., \& Seru, A. (2019). The market for financial adviser misconduct. Journal of Political Economy, 127(1), 233-295.

Ellul, A., Pagano, M., \& Scognamiglio, A. (2020). Careers in Finance. CEPR Press Discussion Paper No. 14767.

Ermisch, J., Gambetta, D., Laurie, H., Siedler, T., \& Uhrig, N. (2009). Measuring people's trust. Journal of the Royal Statistical Society, 172, 749-769.

Etchart-Vincent, N. \& l'Haridon, O. (2011). Monetary incentives in the loss domain and behavior toward risk: An experimental comparison of three reward schemes including real losses. Journal of Risk and Uncertainty, 42, 61-83.

Falk, A., Becker, A., Dohmen, T., Enke, B., Huffman, D., \& Sunde, U. (2018). Global evidence on economic preferences. The Quarterly Journal of Economics, 133(4), 1645-1692.

Fehr, E. (2009). On the Economics and Biology of Trust. Journal of the European Economic Association, 7(2-3), 235-266.

Fehr, E. \& List, J. (2004). The hidden costs and returns of incentives - Trust and trustworthiness among CEOs. Journal of the European Economic Association, 2(5), 743-771.

Fehr, E., Naef, M., \& Schmidt, K. M. (2006). Inequality aversion, efficiency, and maximin preferences in simple distribution experiments: Comment. American Economic Review, 96(5), 1912-1917.

Fehr, E. \& Schmidt, K. M. (1999). A theory of fairness, competition, and cooperation. The Quarterly Journal of Economics, 114(3), 817-868.

Fischbacher, U. \& Föllmi-Heusi, F. (2013). Lies in disguise - An experimental study on cheating. Journal of the European Economic Association, 11(3), 525-547.

Fisman, R., Jakiela, P., \& Kariv, S. (2017). The distributional preferences of Americans. Journal of Public Economics, (155), 1-10.

Fisman, R., Jakiela, P., Kariv, S., \& Markovits, D. (2015). The distributional preferences of an elite. Science, $349(6254)$, aab0096. 
Fungáčová, Z., Hasan, I., \& Weill, L. (2019). Trust in banks. Journal of Economic Behavior and Organization, 157, 452-476.

Gennaioli, N., Shleifer, A., \& Vishny, R. (2015). Money doctors. Journal of Finance, 70(1), 91114.

Georgarakos, D. \& Pasisi, G. (2015). Trust, sociability and stock market participation. Review of Finance, 15(4), 693-725.

Gilad, D. \& Kliger, D. (2008). Priming the risk attitudes of professionals in financial decision making. Review of Finance, 12, 567-586.

Gill, A., Heinz, M., Schumacher, H., \& Sutter, M. (2020). Trustworthiness in the Financial Industry. Working Paper.

Glaser, M., Langer, T., \& Weber, M. (2005). Overconfidence of professionals and lay men: Individual differences within and between tasks? Working Paper.

Gneezy, U. \& Potters, J. (1997). An experiment on risk taking and evaluation periods. The Quarterly Journal of Economics, 112(2), 631-645.

Guenzel, M. \& Malmendier, U. (2020). Behavioral Corporate Finance: The Life Cycle of a CEO Career. Working Paper.

Guiso, L., Sapienza, P., \& Zingales, L. (2008). Trusting the stock market. Journal of Finance, $63(6), 2557-2600$.

Gupta, N., Poulsen, A., \& Villeval, M. C. (2013). Gender matching and competitiveness: Experimental evidence. Economic Inquiry, 51(1), 816-835.

Gurevich, G., Kliger, D., \& Levy, O. (2009). Decision-making under uncertainty: A field study of cumulative prospect theory. Journal of Banking and Finance, 33(7), 1221-1229.

Gurun, U., Stoffman, N., \& Yonker, S. E. (2018). Trust busting: The effect of fraud on investor behavior. The Review of Financial Studies, 31(4), 1341-1376.

Haigh, M. \& List, J. (2005). Do professional traders exhibit myopic loss aversion? An experimental analysis. Journal of Finance, 60(1), 523-534.

Helmreich, R. \& Spence, J. (1978). The work and family orientation questionnaire: An objective instrument to assess components of achievement motivation and attitudes toward family and career. JSAS Catalog of Selected Documents in Psychology, 8(2), 35.

Holzmeister, F. (2017). oTree: Ready-made apps for risk preference elicitation methods. Journal of Behavioral and Experimental Finance, 16, 33-38.

Holzmeister, F., Holmén, M., Kirchler, M., Stefan, M., \& Wengström, E. (2022). Delegation decisions in finance. Management Science, forthcoming.

Holzmeister, F., Huber, J., Kirchler, M., Lindner, F., \& Zeisberger, S. (2020). What drives risk perception? A global survey with financial professionals and laypeople. Management Science, 66 (9), 3799-4358.

Holzmeister, F. \& Kerschbamer, R. (2019). oTree: The equality equivalence test. Journal of Behavioral and Experimental Finance, 22, 214-222.

Holzmeister, F. \& Stefan, M. (2020). The risk elicitation puzzle revisited: Across-methods (in)consistency? Experimental Economics, online first. 
Huber, C. \& Huber, J. (2020). Bad bankers no more? Truth-telling and (dis)honesty in the finance industry. Journal of Economic Behavior \& Organization, 180, 472-493.

Huber, C. \& König-Kersting, C. (2022). Experimenting with Financial Professionals. Working Paper.

Inderst, R. \& Ottaviani, M. (2012a). Financial advice. Journal of Economic Literature, 50(2), 494-512.

Inderst, R. \& Ottaviani, M. (2012b). Regulating Financial Advice. European Business Organization Law Review, 13(2), 237-246.

Johnson, N. \& Mislin, A. A. (2011). Trust games: A meta-analysis. Journal of Economic Psychology, 32, 865-889.

Jonason, P. \& Davis, M. (2018). A gender role view of the Dark Triad traits. Personality and Individual Differences, 125, 102-105.

Jonason, P. \& Webster, G. (2010). The dirty dozen: A concise measure of the Dark Triad. Psychological Assessment, 22(2), 420-432.

Jones, D. (2013). What's mine is mine and what's yours is mine: The Dark Triad and gambling with your neighbor's money. Journal of Research in Personality, 47, 563-571.

Jones, D. (2014). Risk in the face of retribution: Psychopathic individuals persist in financial misbehavior among the Dark Triad. Personality and Individual Differences, 67, 109-113.

Kaustia, M., Alho, E., \& Puttonen, V. (2008). How much does expertise reduce behavioral biases? The case of anchoring effects in stock return estimates. Financial Management, 37(3), 391412.

Kerschbamer, R. (2015). The geometry of distributional preferences and a non-parametric identification approach: The Equality Equivalence Test. European Economic Review, 76, 85103.

Kerschbamer, R. \& Müller, D. (2020). Social preferences and political attitudes: An online experiment on a large heterogeneous sample. Journal of Public Economics, 182, 104076.

Kirchler, M., Lindner, F., \& Weitzel, U. (2018). Rankings and risk-taking in the finance industry. Journal of Finance, 37(5), 2271-2302.

Kirchler, M., Lindner, F., \& Weitzel, U. (2020). Delegated decision making and social competition in the finance industry. Journal of Banking and Finance, forthcoming.

Kocher, M., Schudy, S., \& Spantig, L. (2018). I lie? We lie! Why? Experimental evidence on a dishonesty shift in groups. Management Science, 64 (9), 3995-4008.

Kunda, Z. (1990). The case for motivated reasoning. Psychological Bulletin, 108(3), 480-498.

Lauriola, M. \& Levin, I. (2001). Personality traits and risky decision-making in a controlled experimental task: An exploratory study. Personality and Individual Differences, 31, 215226.

Lazarsfeld, P. F. \& Merton, R. K. (1954). Friendship as a social process: A substantive and methodological analysis. In M. Berger, T. Abel, \& C. H. Page (Eds.), Freedom and control in modern society. New York, NY: Van Nostrang.

McPherson, M., Smith-Lovin, L., \& Cook, J. M. (2001). Birds of a feather: Homophily in social networks. Annual Review of Sociology, 27, 415-444. 
Niederle, M. \& Vesterlund, L. (2011). Gender and competition. Annual Review of Economics, 3, 601-630.

Niessen-Ruenzi, A. \& Ruenzi, S. (2019). Sex Matters: Gender Bias in the Mutual Fund Industry. Management Science, 65(7), 553-565.

Nosić, A. \& Weber, M. (2010). How riskily do I invest? The role of risk attitudes, risk perceptions, and overconfidence. Decision Annals, 7(3), 282-301.

Nyhus, E. \& Pons, E. (2005). The effects of personality on earnings. Journal of Economic Psychology, 26, 363-384.

Open Science Collaboration. (2015). Estimating the reproducibility of psychological science. Science, $349(6251)$, aac4716.

Paulhus, D. L. \& Williams, K. M. (2002). The Dark Triad of personality: Narcissism, Machiavellianism, and psychopathy. Journal of Research in Personality, 36, 556-563.

Picard, R., Selva, M., \& Bironzo, D. (2014). Media Coverage of Banking and Financial News. Reuters Institute for the Study of Journalism.

Pikulina, E., Renneboog, L., \& Tobler, P. N. (2017). Overconfidence and investment: An experimental approach. Journal of Corporate Finance, 43, 175-192.

Rabin, M. (1993). Incorporating fairness into game theory and economics. American Economic Review, 83(5), 1281-1302.

Rahwan, Z., Yoeli, E., \& Fasolo, B. (2019). Heterogeneity in banker culture and its influence on dishonesty. Nature, 575, 345-349.

Rammstedt, B. \& Oliver, J. (2007). Measuring personality in one minute or less: A 10-item short version of the Big Five Inventory in English and German. Journal of Research in Personality, 41, 203-212.

Rau, H. (2014). The disposition effect and loss aversion: Do gender differences matter? Economics Letters, 123(1), 33-36.

Roszkowski, M. \& Snelbecker, G. (1990). Effects of "framing" on measures of risk tolerance: Financial planners are not immune. Journal of Behavioral Economics, 19(3), 237-246.

Sapienza, P., Toldra-Simats, A., \& Zingales, L. (2013). Understanding Trust. The Economic Journal, 123(573), 1313-1332.

Sapienza, P. \& Zingales, L. (2012). A trust crisis. International Review of Finance, 12(2), 123131.

Schmidt, U. \& Traub, S. (2002). An Experimental Test of Loss Aversion. Journal of Risk and Uncertainty, 25, 233-249.

Spurk, D., Keller, A., \& Hirschi, A. (2016). Do bad guys get ahead or fall behind? Relationships of the Dark Triad of personality with objective and subjective career success. Social Psychological and Personality Science, 7(2), 113-121.

Stefan, M., Holmén, M., Holzmeister, F., Kirchler, M., \& Wengström, E. (2022). You can’t always get what you want: An experiment on finance professionals' decisions for others. Working Paper.

Vranka, M. \& Houdek, P. (2015). Many faces of bankers' identity: How (not) to study dishonesty. Frontiers in Psychology, 6, 1-4. 
Weber, M., Weber, E. U., \& Nosić, A. (2013). Who takes risks when and why: Determinants of changes in investor risk-taking. Review of Finance, 17(3), 847-883.

Zillig, L. M. P., Hemenover, S., \& Dienstbier, R. A. (2002). What Do We Assess when We Assess a Big 5 Trait? A Content Analysis of the Affective, Behavioral, and Cognitive Processes Represented in Big 5 Personality Inventories. Personality and Social Psychology Bulletin, $28(6), 847-858$.

Zingales, L. (2015). Does finance benefit society? Journal of Finance, 70(4), 1327-1363. 


\title{
Appendices
}

\author{
Economic Preferences and Personality Traits \\ Among Finance Professionals and the General Population
}

\author{
Martin Holmén ${ }^{\dagger, *}$ Felix Holzmeister ${ }^{\ddagger}$ Michael Kirchler ${ }^{\S, \dagger}$ \\ Matthias Stefan ${ }^{\S}$ Erik Wengström $₫, \|$ \\ $\dagger$ University of Gothenburg, Department of Economics, Centre for Finance \\ $¥$ University of Innsbruck, Department of Economics \\ $\S$ University of Innsbruck, Department of Banking and Finance \\ I Lund University, Department of Economics \\ ॥ Hanken School of Economics, Department of Finance and Economics \\ *Corresponding author: matthias.stefan@uibk.ac.at
}

\section{Contents}

A Data Collection and Recruitment . . . . . . . . . . . . . . . . . . . 1

B Attitudes towards Risk, Loss, and Skewness . . . . . . . . . . . . . . . . . . 5

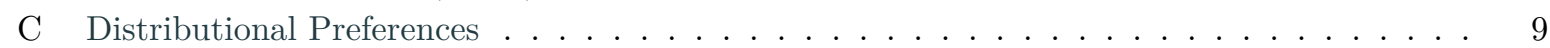

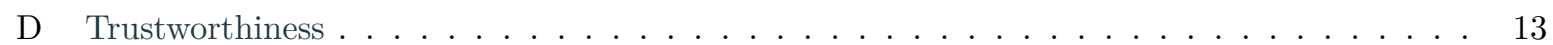

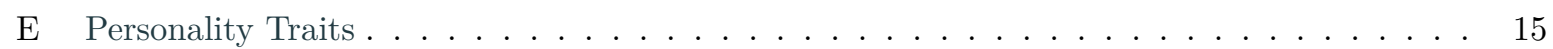

F Comparison Between Job Functions . . . . . . . . . . . . . . . . . . . . . . 19

G Correlational Analysis . . . . . . . . . . . . . . . . . . . . . . . 21 


\section{List of Tables}

A1 Sample characteristics by subject pools. . . . . . . . . . . . . . . . . . . . . 4

B1 Descriptive statistics on risk-taking behavior . . . . . . . . . . . . . . . 6

C1 (x,y)-scores, utility function parameters, and willingness-to-pay in the EET . . . . . . 11

D1 Regression analyses: Trust (first mover behavior in the trust game) . . . . . . . . . . . . . 14

E1 Dark Triad personality test by Jonason and Webster (2010) . . . . . . . . . . . . . . . 15

E2 Competitiveness questionnaire by Helmreich and Spence (1978) . . . . . . . . . . . . . 16

E3 Big-5 personality test by Rammstedt and Oliver (2007) . . . . . . . . . . . . . . . 16

F1 Comparison between job functions . . . . . . . . . . . . . . . . . . . . 20

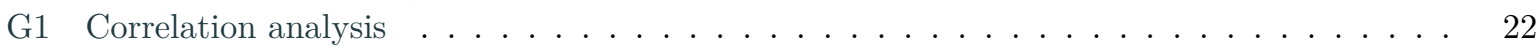

\section{List of Figures}

B1 Cumulative distributions of risk-taking behavior . . . . . . . . . . . . . . . 6

D1 Histograms of amounts returned by the trustees in the trust game . . . . . . . . . . . 13

E1 Cumulative distributions of personality traits . . . . . . . . . . . . . . . . 17 


\section{A. Data Collection and Recruitment}

Recruitment. Statistics Sweden $(S C B)$ sent out hard copy invitations - including a link to the online experiment and a personalized identifier as login credential - for the anonymous online experiment. $S C B$ distributed invitations to 8,215 finance professionals and a randomly selected random sample of 8,215 subjects from Sweden's working population, excluding finance professionals. The sample of finance professionals invited included financial analysts and investment advisors, traders and fund managers, and financial brokers. Following Edin and Fredriksson (2000) and Böhm et al. (2018), we only included people with a declared labor income exceeding the minimum amount that qualifies for the earnings related part of the public pension system. Invitations were sent out in two waves: $20 \%$ of the sample were invited in the first week of 2019 . The remaining $80 \%$ of the sample were invited in the third week of 2019, given that no technical difficulties came up.

The receivers of the invitations logged in to our experiment using a personalized participant code, which was linked to a key only known to $S C B$. After the data collection has been completed, using this key, $S C B$ matched the experimental data with the requested register data (which is described in detail below) for the participants who completed the experiment. Our data handling procedures ensured full pseudonymity of all participants. At the very beginning of the online experiment, participants were informed that register data provided by $S C B$ will be matched with the data collected in the experiment. Moreover, participants were informed that the study has been approved by the ethical review boards in Gothenburg and at $S C B$. So, participants could agree on the conditions and only then continued with the experiment. Please note that before the experiment reported in this paper, participants were invited to a first, independent experiment. Some participants only completed one of the experiments. For details about the first experiment, see Holzmeister et al. (2022) and Stefan et al. (2022).

Experimental software. The experimental software including all instructions, treatment variations, and the Swedish translations has been pre-registered at https://osf.io/ykv7e/. English demo versions of the experiment and all treatments are available via http://hea-2019-02-en.herokuapp.com.

Payments. To ensure full privacy of the data collected during the experiment, payouts were handled by the third party survey firm Enkätfabriken. Once participants completed the online experiment, they were redirected to the website of Enkätfabriken. Participants could log in using the same participant code as in the experiment. For payment purposes, Enkätfabriken collected participants' names, email addresses, "personnummer" (personal identity number), and bank account details. The information collected was handled only by Enkätfabriken and has been used exclusively for sake of ordering the bank remittances. 
Registry data. In addition to the data collected in the online experiment, we obtained the following register data from $S C B$ for each participant who completed all tasks in the experiment:

- Demographics: year born, age, gender, county, municipality, and assembly of residence, marital status, year in marital status, family status, birth country, children living at home age $0-3,4-6$, 7-10, 11-15, 16-17, $\geq 18$, highest finished education level, education orientation, education group, education county, graduation year, primary source of income, work place municipality and county, work place industry 1990-1992, 1993-2001, 2002-2010, and 2007-2014, occupation 2002-2013 and 2014, net income of own business 1991-2003, 2003-2014, and 2004-2014, capital income, disposable income 1990-2004 and 2004-2014, disposable income of family 1990-2004 and 2004-2014, country of birth, date of immigration.

- Firm / workplace: number of employees at firm / workplace, number of men / women at firm / workplace, number of men/women with short/long education at firm/workplace, total salaries paid by firm / workplace.

- Education: high school, high school program, high school grades point average, high school graduation year, university, university program, university major, university graduation year.

- Assets: net wealth, total debt, bank account, listed equity, fixed income funds, other funds, bonds and other securities, taxable insurances, houses, apartments, holiday homes (data only available from 2007)

- Military records: command suitability, non cognitive abilities score, muscle strength, physical capacity for work, length, weight, cognitive scores 1 and 2 in language and logic, one in spatial understanding, and one in technical understanding (only for the male part of our sample).

- Parents: adoptive / biological mother / father, occupation mother / father, primary income source mother / father, net income from own business mother / father, net wealth mother / father.

In our paper, we only use part of the available registry data as adjustment variables in our analyses - i.e., participants' gender (binary indicator for female), age (in years), net income from major employment in 2017 (in thousand SEK's), and maximum education level (dichotomous indicators for high school education or less, university education smaller or equal to three years, and university education larger than three years). Please note the following relevant restrictions in the register data obtained: First, data from the military suitability tests are only available for males in our sample. Thus, usage of data from these records would substantially decrease the sample size in our data analysis and, in turn, its generalizability. Second, records of wealth data provided by $S C B$ are not available after 2008. Moreover, additional relevant data, such as financial asset holdings or bank account data is not available from $S C B$ either.

Response rate analysis and self-selection. Please note that the response rate discussed hereafter refers to both, the experiment reported in this paper as well as the preceding, accompanying experiment reported in Holzmeister et al. (2022) and Stefan et al. (2022). For the finance professionals group, the response rate analysis shows that men responded to a greater extent than women, and that finance individuals in the age group 45-59 years responded to a slightly lesser extent than other ages. Furthermore, the non-response analysis shows that those with the lowest income responded to a somewhat higher degree compared to the others, and that those with a post-secondary education level of three years or more responded to greater extent than others. In the case of country of birth, the response rate was slightly higher for those born in Sweden compared to other countries. In the finance group there was a certain difference between the different job codes where the response frequency was slightly lower $(5 \%)$ 
in the group of traders and portfolio managers (job code "2414") compared with analysts and advisers (code "2413") and brokers (code "3311") (6.4\%).

For the general population group, the response rate analysis shows similar patterns regarding gender, i.e., men responded to a greater extent than women. The response rate was lowest among the elderly. Furthermore, the response rate analysis indicates that those with the lowest and highest income responded to a somewhat higher extent compared to other income groups. When it comes to the level of education, those with a post-secondary education of three years or more tend to be over-represented in our sample. In the case of country of birth, the response rate was slightly higher for the ones born in Sweden compared to other countries.

A detailed summary of participants demographics compared to the characteristics of the sample invited is presented in Table A1. In particular, Table A1 reports the number of respondents and non-respondents per category of several socio-demographic characteristics, separated for both samples, as reported by $S C B$. Moreover, we report $\chi^{2}$-tests comparing whether participants in our samples differ significantly from those who have been invited by $S C B$ but did not participate in the experiment. We report self-selection effects in terms of gender, age, country of birth, income, and education for the general population sample, and self-selection effects with respect to gender, age, and education for the finance professionals sample. 
Table A1: Sample characteristics by subject pools. This table depicts the number (in \%) of respondents ("Resp."), i.e., those who participated in our experiment, and non-respondents ("No Resp."), i.e., those who were invited but did not participate, for a number of different characteristics, separated for the general population and the finance profession sample. $\chi^{2}$-tests (with $k-1$ degrees of freedom) and the corresponding $p$-values are reported.

\begin{tabular}{|c|c|c|c|c|c|c|}
\hline & \multicolumn{3}{|c|}{ General Population } & \multicolumn{3}{|c|}{ Finance Professionals } \\
\hline & Resp. & No Resp. & $\chi^{2} / p$ & Resp. & No Resp. & $\chi^{2} / p$ \\
\hline \multicolumn{7}{|l|}{ Gender: } \\
\hline Male & 55.35 & 49.36 & 9.322 & 75.30 & 68.47 & 10.169 \\
\hline Female & 44.65 & 50.64 & $(0.002)$ & 24.70 & 31.53 & $(0.001)$ \\
\hline \multicolumn{7}{|l|}{ Age: } \\
\hline $20-29$ years & 11.55 & 10.28 & 37.789 & 11.85 & 8.73 & 14.062 \\
\hline $30-39$ years & 31.69 & 23.18 & $(<0.001)$ & 31.12 & 28.79 & $(0.015)$ \\
\hline $40-49$ years & 26.62 & 26.39 & & 28.51 & 30.04 & \\
\hline $50-59$ years & 20.99 & 26.74 & & 17.27 & 22.83 & \\
\hline $60-69$ years & 9.15 & 13.41 & & 10.04 & 8.60 & \\
\hline $70-79$ years & 0.00 & 0.00 & & 1.20 & 1.00 & \\
\hline \multicolumn{7}{|l|}{ Country of Birth: } \\
\hline Sweden & 88.17 & 82.84 & 13.248 & 89.76 & 88.95 & 0.311 \\
\hline Abroad & 11.83 & 17.16 & $(<0.001)$ & 10.24 & 11.05 & $(0.577)$ \\
\hline \multicolumn{7}{|l|}{ Citizenship: } \\
\hline Swedish & 97.04 & 95.64 & 3.132 & 97.59 & 96.53 & 1.604 \\
\hline Foreign & 2.96 & 4.36 & $(0.077)$ & 2.41 & 3.47 & $(0.205)$ \\
\hline \multicolumn{7}{|l|}{ Marital Status: } \\
\hline Married & 46.90 & 46.26 & 2.247 & 52.21 & 56.31 & 4.910 \\
\hline Unmarried & 41.41 & 40.49 & $(0.523)$ & 40.36 & 35.46 & $(0.179)$ \\
\hline Divorced & 11.27 & 12.42 & & 7.03 & 7.79 & \\
\hline Widowed & 0.42 & 0.83 & & 0.40 & 0.45 & \\
\hline \multicolumn{7}{|l|}{ Income: } \\
\hline$<124,999$ SEK & 3.24 & 2.70 & 25.646 & 2.01 & 1.53 & 2.985 \\
\hline $125,000-199,999$ SEK & 5.63 & 5.79 & $(<0.001)$ & 2.41 & 2.16 & $(0.560)$ \\
\hline 200,000 - 279,999 SEK & 12.82 & 15.25 & & 3.01 & 3.41 & \\
\hline $280,000-369,999$ SEK & 24.08 & 31.16 & & 5.22 & 6.85 & \\
\hline$>370,000 \mathrm{SEK}$ & 54.23 & 45.11 & & 87.35 & 86.06 & \\
\hline \multicolumn{7}{|l|}{ Education: } \\
\hline No High School & 1.83 & 8.89 & 198.587 & 0.80 & 1.08 & 32.058 \\
\hline High School & 28.45 & 46.89 & $(<0.001)$ & 7.83 & 17.06 & $(<0.001)$ \\
\hline University (< 3 years) & 19.86 & 14.95 & & 11.45 & 11.32 & \\
\hline University (> 3 years) & 49.86 & 28.61 & & 79.72 & 69.95 & \\
\hline Unknown, $n / a$ & 0.00 & 0.66 & & 0.20 & 0.59 & \\
\hline
\end{tabular}




\section{B. Attitudes towards Risk, Loss, and Skewness}

Method. We elicit attitudes towards risk, losses, and skewness with four tasks each using a single choice list procedure (Eckel and Grossman, 2002). The experimental implementation of the tasks was based on the ready-to-use oTree software module "SCL" by Holzmeister (2017). The parametrization of the four tasks used in our experiment is shown in Table 1 in the main text.

The parametrization of the tasks was inspired by the design choice in Holzmeister et al. (2020): In a $2 \times 2$ factorial design, we varied the lotteries' prospective payoffs in such a way, that a single characteristic of the gambles was systematically varied while holding the other characteristics constant. In the two tasks $S_{0} L_{0}$ and $S_{1} L_{0}$, all lottery payoffs were strictly positive, i.e., all gambles presented to participants were in the gain domain. The two tasks $S_{0} L_{1}$ and $S_{1} L_{1}$ were identical to the other two tasks, but with a constant amount of 80 SEK subtracted from all lottery payoffs. By this means, the expected value of the six prospects was reduced by the same amount while holding the standard deviation as well as the skewness of the gambles constant. For both tasks involving negative lottery outcomes, participants were informed that they receive an extra endowment of 80 SEK to cover potential losses. ${ }^{23}$ Taking into account the additional endowment, lotteries $S_{0} L_{0}$ and $S_{0} L_{1}$ as well as lotteries $S_{1} L_{0}$ and $S_{1} L_{1}$ were virtually identical - except for the framing. Thus, differences in the choice behavior between the tasks $S_{0} L_{0}$ and $S_{1} L_{0}$ can be attributed to participants' attitudes towards losses (in symmetric gambles, i.e., in absence of skewness). Likewise, deviations in choices between $S_{1} L_{0}$ and $S_{1} L_{1}$ can be attributed to participants' degree of loss tolerance in skewed gambles.

The tasks $S_{0} L_{0}$ and $S_{0} L_{1}$ involved two possible states of the world $\left(x_{1}\right.$ and $\left.x_{2}\right)$-realized with a probability of $50 \%$ each - which implied that the gambles were symmetric (i.e., they involved zero skewness). In the tasks $S_{1} L_{0}$ and $S_{1} L_{1}$, the probability of $x_{2}$ was reduced to $49 \%$ and a third outcome $\left(x_{3}\right)$ was introduced (occurring with a probability of $1 \%$ ), which allows modelling positively skewed prospects. In particular, the three lottery outcomes in the two tasks involving skewness were chosen in such a way that the expected values and standard deviations of each prospect mirrored the properties of the symmetric gambles. ${ }^{24}$ Thus, by construction of the tasks, differences in choice behavior between $S_{0} L_{0}$ and $S_{1} L_{0}$ can be attributed to participants' degree of skewness tolerance. Likewise, deviations in choices between $S_{0} L_{1}$ and $S_{1} L_{1}$ are attributable to skewness tolerance in lotteries with mixed gambles.

Note that the fifth and sixth lottery in each of the four tasks shared the same expected return but differed in standard deviation. Thus, in terms of participants' utility function curvature, a slightly risk averse (or risk neutral) decision-maker-i.e., participants with a concave utility function-would choose lottery 5 in all four tasks (given skewness and loss neutrality); while a risk seeking (or risk neutral) decision-makeri.e., participants with a convex utility function-would choose lottery 6 in all four tasks.

In case the experimental part eliciting attitudes towards risk, losses, and skewness was randomly selected for a payment, a participants' final payment was determined in two steps: First, one of the four tasks was picked at random. Then, a second random draw determined the state of nature, i.e., which of the outcomes in the chosen lottery was realized.

Descriptive results. Panel (a) in Table B1 reports the means and standard deviations of the lottery choices in each of the four tasks, separated for the general population and the finance professionals sample. The cumulative distributions of risky choices per task are depicted in Figure B1. Recall that-by

${ }^{23}$ See Etchart-Vincent and l'Haridon (2011) for evidence that such a procedure with losses covered by an endowment does not lead to systematic differences in observed behavior in experiments.

${ }^{24}$ Note that the standard deviation of the sixth lottery varied marginally between the tasks with positive skewness $(\mathrm{sd}=111.5 \mathrm{SEK})$ and the tasks with zero skewness ( $\mathrm{sd}=112.0 \mathrm{SEK}$. This is due to the fact that the lottery outcomes were rounded to one decimal place. 
construction of the four tasks - a risk neutral decision-maker would opt for lottery 5 or 6 . We find that participants from both subject pools, on average, are averse towards risk with mean choices well below 5 in all four tasks (one-sample $t$-tests for a hypothesized population mean of 5 are statistically significant $(p<0.005)$ for all tasks for both subject pools $)$.

Table B1: Descriptive statistics on attitudes towards risk, losses, and skewness. (a) The table shows the means and standard deviations (in parentheses) of the chosen lotteries (1-6) in each of the four tasks, separated for the general population and the finance professionals sample. $S_{i}$ and $L_{i}$ are indicator functions for skewness and losses, respectively; e.g., $S_{1} L_{0}$ indicates the task with skewed lottery outcomes in the gain domain. (b) The table shows the means and standard deviations (in parentheses) of the differences between the chosen lotteries in pairwise comparisons of the four tasks ( -5 to 5 ), separated for the general population and the finance professionals sample. $S_{0} L_{1}-S_{0} L_{0}$, for instance, indicates the difference in choice behavior attributable to participants' attitudes towards losses (in lotteries without skewed outcomes). Negative (positive) values indicate negative (positive) attitudes towards losses/skewness. $n_{G P}=$ $395, n_{F P}=298$.

\section{(a) Tasks}

\begin{tabular}{ccc}
\hline & $G P$ & $F P$ \\
\hline$S_{0} L_{0}$ & 3.646 & 4.074 \\
& $(1.764)$ & $(1.739)$ \\
$S_{0} L_{1}$ & 3.430 & 3.926 \\
& $(1.817)$ & $(1.770)$ \\
$S_{1} L_{0}$ & 3.825 & 4.470 \\
& $(1.722)$ & $(1.690)$ \\
$S_{1} L_{1}$ & 3.592 & 4.359 \\
& $(1.733)$ & $(1.682)$ \\
\hline
\end{tabular}

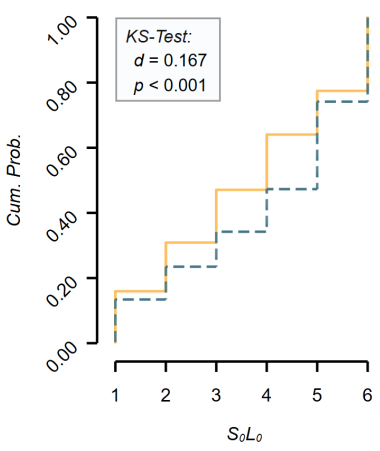

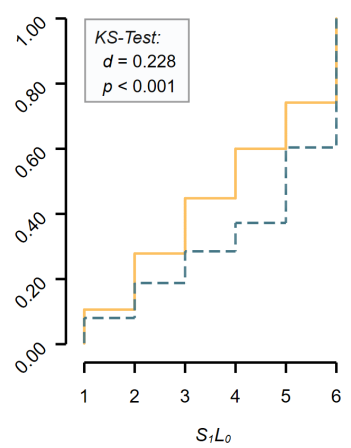

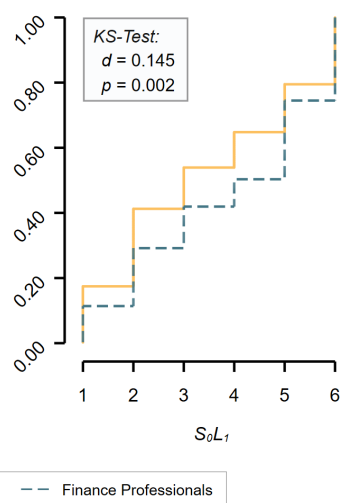

(b) Differences

\begin{tabular}{ccc}
\hline & $G P$ & $F P$ \\
\hline$S_{0} L_{1}-S_{0} L_{0}$ & -0.215 & -0.148 \\
& $(1.965)$ & $(1.928)$ \\
$S_{1} L_{0}-S_{0} L_{0}$ & 0.180 & 0.396 \\
& $(1.673)$ & $(1.677)$ \\
$S_{1} L_{1}-S_{1} L_{0}$ & -0.233 & -0.111 \\
& $(1.814)$ & $(1.736)$ \\
$S_{1} L_{1}-S_{0} L_{1}$ & 0.162 & 0.433 \\
& $(1.758)$ & $(1.642)$ \\
\hline
\end{tabular}

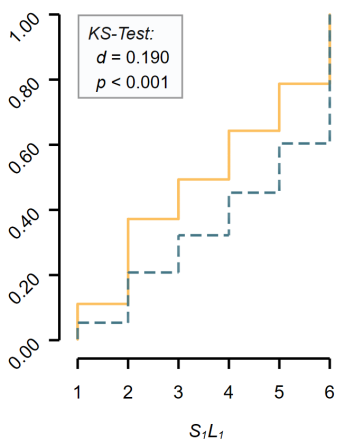

Figure B1: Cumulative distributions of lottery choices in each of the four tasks used to elicit attitudes towards risk, losses, and skewness, separated for the general population and the finance professionals sample. $S_{i}$ and $L_{i}$ are indicator functions for skewness and losses, respectively; e.g., $S_{1} L_{0}$ indicates the task with skewed lottery outcomes in the gain domain. Kolmogorov-Smirnov $(K S)$ tests are reported in boxes. $n_{G P}=395, n_{F P}=298$.

Panel (b) in Table B1 provides summary statistics of the differences in choices between tasks attributable to participants' attitudes towards skewness and losses, respectively. Note that positive (negative) differences can be attributed to a higher (lower) tolerance towards skewness/losses. For the finance professionals sample, one-sample $t$-tests (for a population mean of zero) indicate that we cannot reject the null hypothesis of loss neutrality, neither in the absence $\left(S_{0} L_{1}-S_{0} L_{0}: m=-0.147, t(297)=1.322, p=0.187\right.$; $n=298)$, nor in the presence of skewed lotteries $\left(S_{1} L_{1}-S_{1} L_{0}: m=-0.111, t(297)=1.101, p=0.272\right.$; 
$n=298)$. Participants from the general population sample, on average, tend to be slightly loss averse, in both the absence $\left(S_{0} L_{1}-S_{0} L_{0}: m=-0.215, t(394)=2.177, p=0.030 ; n=395\right)$ and the presence of skewed gambles $\left(S_{1} L_{1}-S_{1} L_{0}: m=-0.233, t(394)=2.552, p=0.011 ; n=395\right)$.

With respect to skewness attitudes, we report that finance professionals in our sample, on average, show significant positive attitudes towards skewness, irrespective of whether the lotteries are framed in the gain domain $\left(S_{1} L_{0}-S_{0} L_{0}: m=0.396, t(297)=4.076, p<0.001 ; n=298\right)$ or in terms of mixed gambles involving losses $\left(S_{1} L_{1}-S_{0} L_{1}: m=0.433, t(297)=4.550, p<0.001 ; n=298\right)$. The general population sample, on average, tends to show positive attitudes towards skewness if the prospects do not involve losses $\left(S_{1} L_{0}-S_{0} L_{0}: m=0.180, t(394)=2.136, p=0.033 ; n=395\right)$, but tend to be neutral towards skewness if lotteries involve negative outcomes $\left(S_{1} L_{1}-S_{0} L_{1}: m=0.162, t(394)=1.832, p=0.068\right.$; $n=395)$.

Supplementary results. Table B2 reports the main results as depicted in Figure 1 in the main text.

Table B2 shows a significant difference in risk tolerance $\left(S_{0} L_{0}\right)$ between males and females, which is consistent with existing findings in the literature (see, e.g., Croson and Gneezy, 2009; Charness and Gneezy, 2012). Comparable but smaller effects are also found in the tasks $S_{0} L_{1}$ and $S_{1} L 0$; for the task $S_{1} L_{1}$, the gender effect is not significantly different from zero. Notably, we do not find any evidence for a gender effect in attitudes towards losses or skewness (see panel (b) of Table B2) - in contrast to existing literture (see, e.g., Schmidt and Traub, 2002; Rau, 2014). The effects of the other adjustment variables - age, income, and education - turn out to be statistically insignificant for attitudes towards risk, losses, and skewness alike. 
Table B2: Regression analyses of participants' attitudes towards risk, losses, and skewness. (a) Ordinary least squares regressions (organized in rows) of participants' lottery choices in each of the four tasks on an indicator variable for the finance professionals subject pool and socio-economic adjustment variables (gender, age, income, and education). $S_{i}$ and $L_{i}$ are indicator functions for skewness and losses, respectively; e.g., $S_{1} L_{0}$ indicates the task with skewed lottery outcomes in the gain domain. (b) Estimates of the differences in coefficient estimates between tasks on the same covariates based on seemingly unrelated regressions, i.e., estimates isolating the effects of attitudes towards losses and skewness, respectively. $S_{0} L_{1}-S_{0} L_{0}$, for instance, captures the difference in choice behavior attributable to loss tolerance (in lotteries without skewed outcomes). Robust standard errors are provided in parentheses. $n=693$ in models without adjustments; $n=688$ in models with adjustments. ${ }^{*} p<0.05,{ }^{* *} p<0.005$.

\section{(a) Tasks}

\begin{tabular}{cccccccc}
\hline & Fin. Prof. & Female & Age & Income & Edu. $=2$ & Edu. $=3$ & Constant \\
\hline$S_{0} L_{0}$ & $0.428^{* *}$ & & & & & & $3.646^{* *}$ \\
& $(0.134)$ & & & & & $(0.089)$ \\
$S_{0} L_{0}$ & $0.318^{*}$ & $-0.481^{* *}$ & -0.004 & 0.071 & -0.089 & -0.020 & $3.958^{* *}$ \\
& $(0.149)$ & $(0.147)$ & $(0.006)$ & $(0.092)$ & $(0.184)$ & $(0.194)$ & $(0.789)$ \\
$S_{0} L_{1}$ & $0.496^{* *}$ & & & & & & $3.430^{* *}$ \\
& $(0.137)$ & & & & & $(0.091)$ \\
$S_{0} L_{1}$ & $0.384^{*}$ & $-0.403^{*}$ & -0.004 & 0.020 & -0.039 & 0.206 & $3.960^{* *}$ \\
& $(0.150)$ & $(0.150)$ & $(0.006)$ & $(0.091)$ & $(0.193)$ & $(0.199)$ & $(0.777)$ \\
$S_{1} L_{0}$ & $0.644^{* *}$ & & & & & & $3.825^{* *}$ \\
$S_{1} L_{0}$ & $(0.131)$ & & & & & $(0.087)$ \\
& $0.530^{* *}$ & $-0.310^{*}$ & -0.010 & 0.084 & -0.136 & 0.119 & $4.001^{* *}$ \\
$S_{1} L_{1}$ & $(0.147)$ & $(0.140)$ & $(0.006)$ & $(0.086)$ & $(0.172)$ & $(0.180)$ & $(0.746)$ \\
$S_{1} L_{1}$ & $0.767^{* *}$ & & & & & & $3.592^{* *}$ \\
& $(0.131)$ & & & & & & $(0.087)$ \\
& $0.738^{* *}$ & -0.211 & -0.009 & -0.031 & -0.079 & 0.099 & $4.510^{* *}$ \\
& $(0.144)$ & $(0.143)$ & $(0.006)$ & $(0.086)$ & $(0.182)$ & $(0.194)$ & $(0.754)$ \\
\hline
\end{tabular}

\section{(b) Differences}

\begin{tabular}{|c|c|c|c|c|c|c|c|}
\hline & Fin. Prof. & Female & Age & Income & $E d u .=2$ & $E d u .=3$ & Constant \\
\hline$S_{0} L_{1}-S_{0} L_{0}$ & $\begin{array}{c}0.068 \\
(0.149)\end{array}$ & & & & & & $\begin{array}{c}-0.215^{*} \\
(0.099)\end{array}$ \\
\hline$S_{0} L_{1}-S_{0} L_{0}$ & $\begin{array}{c}0.066 \\
(0.170)\end{array}$ & $\begin{array}{c}0.078 \\
(0.173)\end{array}$ & $\begin{array}{c}0.000 \\
(0.007)\end{array}$ & $\begin{array}{r}-0.051 \\
(0.111)\end{array}$ & $\begin{array}{c}0.050 \\
(0.222)\end{array}$ & $\begin{array}{c}0.226 \\
(0.225)\end{array}$ & $\begin{array}{c}0.002 \\
(0.947)\end{array}$ \\
\hline$S_{1} L_{0}-S_{0} L_{0}$ & $\begin{array}{c}0.216 \\
(0.128)\end{array}$ & & & & & & $\begin{array}{c}0.180^{*} \\
(0.084)\end{array}$ \\
\hline$S_{1} L_{0}-S_{0} L_{0}$ & $\begin{array}{c}0.212 \\
(0.142)\end{array}$ & $\begin{array}{c}0.171 \\
(0.143)\end{array}$ & $\begin{array}{r}-0.006 \\
(0.006)\end{array}$ & $\begin{array}{c}0.013 \\
(0.081)\end{array}$ & $\begin{array}{r}-0.047 \\
(0.172)\end{array}$ & $\begin{array}{c}0.139 \\
(0.187)\end{array}$ & $\begin{array}{c}0.043 \\
(0.722)\end{array}$ \\
\hline$S_{1} L_{1}-S_{1} L_{0}$ & $\begin{array}{c}0.122 \\
(0.136)\end{array}$ & & & & & & $\begin{array}{r}-0.233^{*} \\
(0.091)\end{array}$ \\
\hline$S_{1} L_{1}-S_{1} L_{0}$ & $\begin{array}{c}0.208 \\
(0.152)\end{array}$ & $\begin{array}{c}0.099 \\
(0.152)\end{array}$ & $\begin{array}{c}0.001 \\
(0.006)\end{array}$ & $\begin{array}{r}-0.115 \\
(0.078)\end{array}$ & $\begin{array}{c}0.057 \\
(0.197)\end{array}$ & $\begin{array}{c}-0.020 \\
(0.201)\end{array}$ & $\begin{array}{c}0.509 \\
(0.700)\end{array}$ \\
\hline$S_{1} L_{1}-S_{0} L_{1}$ & $\begin{array}{c}0.271^{*} \\
(0.130)\end{array}$ & & & & & & $\begin{array}{c}0.162 \\
(0.088)\end{array}$ \\
\hline$S_{1} L_{1}-S_{0} L_{1}$ & $\begin{array}{c}0.354^{*} \\
(0.147)\end{array}$ & $\begin{array}{c}0.192 \\
(0.147)\end{array}$ & $\begin{array}{r}-0.005 \\
(0.006)\end{array}$ & $\begin{array}{r}-0.051 \\
(0.097)\end{array}$ & $\begin{array}{r}-0.040 \\
(0.178)\end{array}$ & $\begin{array}{r}-0.107 \\
(0.182)\end{array}$ & $\begin{array}{c}0.550 \\
(0.825)\end{array}$ \\
\hline
\end{tabular}

Notes: Estimates of the regressions are organized in rows, i.e., the row headings indicate the dependent variable and the column headings indicate the covariates in the model. Fin. Prof. is a dummy variable taking value 0 for the general population sample, and 1 for finance professionals. Female is a dummy variable indicating participants' gender; Age is measured in years. Income is measured in logs of 1,000 SEK (gross) per year. Edu. = 2 denotes a dummy variable for university education smaller or equal to three years; $E d u$. $=3$ indicates a dummy for university education larger than three years. 


\section{Distributional Preferences}

Method. To elicit participants' distributional preferences, we use the Equality Equivalence Test (EET) introduced by Kerschbamer (2015). In our experiment, the EET was implemented using the ready-made software module for oTree by Holzmeister and Kerschbamer (2019). The EET is an experimental procedure to measure and assess individual-level distributional preferences and their intensities based on a multiple choice list format. In particular, the EET requires participants to indicate their preferences in a menu of binary choices, where one of the two alternatives is held constant across the set of decision-making problems. The methodology of the EET stems from a small set of assumptions about the decision-maker's preferences, resulting in a mutually exclusive delineation of different archetypes of distributional concerns (see Kerschbamer, 2015, for details). The parametrization used in the experiment is summarized in Table 2 in the main text. Note that the characterization of preference types and the definition of measures can only be plausibly applied if participants' revealed preferences are transitive and monotone. To avoid multiple switching behavior, the experimental software enforced a single switching point from option "Right" to option "Left" in both lists, as it is frequently applied in risk preference elicitation methods (see, e.g., Holzmeister and Stefan, 2020, for a discussion).

The EET implies a two-player context with two different roles: the role of an "active" player (the decisionmaker) and the role of an "inactive" player. In our experiment, all participants from the finance professionals sample were assigned the "active" role and were informed that the randomly matched ("inactive") player is a participant from the general population. All participants from the general population sample completed the task as the "active" player too, but were informed that they will be randomly assigned the "active" or "inactive" role if the task should be selected for payment. Moreover, participants from the general population were randomized into two conditions: participants were assigned an "inactive" player from (i) the general population or from (ii) the finance professionals pool, which they were informed about in the instructions.

In case the EET was chosen for payout, each participant got randomly assigned one "inactive" playerfrom the finance professionals or the general population sample - once all participants have finished the experiment. For the general population, a second random draw assigned one participant the role of the "active" player, whereas the counterpart was assigned the role of the "inactive" player. Finally, one of the $2 \times 5$ binary decisions was drawn at random and constituted the payment for both the "active" and the "inactive" player.

Based on a participant's switching point in the menu of binary decision problems in the two lists, Kerschbamer (2015) introduced an (ordinal) two-dimensional index to characterize both the archetype and the intensity of the decision-maker's distributional concerns, referred to as the $(x, y)$-score. While the $x$-score characterizes a participant's distributional preferences in the domain of disadvantageous inequality, the $y$-score characterizes a participant's preferences in the domain of advantageous inequality. In particular, the $x$ - and the $y$-score are defined by

$$
x=2.5-\sum_{i=1}^{5} R_{i} \quad \text { and } \quad y=\sum_{i=1}^{5} L_{i}-2.5
$$

where $R_{i}\left(L_{i}\right)$ is an indicator variable taking value one if the participant revealed to prefer option "Right" ("Left") over "Left" ("Right") for some decision problem $i \in\{1,2, \ldots, 5\}$. By construction, positive (negative) scores correspond to benevolent (malevolent) behavior in the domain of disadvantageous and advantageous inequality, respectively.

Depending on whether $x$ and $y$ take values smaller than -0.5 , values in the interval $[-0.5,0.5]$, or values larger than 0.5 , the EET allows to delineate nine different archetypes of distributional preferences: (i) $x>$ $0.5, y>0.5$ : altruistic; (ii) $x>0.5, y \in[-0.5,0.5]$ : kiss-up; (iii) $x>0.5, y<-0.5$ : equality-averse; (iv) 
$x \in[-0.5,0.5], y>0.5:$ maximin; (v) $x \in[-0.5,0.5], y \in[-0.5,0.5]:$ selfish; (vi) $x \in[-0.5,0.5], y<-0.5$ : kick-down; (vii) $x<-0.5, y>0.5$ : inequality-averse; (viii) $x<-0.5, y \in[-0.5,0.5]$ : envious; and (ix) $x<-0.5, y<-0.5$ : spiteful. The magnitude of each of the two scores serves as an ordinal measure of the intensity of distributional concerns in the corresponding inequality domain.

The $(x, y)$-score can be directly translated into lower and upper bounds of parameter intervals in the piece-wise linear utility model (Fehr and Schmidt, 1999; Charness and Rabin, 2002). The utility function in the piece-wise linear model is defined as

$$
u_{\gamma, \sigma}(m, o)=\left\{\begin{array}{lll}
(1-\sigma) m+\sigma o & \text { if } & m \leq o \\
(1-\gamma) m+\gamma o & \text { if } & m>o,
\end{array}\right.
$$

where $m$ and $o$ denote the monetary payoffs of the "active" and "inactive" players, respectively, and $\gamma, \sigma<$ 1 to preserve monotonicity. Thus, a decision-maker's utility is described as a linear combination of the own $(m)$ and the other player's $(o$ ) material payoff, where the weight put on the other's payoff might depend on whether the decision-maker is behind (disadvantageous inequality) or ahead (advantageous inequality). Thus, $\sigma=0, \sigma>0$, and $\sigma<0$ corresponds to individualistic, benevolent, and malevolent behavior in the domain of disadvantages inequality; likewise, $\gamma=0, \gamma>0$, and $\gamma<0$ corresponds to individualistic, benevolent, and malevolent behavior in the domain of advantageous inequality. For a comprehensive discussion on how participants' preferences characterized by the piece-wise linear utility function translate into parameter intervals and the implied relationship to $(x, y)$-scores, refer to Kerschbamer (2015).

As an alternative to parameters in the piece-wise linear model, distributional preferences (and intensities) can be expressed in terms of the decision-maker's willingness to pay for an increase or decrease of the other person's material payoff in both the domain of disadvantageous inequality $\left(w t p^{d}\right)$ and the domain of advantageous inequality $\left(w t p^{a}\right)$. The decision-maker's willingness to pay is defined as

$$
w t p=\frac{\partial_{o} u(m, o)}{\partial_{m} u(m, o)}
$$

-where $\partial_{o} u(m, o)$ and $\partial_{o} u(m, o)$ denote the partial derivatives of $u_{\gamma, \sigma}(m, o)$ with respect to $o$ and $m$, respectively. If $\sigma \geq 0(\gamma \geq 0), w t p^{d}=\sigma(1-\sigma)^{-1}\left(w t p^{a}=\gamma(1-\gamma)^{-1}\right)$ gives the amount in terms of the own material payoff $(m)$ the decision-maker is willing to pay in the domain of disadvantageous inequality (advantageous inequality) in order to increase the other player's material payoff ( $o$ ) by one unit; symmetrically, if $\sigma<0(\gamma<0), w t p^{d}=-\sigma(1+\sigma)^{-1}\left(w t p^{a}=-\gamma(1+\gamma)^{-1}\right)$ gives the amount in terms of the own material payoff $(m)$ the decision-maker is willing to pay in the domain of disadvantageous inequality (advantageous inequality) in order to decrease the other person's material payoff (o) by one unit. Table C1 summarizes how participants' choice behavior translates into $(x, y)$-scores, parameter intervals for $\sigma$ and $\gamma$, as well as intervals of the willingness-to-pay in the domain of disadvantageous $\left(w t p^{d}\right)$ and advantageous inequality $\left(w t p^{a}\right)$ given the parametrization used in our experiment.

For the sake of interpretability, we restrict our attention in all analyses to participants' willingness to pay for an increase/decrease in the other player's monetary payoff (rather than the parameters, $\sigma$ and $\gamma$, in the piece-wise linear utility model). As the intervals of $w t p^{d}$ and $w t p^{a}$ can be directly translated from the intervals for $\sigma$ and $\gamma$, results for the parameters in the piece-wise linear utility model would be qualitatively identical. As a non-parametric robustness test, however, we replicate the analyses for participants' $(x, y)$-scores - results turn out to be highly robust (see below).

Descriptive results. Descriptive results on the fractions of distributional preference archetypes separated for the two subject pools are provided in Figure 2 in the main text. With regards to the treatment variation in the general population subject pool, we do not find evidence that the distribution of archetypes 
Table C1: Non-parametric $(x, y)$-scores, intervals of utility function parameters $\sigma$ and $\gamma$ in the piece-wise linear model, and willingness to pay in the domain of disadvantageous $\left(w t p^{d}\right)$ and advantageous inequality $\left(w t p^{a}\right)$ inferred from participants' choice behavior in the Equality Equivalence Test (EET). $\Sigma R_{i}$ denotes the number of times participants reveal to prefer option "Right" over option "Left;" $l b$ and $u b$ denote the lower and upper bound of the implied intervals for utility function parameters $(\sigma$ and $\gamma)$ and participants' willingness-to-pay $\left(w t p^{d}\right.$ and $\left.w t p^{a}\right)$, respectively.

\begin{tabular}{|c|c|c|c|}
\hline$\Sigma R_{i}$ & $x$ & {$\left[\sigma_{l b}, \sigma_{u b}\right)$} & {$\left[w t p_{l b}^{d}, w t p_{u b}^{d}\right)$} \\
\hline 0 & 2.5 & $0.40, \quad+\infty)$ & $0.67, \quad+\infty)$ \\
\hline 1 & 1.5 & $0.25, \quad 0.40)$ & $0.33, \quad 0.67)$ \\
\hline 2 & 0.5 & $0.00, \quad 0.25)$ & $0.00, \quad 0.33)$ \\
\hline 3 & -0.5 & {$[-0.25, \quad 0.00)$} & {$[-0.33, \quad 0.00)$} \\
\hline 4 & -1.5 & {$[-0.40,-0.25)$} & {$[-0.67,-0.33)$} \\
\hline 5 & -2.5 & $-\infty,-0.40)$ & $-\infty,-0.67)$ \\
\hline
\end{tabular}

\begin{tabular}{|c|c|c|c|}
\hline$\Sigma R_{i}$ & $y$ & {$\left[\gamma_{l b}, \gamma_{u b}\right)$} & {$\left[w t p_{l b}^{a}, w t p_{u b}^{a}\right)$} \\
\hline 0 & -2.5 & $(-\infty,-0.40]$ & $(-\infty,-0.67]$ \\
\hline 1 & -1.5 & $(-0.40,-0.25]$ & $(-0.67,-0.33]$ \\
\hline 2 & -0.5 & $\left(\begin{array}{ll}-0.25, & 0.00\end{array}\right]$ & $\left(\begin{array}{ll}-0.33, & 0.00\end{array}\right]$ \\
\hline 3 & 0.5 & $\left(\begin{array}{ll}0.00, & 0.25]\end{array}\right.$ & $\left(\begin{array}{ll}0.00, & 0.33\end{array}\right]$ \\
\hline 4 & 1.5 & $\left(\begin{array}{ll}0.25, & 0.40\end{array}\right]$ & $\left(\begin{array}{ll}0.33, & 0.67\end{array}\right]$ \\
\hline 5 & 2.5 & $(0.40,+\infty]$ & $(0.67,+\infty]$ \\
\hline
\end{tabular}

among the general population sample differs between the treatment where the second player is assigned from the general population sample and the treatment where the second player is a finance professional (Fischer's exact test: $\chi^{2}(1)=11.446, p=0.178 ; n=395$ ). Likewise, we do not find evidence for differences in the willingness-to-pay between treatments, neither in the domain of disadvantageous inequality (interval regression: $\beta=0.046, z=0.704, p=0.481 ; n=395$ ), nor in the domain of advantageous inequality (interval regression: $\beta=0.152, z=1.446, p=0.148 ; n=395$ ). Therefore, we pool the data from the general population sample in all analyses presented in the main text and below, since our focus in this paper is on differences between finance professionals and the general population-i.e., for participants from the general population we do not condition on whether the randomly assigned "inactive" player is a participant from the general population or from the finance professionals sample.

In the domain of disadvantageous inequality, finance professionals in our sample, on average, are willing to pay $0.104 \mathrm{SEK}(s e=0.027, z=3.776, p<0.001 ; n=298)$ to increase the payoff of the other player by one SEK, whereas the willingness to pay in the general population sample is -0.002 ( $s e=0.033, z=0.052$, $p=0.959 ; n=395) .{ }^{25}$ That is, finance professionals tend to be benevolent towards the other player when falling behind in terms of payoffs, whereas participants from the general population, on average, tend to be only concerned about their own self-interest. In the domain of advantageous inequality, finance professionals, on average, are willing to pay $0.643 \mathrm{SEK}(s e=0.053, z=12.109, p<0.001 ; n=298)$ to increase the second player's material payoff by one SEK; comparable in magnitude, the willingness to pay in the general population sample is 0.661 SEK $(s e=0.060, z=11.103, p<0.001 ; n=395)$. Thus, players from both the finance professionals sample and the general population, on average, tend to be benevolent towards the second player if they are ahead in terms of monetary payoffs.

Supplementary results. Panel (a) in Table C2 reports the main results as graphically illustrated in Figure 2 in the main text, i.e., interval regression estimates of participants' willingness-to-pay in the domain of disadvantageous and advantageous inequality on a dichotomous variable indicating the finance professionals subject pool and adjustments for participants' socio-economic characteristics. With respect to the latter, we find a significant negative effect of the gender indicator on participants' willingnessto-pay in the domain of disadvantageous inequality (but not in the domain of advantageous inequality): When behind in terms of monetary payoffs, females, on average, tend to be significantly less benevolent towards the second player - a result that is in line with the findings reported by Kerschbamer and Müller

\footnotetext{
${ }^{25}$ Since the EET does not allow to infer point estimates of the decision-makers' willingness-to-pay, but rather lower and upper bounds, we estimate the means and (robust) standard errors of the mean of $w t p^{d}$ and $w t p^{a}$ for each of the two subject pools using interval regressions.
} 
(2020). Moreover, we report a v-shaped effect of participants' income on their distributional preferences: in the domain of disadvantageous inequality, participants tend to be more benevolent given higher levels of income; in the domain of advantageous inequality, participants turn out to be more malevolent with higher income levels, again in line with the results reported by Kerschbamer and Müller (2020). ${ }^{26}$ Finally, while Kerschbamer and Müller (2020) report a significantly positive effect of education on benevolence (irrespective of the domain), we only find some anecdotal evidence that benevolence tends to increase with higher educational levels if the decision-maker is ahead in terms of monetary payoffs.

Table C2: Regression analyses of participants' distributional preferences. (a) Interval regressions (organized in rows) of participants' willingness-to-pay in the domain of disadvantageous and advantageous inequality on an indicator variable for the finance professionals subject pool and socio-economic adjustment variables (gender, age, income, and education). (b) Ordered logistic regressions (reported in terms of odds ratios and organized in rows) of participants' $x$ - and $y$-scores (i.e., an ordinal index of distributional preferences in the domain of disadvantageous and advantageous inequality derived from the responses in the Equality Equivalence Test) on the same set of covariates. Robust standard errors are provided in parentheses. $n=693$ in models without adjustments; $n=688$ in models with adjustments. ${ }^{*} p<0.05$, ** $p<0.005$.

\section{(a) Willingness to Pay}

\begin{tabular}{lccccccc}
\hline & Fin. Prof. & Female & Age & Income & Edu. $=2$ & Edu. $=3$ & Constant \\
\hline Disadv. Inequ. & $0.104^{*}$ & & & & & & 0.001 \\
& $(0.042)$ & & & & & $(0.031)$ \\
Disadv. Inequ. & 0.015 & $-0.171^{* *}-0.003$ & $0.102^{* *}$ & 0.034 & 0.059 & -0.493 \\
& $(0.045)$ & $(0.048)$ & $(0.002)$ & $(0.029)$ & $(0.063)$ & $(0.067)$ & $(0.264)$ \\
Adv. Inequ. & 0.086 & & & & & & $0.617^{* *}$ \\
& $(0.071)$ & & & & & $(0.051)$ \\
Adv. Inequ. & 0.131 & 0.076 & 0.004 & $-0.141^{* *}$ & $0.238^{*}$ & 0.189 & $1.331^{* *}$ \\
& $(0.078)$ & $(0.082)$ & $(0.003)$ & $(0.050)$ & $(0.105)$ & $(0.109)$ & $(0.453)$ \\
\hline
\end{tabular}

(b) $(x, y)$-Scores

\begin{tabular}{lccccccc}
\hline & Fin. Prof. & Female & Age & Income & Edu. $=2$ & Edu. $=3$ & Constant \\
\hline Disadv. Inequ. & $1.403^{*}$ & & & & & & $0.562^{* *}$ \\
& $(0.196)$ & & & & & & $(0.060)$ \\
Disadv. Inequ. & 1.041 & $0.551^{* *}$ & $0.988^{*}$ & $1.369^{* *}$ & 1.250 & 1.373 & 2.198 \\
& $(0.156)$ & $(0.088)$ & $(0.006)$ & $(0.127)$ & $(0.268)$ & $(0.313)$ & $(1.922)$ \\
Adv. Inequ. & 1.126 & & & & & & $0.227^{* *}$ \\
& $(0.159)$ & & & & & $(0.029)$ \\
Adv. Inequ. & 1.271 & 1.247 & 1.011 & $0.736^{* *}$ & $1.588^{*}$ & 1.499 & $0.053^{* *}$ \\
& $(0.199)$ & $(0.212)$ & $(0.007)$ & $(0.079)$ & $(0.352)$ & $(0.344)$ & $(0.051)$ \\
\hline
\end{tabular}

Notes: Estimates of the regressions are organized in rows, i.e., the row headings indicate the dependent variable and the column headings indicate the covariates in the model. Fin. Prof. is a dummy variable taking value 0 for the general population sample, and 1 for finance professionals. Female is a dummy variable indicating participants' gender; Age is measured in years. Income is measured in logs of 1,000 SEK (gross) per year. Edu. = 2 denotes a dummy variable for university education smaller or equal to three years; $E d u$. $=3$ indicates a dummy for university education larger than three years.

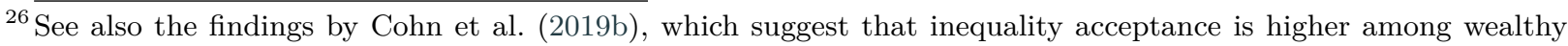
participants.
} 


\section{Trustworthiness}

Descriptive results. Figure D1 shows histograms of the amounts returned by the second movers in the trust game, for each of the potential amounts sent by the first movers. Comparing the distributions using Kolmogorov-Smirnov $(K S)$ tests reveals that only the distributions for 20 SEK and 40 SEK sent by the trustors are significantly different between the pools $(p<0.05) ; K S$ tests of the distributions conditional on first movers sending 60 SEK or more do not statistically differ $(p>0.05)$ between the general population sample and the finance professionals sample.

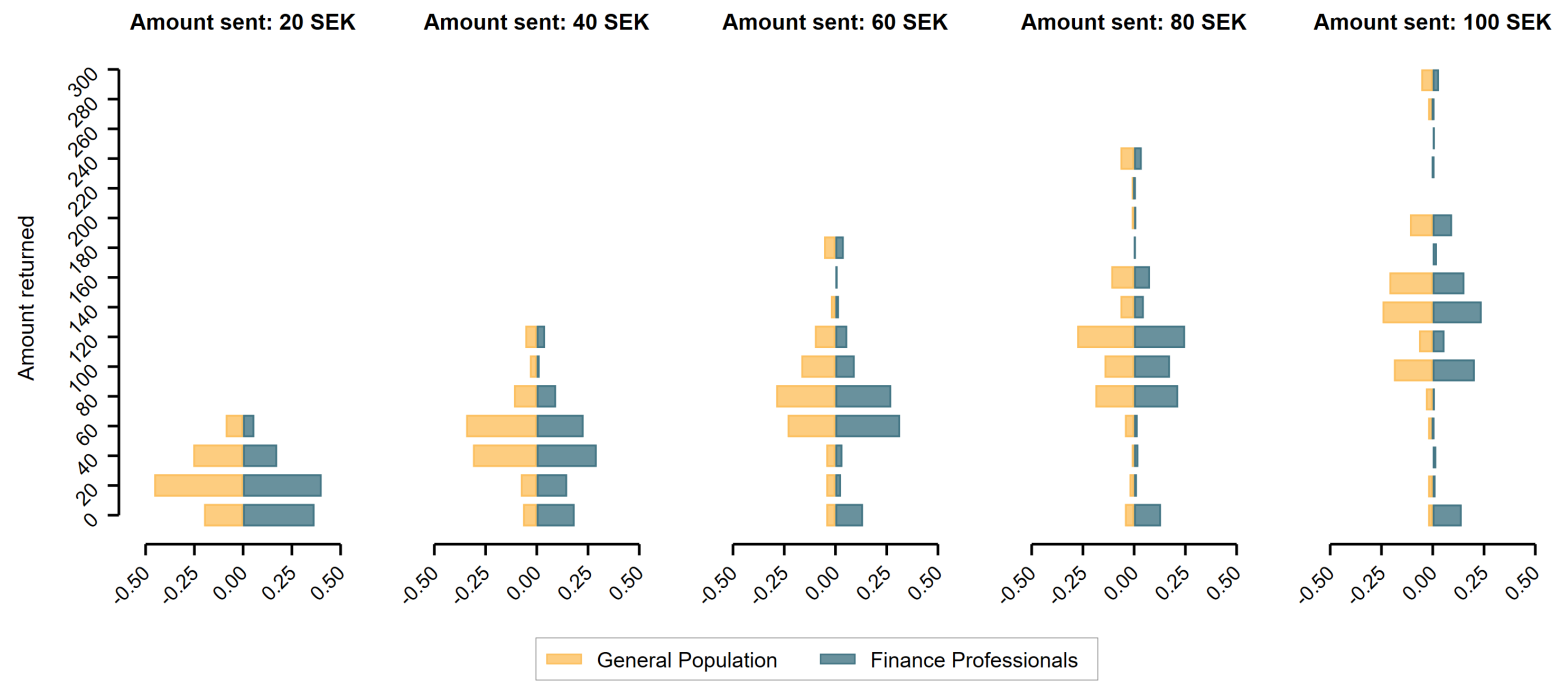

Figure D1: Histograms of amounts returned by the trustees in the (strategy method) trust game for each potential amount sent by the first mover, separated for the general population and the finance professionals sample. $n_{G P}=90, n_{F P}=298$.

Supplementary results. Table D1 shows the results from ordinary least squares regressions of the amount sent by first movers on a dichotomous variable indicating the treatment-i.e., whether the trustee is a participant from the finance professionals or general population sample - and socio-economic adjustment variables. From their endowment of $100 \mathrm{SEK}$, first movers, on average, send 3.1 SEK less to the second mover if the trustor is a participant from the finance professionals sample (as compared to trustors from the general population sample). This difference, however, does not significantly differ from zero. This finding deviates from self-reported evidence found in Holzmeister et al. (2022), where participants indicate lower trust in finance professionals. However, while we are reporting findings from the incentivized investment game, Holzmeister et al. (2022) refer to self-reported survey measures. Sapienza et al. (2013) explain differences in results from survey methods and the investment game by attributing first mover behaviour in a trust game to beliefs and preferences, while survey measures are mainly attributable to beliefs. Moreover, as can be seen in Table D1, we do not find any evidence of systematic effects of gender, age, income, or education on the first movers' behavior in the trust game. ${ }^{27}$

Table D2 focuses on the second mover behavior. In particular, the table reports the main results of ordinary least squares regressions of the amount returned for each potential amount sent by the first mover on a dummy variable indicating the finance professionals sample, as well as the full models including adjustments for participants' socio-economic characteristics (as depicted in Figure 3 in the main text). With respect to socio-economic covariates, we find indicative evidence on age: on average, older participants

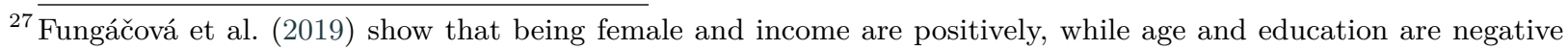
associated with self-reported trust in banks. Please note, however, that they are investigating trust in banks (as institutions), while we examine trust in finance professionals (as individuals). 
Table D1: Regression analyses of the general population sample's trust. This table shows the results of ordinary least squares regressions (organized in rows) of the amount sent by the first mover in the trust game on an indicator variable for the treatment (indicating whether the second mover is a participant from the general population or the finance professionals sample) and socio-economic adjustment variables (gender, age, income, and education). Robust standard errors are provided in parentheses. $n=693$ in models without adjustments; $n=688$ in models with adjustments. ${ }^{*} p<0.05,{ }^{* *} p<0.005$.

\begin{tabular}{lccccccc}
\hline & Fin. Prof. & Female & Age & Income & Edu. $=2$ & Edu. $=3$ & Constant \\
\hline Amount sent & -3.133 & & & & & & $69.333^{* *}$ \\
& $(3.659)$ & & & & & & $(2.924)$ \\
Amount sent & -3.882 & -3.723 & -0.262 & -3.917 & 1.333 & 2.650 & $116.165^{* *}$ \\
& $(3.721)$ & $(3.576)$ & $(0.177)$ & $(2.117)$ & $(4.244)$ & $(4.807)$ & $(18.590)$ \\
\hline
\end{tabular}

Notes: Estimates of the regressions are organized in rows, i.e., the row headings indicate the dependent variable and the column headings indicate the covariates in the model. Fin. Prof. is a dummy variable taking value 0 if the trustor is a participant from the general population sample, and 1 if the trustor is a participant from the finance professionals sample. Female is a dummy variable indicating participants' gender; Age is measured in years. Income is measured in logs of 1,000 SEK (gross) per year. $E d u .=2$ denotes a dummy variable for university education smaller or equal to three years; Edu. $=3$ indicates a dummy for university education larger than three years.

tend to be more trustworthy. However, the effects are only statistically significant for amounts of up to 60 SEK sent by first movers.

Table D2: Regression analyses of participants' trustworthiness. This table shows the results of ordinary least squares regressions (organized in rows) of the amount returned by the second mover in the strategy method trust game (for each amount sent by the first mover) on an indicator variable for the finance professionals subject pool and socio-economic adjustment variables (gender, age, income, and education). Robust standard errors are provided in parentheses. $n=693$ in models without adjustments; $n=688$ in models with adjustments. ${ }^{*} p<0.05,{ }^{* *} p<0.005$.

\begin{tabular}{|c|c|c|c|c|c|c|c|}
\hline & Fin. Prof. & Female & Age & Income & $E d u .=2$ & $E d u .=3$ & Constant \\
\hline Amount returned (20) & $\begin{array}{c}-6.210^{* *} \\
(2.100)\end{array}$ & & & & & & $\begin{array}{c}24.667^{* *} \\
(1.839)\end{array}$ \\
\hline Amount returned (20) & $\begin{array}{r}-4.484^{*} \\
(2.250)\end{array}$ & $\begin{array}{c}4.197^{*} \\
(1.855)\end{array}$ & $\begin{array}{c}0.238^{* *} \\
(0.078)\end{array}$ & $\begin{array}{r}-0.367 \\
(1.329)\end{array}$ & $\begin{array}{r}-1.962 \\
(2.737)\end{array}$ & $\begin{array}{c}-2.538 \\
(2.856)\end{array}$ & $\begin{array}{c}13.146 \\
(11.955)\end{array}$ \\
\hline Amount returned (40) & $\begin{array}{c}-11.542^{* *} \\
(3.369)\end{array}$ & & & & & & $\begin{array}{c}53.556^{* *} \\
(2.885)\end{array}$ \\
\hline Amount returned (40) & $\begin{array}{c}-10.265^{* *} \\
(3.568)\end{array}$ & $\begin{array}{c}5.594 \\
(3.078)\end{array}$ & $\begin{array}{c}0.411^{* *} \\
(0.132)\end{array}$ & $\begin{array}{r}-1.746 \\
(2.157)\end{array}$ & $\begin{array}{c}4.017 \\
(4.150)\end{array}$ & $\begin{array}{c}3.771 \\
(4.351)\end{array}$ & $\begin{array}{c}39.959^{*} \\
(19.436)\end{array}$ \\
\hline Amount returned (60) & $\begin{array}{r}-11.556^{*} \\
(4.702)\end{array}$ & & & & & & $\begin{array}{c}81.556^{* *} \\
(4.050)\end{array}$ \\
\hline Amount returned (60) & $\begin{array}{r}-10.268^{*} \\
(5.137)\end{array}$ & $\begin{array}{c}4.797 \\
(4.239)\end{array}$ & $\begin{array}{c}0.370^{*} \\
(0.183)\end{array}$ & $\begin{array}{r}-3.718 \\
(2.831)\end{array}$ & $\begin{array}{c}1.854 \\
(6.091)\end{array}$ & $\begin{array}{c}7.279 \\
(6.442)\end{array}$ & $\begin{array}{c}86.519^{* *} \\
(26.073)\end{array}$ \\
\hline Amount returned (80) & $\begin{array}{r}-15.967^{*} \\
(6.390)\end{array}$ & & & & & & $\begin{array}{c}114.222^{* *} \\
(5.559)\end{array}$ \\
\hline Amount returned (80) & $\begin{array}{r}-17.464^{*} \\
(6.774)\end{array}$ & $\begin{array}{c}1.482 \\
(5.382)\end{array}$ & $\begin{array}{c}0.392 \\
(0.239)\end{array}$ & $\begin{array}{r}-3.823 \\
(3.742)\end{array}$ & $\begin{array}{c}9.975 \\
(8.025)\end{array}$ & $\begin{array}{l}15.681 \\
(8.326)\end{array}$ & $\begin{array}{c}118.366^{* *} \\
(34.482)\end{array}$ \\
\hline Amount returned (100) & $\begin{array}{c}-21.290^{* *} \\
(7.538)\end{array}$ & & & & & & $\begin{array}{c}144.444^{* *} \\
(6.402)\end{array}$ \\
\hline Amount returned (100) & $\begin{array}{r}-21.402^{*} \\
(8.247)\end{array}$ & $\begin{array}{c}1.168 \\
(6.711)\end{array}$ & $\begin{array}{c}0.393 \\
(0.297)\end{array}$ & $\begin{array}{r}-5.331 \\
(4.478)\end{array}$ & $\begin{array}{c}4.886 \\
(9.762)\end{array}$ & $\begin{array}{c}13.646 \\
(10.192)\end{array}$ & $\begin{array}{l}163.570^{* *} \\
(40.933)\end{array}$ \\
\hline
\end{tabular}

Notes: Estimates of the regressions are organized in rows, i.e., the row headings indicate the dependent variable and the column headings indicate the covariates in the model. Fin. Prof. is a dummy variable taking value 0 for the general population sample, and 1 for finance professionals. Female is a dummy variable indicating participants' gender; Age is measured in years. Income is measured in logs of 1,000 SEK (gross) per year. Edu. = 2 denotes a dummy variable for university education smaller or equal to three years; $E d u$. = 3 indicates a dummy for university education larger than three years. 


\section{E. Personality Traits}

Method. The questions used in the Dark Triad, Competitiveness and the Big-5 inventories are listed in Tables E1-E3. To avoid order effects, the three questionnaires were presented in random order and questions were shuffled within each inventory. All questions in each of the three questionnaires were answered on a Likert scale ranging from 1 ("does not describe me at all") to 7 ("describes me very well"). While half of the questions in the Big-5 inventory are negatively phrased (as indicated in Tables E3-E2), all questions in the Dark Triad and WOFO survey were positively phrased.

The score for each personality trait is constructed as follows. In a first step, negatively phrased items in the Big-5 inventory are reversed in scores. In a second step, answers to each question in each of the three inventories are $z$-standardized across the pooled sample of respondents. In a third step, we aggregate the questions associated with a particular trait, resulting in five scores for the Big-5 inventory, three scores for the Dark Triad survey, and one score for competitiveness. Finally, we $z$-standardize the aggregated score for each personality characteristic. By this means, for each personality trait elicited in our experiment, the score used in the analyses has a mean of zero and a standard deviation of one.

Table E1: Dark Triad personality test by Jonason and Webster (2010). The table summarizes the statements used to assess participants' malevolent qualities of narcissism, Machiavellianism, and psychopathy. All items were answered on a 7-point scale: 1 ("does not describe me at all") to 7 ("describes me very well").

\begin{tabular}{ll}
\hline How much do you agree with the following statements? & Trait (Scoring) \\
\hline I tend to want others to admire me. & Narcissism (+) \\
\hline I tend to want others to pay attention to me. & Narcissism (+) \\
\hline I tend to expect special favors from others. & Narcissism (+) \\
\hline I tend to seek prestige or status. & Narcissism (+) \\
\hline I have used deceit or lied to get my way. & Machiavellianism (+) \\
\hline I tend to manipulate others to get my way. & Machiavellianism (+) \\
\hline I have used flattery to get my way. & Machiavellianism (+) \\
\hline I tend to exploit others towards my own end. & Machiavellianism (+) \\
\hline I tend to lack remorse. & Psychopathy (+) \\
\hline I tend to be callous or insensitive. & Psychopathy $(+)$ \\
\hline I tend to not be too concerned with morality or the morality of my actions. & Psychopathy $(+)$ \\
\hline I tend to be cynical. & Psychopathy $(+)$ \\
\hline
\end{tabular}


Table E2: Competitiveness questionnaire based on the Work and Family Life Orientation questionnaire ( WOFO) proposed by Helmreich and Spence (1978). The table summarizes the statements used to assess participants' competitiveness. All items were answered on a 7-point scale: 1 ("does not describe me at all") to 7 ("describes me very well").

\section{How much do you agree with the following statements?}

It annoys me when other people perform better than I do.

I feel that winning is important in both work and games.

I enjoy working in situations involving competition with others.

I try harder when I am in competition with other people.

It is important to me to perform better than others on a task.

Table E3: Big-5 personality test by Rammstedt and Oliver (2007). The table summarizes the statements used to assess participants' extroversion, agreeableness, conscientiousness, neuroticism, and openness. All items were answered on a 7-point scale: 1 ("does not describe me at all") to 7 ("describes me very well").

\begin{tabular}{ll}
\hline I see myself as someone who... & Trait (Scoring) \\
\hline is outgoing and sociable. & Extroversion $(+)$ \\
\hline is reserved. & Extroversion $(-)$ \\
\hline is generally trusting. & Agreeableness $(+)$ \\
\hline tends to find fault with others. & Agreeableness $(-)$ \\
\hline does a thorough job. & Conscientiousness $(+)$ \\
\hline tends to be lazy. & Conscientiousness $(-)$ \\
\hline gets nervous easily. & Neuroticism $(+)$ \\
\hline is relaxed and handles stress well. & Neuroticism $(-)$ \\
\hline has an active imagination. & Openness $(+)$ \\
\hline has few artistic interests. & Openness $(-)$ \\
\hline
\end{tabular}

Descriptive results. Figure E1 shows the cumulative distributions of the standardized scores on the traits elicited using the Dark Triad, the competitiveness, and the Big-5 inventory, separated for the general population and the finance professionals sample. Apparently, the scores of traits assessed using the Big-5 questionnaire do not significantly differ in location and shape between the two samples (Kolmogorov-Smirnov tests; $p>0.05$ for all five traits). However, we find that the distributions of Dark Triad scores do significantly differ between the two subject pools: finance professionals, on average, score higher on all three socially undesirable personality characteristics (Kolmogorov-Smirnov tests; $p<0.05$ for all three traits). Likewise, we report that finance professionals score significantly higher on the measure of self-reported competitiveness (Kolmogorov-Smirnov test; $p<0.005$ ).

Supplementary results. Table E4 reports the main results of ordinary least squares regressions of the various personality traits on a dummy variable indicating the finance professionals sample, as well as the full models including adjustments for participants' socio-economic characteristics (as depicted in 
(a)

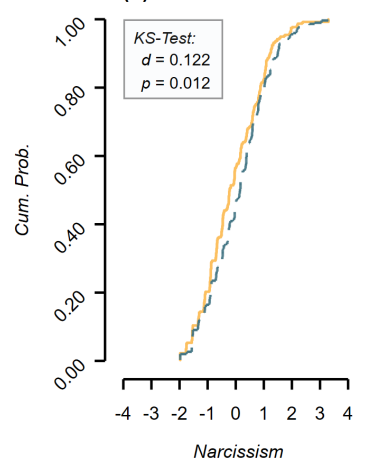

(c)

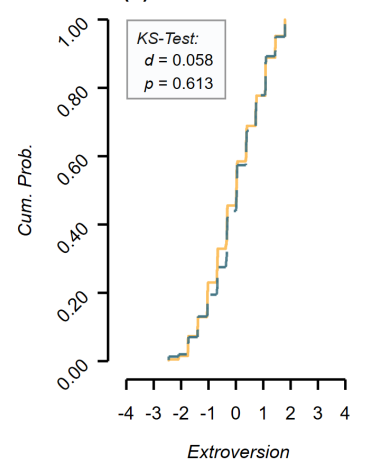

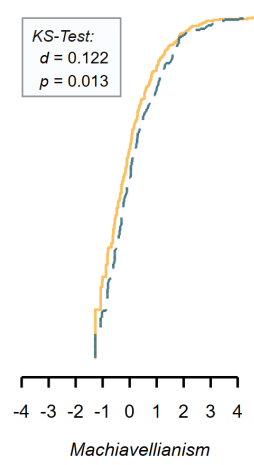

Machiavellianism

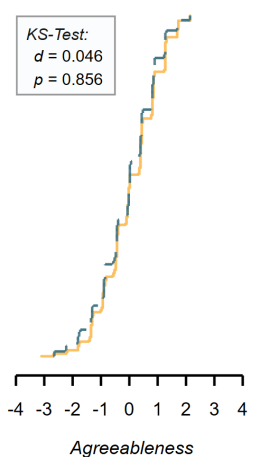

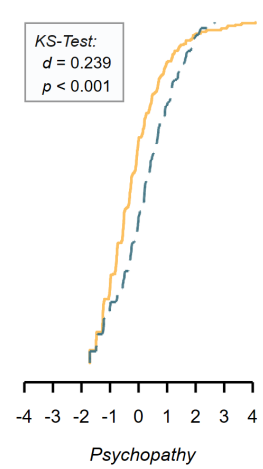

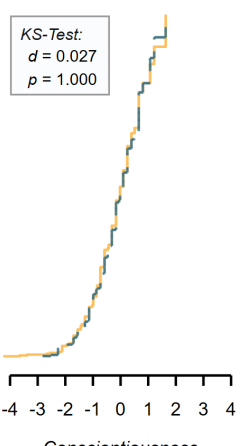

Conscientiousness

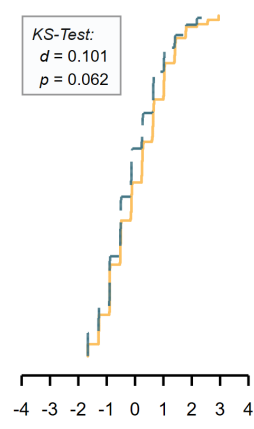

Neuroticism
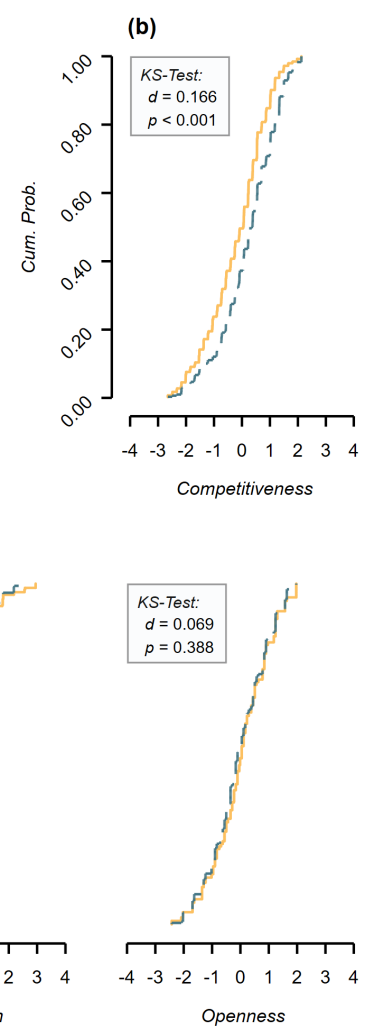

General Population

- - Finance Professionals

Figure E1: Cumulative distributions of the standardized scores on (a) traits elicited using the Dark Triad inventory, (b) the competitiveness sub-scale from the Work and Family Life Orientation (WOFO) survey, and (c) traits assessed using the Big-5 personality test, separated for the general population and the finance professionals sample. Kolmogorov-Smirnov $(K S)$ tests are reported in boxes. $n_{G P}=395$, $n_{F P}=298$.

Figure 4 in the main text).

With respect to socio-economic covariates, we find that gender explains a significant share of the variation in Machiavellianism and psychopathy, which is partly in line the results reported by Jonason and Davis (2018). Consistent with the results by Barlett and Barlett (2015), we find a significantly negative effect of participants' age on all three dark traits. Moreover, we report a significantly positive effect of income on Machiavellianism (see, e.g., Spurk et al., 2016) and a positive effect of education on Narcissism. In line with previous findings (see, e.g., Niederle and Vesterlund, 2011; Gupta et al., 2013), gender turns out being explanatory for the variation in participants' competitiveness scores. Moreover, we find that older participants and participants with less income, on average, turn out being less competitive. With respect to the Big-5 traits, we find that our sample of finance professionals only differs from the general population sample with respect to their scores in neuroticism. Once we control for socio-economic characteristics, the significant difference between pools is considerably attenuated in size due to significant effects of gender, age, and income, which tends to be inline with results reported in the literature (see, e.g., Nyhus and Pons, 2005). 
Table E4: Regression analyses of participants' personality traits. This table shows the results of ordinary least squares regressions (organized in rows) of the standardized scores of (a) traits elicited using the Dark Triad inventory, (b) the competitiveness sub-scale from the Work and Family Life Orientation (WOFO) survey, and (c) traits assessed using the Big-5 personality test on an indicator variable for the finance professionals subject pool and socio-economic adjustment variables (gender, age, income, and education). Robust standard errors are provided in parentheses. $n=693$ in models without adjustments; $n=688$ in models with adjustments. ${ }^{*} p<0.05,{ }^{* *} p<0.005$.

\section{(a) Dark Triad}

\begin{tabular}{|c|c|c|c|c|c|c|c|}
\hline & Fin. Prof. & Female & Age & Income & $E d u .=2$ & $E d u .=3$ & Constant \\
\hline Narcisism (std.) & $\begin{array}{c}0.195^{*} \\
(0.081)\end{array}$ & & & & & & $\begin{array}{c}-0.084 \\
(0.053)\end{array}$ \\
\hline Narcisism (std.) & $\begin{array}{c}0.047 \\
(0.086)\end{array}$ & $\begin{array}{r}-0.134 \\
(0.086)\end{array}$ & $\begin{array}{c}-0.019^{* *} \\
(0.004)\end{array}$ & $\begin{array}{c}0.106 \\
(0.055)\end{array}$ & $\begin{array}{l}0.457^{* *} \\
(0.112)\end{array}$ & $\begin{array}{c}0.361^{* *} \\
(0.116)\end{array}$ & $\begin{array}{r}-0.266 \\
(0.471)\end{array}$ \\
\hline Machiavellianism (std.) & $\begin{array}{c}0.229^{* *} \\
(0.081)\end{array}$ & & & & & & $\begin{array}{r}-0.098 \\
(0.052)\end{array}$ \\
\hline Machiavellianism (std.) & $\begin{array}{c}0.074 \\
(0.084)\end{array}$ & $\begin{array}{c}-0.310^{* *} \\
(0.081)\end{array}$ & $\begin{array}{c}-0.019^{* *} \\
(0.003)\end{array}$ & $\begin{array}{c}0.192^{* *} \\
(0.048)\end{array}$ & $\begin{array}{c}0.106 \\
(0.107)\end{array}$ & $\begin{array}{r}-0.041 \\
(0.115)\end{array}$ & $\begin{array}{c}-0.452 \\
(0.420)\end{array}$ \\
\hline Psychopathy (std.) & $\begin{array}{c}0.389^{* *} \\
(0.080)\end{array}$ & & & & & & $\begin{array}{c}-0.167^{* *} \\
(0.053)\end{array}$ \\
\hline Psychopathy (std.) & $\begin{array}{c}0.271^{* *} \\
(0.084)\end{array}$ & $\begin{array}{c}-0.723^{* *} \\
(0.079)\end{array}$ & $\begin{array}{c}-0.012^{* *} \\
(0.003)\end{array}$ & $\begin{array}{c}0.036 \\
(0.056)\end{array}$ & $\begin{array}{c}-0.029 \\
(0.112)\end{array}$ & $\begin{array}{r}-0.118 \\
(0.115)\end{array}$ & $\begin{array}{c}1.114^{*} \\
(0.498)\end{array}$ \\
\hline
\end{tabular}

\section{(b) Competitiveness}

\begin{tabular}{lccccccc}
\hline & Fin. Prof. & Female & Age & Income & Edu. $=2$ & Edu. $=3$ & Constant \\
\hline Competitiveness (std.) & $0.399^{* *}$ & & & & & & $-0.172^{* *}$ \\
& $(0.080)$ & & & & & & $(0.053)$ \\
Competitiveness (std.) & $0.232^{*}$ & $-0.198^{*}$ & $-0.016^{* *}$ & $0.226^{* *}$ & 0.086 & 0.091 & $-1.132^{*}$ \\
& $(0.084)$ & $(0.087)$ & $(0.004)$ & $(0.054)$ & $(0.120)$ & $(0.124)$ & $(0.460)$ \\
\hline
\end{tabular}

\section{(c) Big Five}

\begin{tabular}{|c|c|c|c|c|c|c|c|}
\hline & Fin. Prof. & Female & Age & Income & $E d u .=2$ & $E d u .=3$ & Constant \\
\hline Extroversion (std.) & $\begin{array}{c}0.042 \\
(0.077)\end{array}$ & & & & & & $\begin{array}{c}-0.018 \\
(0.051)\end{array}$ \\
\hline Extroversion (std.) & $\begin{array}{c}0.009 \\
(0.083)\end{array}$ & $\begin{array}{c}0.226^{*} \\
(0.083)\end{array}$ & $\begin{array}{c}0.002 \\
(0.003)\end{array}$ & $\begin{array}{c}0.130^{* *} \\
(0.044)\end{array}$ & $\begin{array}{c}0.027 \\
(0.107)\end{array}$ & $\begin{array}{r}-0.017 \\
(0.114)\end{array}$ & $\begin{array}{c}-1.483^{* *} \\
(0.397)\end{array}$ \\
\hline Agreeableness (std.) & $\begin{array}{c}-0.110 \\
(0.077)\end{array}$ & & & & & & $\begin{array}{c}0.047 \\
(0.050)\end{array}$ \\
\hline Agreeableness (std.) & $\begin{array}{r}-0.145 \\
(0.081)\end{array}$ & $\begin{array}{c}0.140 \\
(0.081)\end{array}$ & $\begin{array}{c}0.019^{* *} \\
(0.003)\end{array}$ & $\begin{array}{r}-0.012 \\
(0.045)\end{array}$ & $\begin{array}{c}0.098 \\
(0.108)\end{array}$ & $\begin{array}{c}0.315^{*} \\
(0.114)\end{array}$ & $\begin{array}{c}-0.986^{*} \\
(0.406)\end{array}$ \\
\hline Conscientiousness (std.) & $\begin{array}{c}0.017 \\
(0.076)\end{array}$ & & & & & & $\begin{array}{r}-0.007 \\
(0.052)\end{array}$ \\
\hline Conscientiousness (std.) & $\begin{array}{c}0.054 \\
(0.081)\end{array}$ & $\begin{array}{c}0.175^{*} \\
(0.083)\end{array}$ & $\begin{array}{c}0.004 \\
(0.003)\end{array}$ & $\begin{array}{c}0.026 \\
(0.048)\end{array}$ & $\begin{array}{r}-0.172 \\
(0.104)\end{array}$ & $\begin{array}{r}-0.121 \\
(0.111)\end{array}$ & $\begin{array}{r}-0.517 \\
(0.444)\end{array}$ \\
\hline Neuroticism (std.) & $\begin{array}{c}-0.195^{*} \\
(0.076)\end{array}$ & & & & & & $\begin{array}{c}0.084 \\
(0.051)\end{array}$ \\
\hline Neuroticism (std.) & $\begin{array}{r}-0.114 \\
(0.080)\end{array}$ & $\begin{array}{c}0.329^{* *} \\
(0.083)\end{array}$ & $\begin{array}{c}-0.013^{* *} \\
(0.003)\end{array}$ & $\begin{array}{c}-0.163^{* *} \\
(0.048)\end{array}$ & $\begin{array}{c}0.187 \\
(0.103)\end{array}$ & $\begin{array}{c}0.272^{*} \\
(0.107)\end{array}$ & $\begin{array}{l}1.328^{* *} \\
(0.436)\end{array}$ \\
\hline Openness (std.) & $\begin{array}{r}-0.070 \\
(0.077)\end{array}$ & & & & & & $\begin{array}{c}0.030 \\
(0.051)\end{array}$ \\
\hline Openness (std.) & $\begin{array}{c}-0.098 \\
(0.082)\end{array}$ & $\begin{array}{c}0.167^{*} \\
(0.082)\end{array}$ & $\begin{array}{c}0.000 \\
(0.003)\end{array}$ & $\begin{array}{c}0.006 \\
(0.048)\end{array}$ & $\begin{array}{c}0.225^{*} \\
(0.109)\end{array}$ & $\begin{array}{c}0.213 \\
(0.111)\end{array}$ & $\begin{array}{c}-0.422 \\
(0.414)\end{array}$ \\
\hline
\end{tabular}

Notes: Estimates of the regressions are organized in rows, i.e., the row headings indicate the dependent variable and the column headings indicate the covariates in the model. Fin. Prof. is a dummy variable taking value 0 for the general population sample, and 1 for finance professionals. Female is a dummy variable indicating participants' gender; Age is measured in years. Income is measured in logs of $1,000 \mathrm{SEK}$ (gross) per year. Edu. $=2$ denotes a dummy variable for university education smaller or equal to three years; $E d u$. $=3$ indicates a dummy for university education larger than three years. 


\section{F. Comparison Between Job Functions}

Finance professionals in our experiment were sampled from three different job codes (as categorized by SCB): "2413" (financial analysts and investment advisers; $n=203$ ), "2414" (traders and fund managers; $n=48$ ), and "3311" (financial brokers; $n=48$ ). In an exploratory analysis, we test whether participants from different job functions within the finance industry differ systematically from one another with respect to the economic preferences and personality traits elicited in our experiment in pairwise comparisons. The results are tabulated in Table F1.

As indicated by the pairwise comparisons in Table F1, we do not find evidence that finance professionals in different job functions differ systematically in terms of attitudes towards risk, distributional concerns, or trustworthiness. With respect to personality traits, the comparisons suggest that financial brokers ("3311") in our sample tend to be more Machiavellian than financial analysts/investment advisers ("2413") and traders/fund managers ("2414"); likewise, the pairwise tests suggest that financial brokers are more competitive than financial analysts/investment advisers (but not traders/fund managers). In terms of the remaining Dark Triad traits (Narcissism and Psychopathy) and the Big-5 traits, we do not find evidence for differences between the different job functions. Yet, given the small sample sizes for two of the three job codes, we call for caution when interpreting the results, as the tests are only moderately powered $(\geq 80 \%$ ) for medium-sized to large effect sizes. 
Table F1: Comparison of the various preferences and traits elicited in the experiment between the three job functions finance professionals were sampled from. The table reports means and standard deviations, separated for each job code, and differences in means and $t$-statistics (based on two-sample $t$-tests) in pairwise comparisons between job codes: "2413" (financial analysts and investment advisers; $n=203$ ), "2414" (traders and fund managers; $n=48$ ), and "3311" (financial brokers; $n=48$ ). ${ }^{*} p<0.05$, ** $p<0.005$.

\begin{tabular}{|c|c|c|c|c|c|c|}
\hline & \multicolumn{3}{|c|}{ Job Codes } & \multicolumn{3}{|c|}{ Pairwise Differences [t-Statistic] } \\
\hline & 2413 & 2414 & 3311 & $\begin{array}{c}2413 \text { vs. } \\
2414\end{array}$ & $\begin{array}{c}2413 \text { vs. } \\
3311\end{array}$ & $\begin{array}{c}2414 \text { vs. } \\
3311\end{array}$ \\
\hline \multicolumn{7}{|l|}{ Attitudes Towards Risk: } \\
\hline$S_{0} L_{0}$ (Risk Tolerance) & $\begin{array}{c}4.005 \\
(1.765)\end{array}$ & $\begin{array}{c}4.042 \\
(1.738)\end{array}$ & $\begin{array}{c}4.404 \\
(1.624)\end{array}$ & $\begin{array}{c}-0.037 \\
{[-0.130]}\end{array}$ & $\begin{array}{c}-0.399 \\
{[-1.418]}\end{array}$ & $\begin{array}{c}-0.363 \\
{[-1.050]}\end{array}$ \\
\hline$S_{1} L_{0}-S_{0} L_{0}$ (Skewness Tolerance) & $\begin{array}{c}0.498 \\
(1.552)\end{array}$ & $\begin{array}{c}0.208 \\
(1.890)\end{array}$ & $\begin{array}{c}0.149 \\
(1.945)\end{array}$ & $\begin{array}{l}0.289 \\
{[1.111]}\end{array}$ & $\begin{array}{c}0.349 \\
{[1.319]}\end{array}$ & $\begin{array}{c}0.059 \\
{[0.151]}\end{array}$ \\
\hline$S_{0} L_{1}-S_{0} L_{0}$ (Loss Tolerance) & $\begin{array}{c}-0.103 \\
(2.016)\end{array}$ & $\begin{array}{c}-0.313 \\
(1.776)\end{array}$ & $\begin{array}{c}-0.170 \\
(1.698)\end{array}$ & $\begin{array}{c}0.209 \\
{[0.660]}\end{array}$ & $\begin{array}{c}0.067 \\
{[0.210]}\end{array}$ & $\begin{array}{c}-0.142 \\
{[-0.399]}\end{array}$ \\
\hline \multicolumn{7}{|l|}{ Distributional Preferences: } \\
\hline$W T P:$ Disadvantageous Inequality & $\begin{array}{c}0.092 \\
(0.216)\end{array}$ & $\begin{array}{c}0.124 \\
(0.178)\end{array}$ & $\begin{array}{l}0.060 \\
(0.234)\end{array}$ & $\begin{array}{c}-0.032 \\
{[-0.855]}\end{array}$ & $\begin{array}{c}0.031 \\
{[0.791]}\end{array}$ & $\begin{array}{c}0.064 \\
{[1.337]}\end{array}$ \\
\hline$W T P$ : Advantageous Inequality & $\begin{array}{c}0.119 \\
(0.215)\end{array}$ & $\begin{array}{c}0.126 \\
(0.201)\end{array}$ & $\begin{array}{c}0.085 \\
(0.195)\end{array}$ & $\begin{array}{c}-0.006 \\
{[-0.126]}\end{array}$ & $\begin{array}{c}0.034 \\
{[0.711]}\end{array}$ & $\begin{array}{c}0.041 \\
{[0.692]}\end{array}$ \\
\hline \multicolumn{7}{|l|}{ Trustworthiness: } \\
\hline$\%$ Returned if Trustor Sent 20SEK & $\begin{array}{c}0.309 \\
(0.298)\end{array}$ & $\begin{array}{c}0.292 \\
(0.254)\end{array}$ & $\begin{array}{c}0.319 \\
(0.303)\end{array}$ & $\begin{array}{c}0.017 \\
{[0.365]}\end{array}$ & $\begin{array}{c}-0.010 \\
{[-0.216]}\end{array}$ & $\begin{array}{c}-0.027 \\
{[-0.480]}\end{array}$ \\
\hline$\%$ Returned if Trustor Sent $40 \mathrm{seK}$ & $\begin{array}{c}0.351 \\
(0.255)\end{array}$ & $\begin{array}{c}0.351 \\
(0.213)\end{array}$ & $\begin{array}{c}0.348 \\
(0.269)\end{array}$ & $\begin{array}{r}0.000 \\
{[-0.003]}\end{array}$ & $\begin{array}{c}0.003 \\
{[0.073]}\end{array}$ & $\begin{array}{c}0.003 \\
{[0.064]}\end{array}$ \\
\hline$\%$ Returned if Trustor Sent $60 \mathrm{SEK}$ & $\begin{array}{c}0.389 \\
(0.230)\end{array}$ & $\begin{array}{c}0.380 \\
(0.187)\end{array}$ & $\begin{array}{c}0.397 \\
(0.263)\end{array}$ & $\begin{array}{c}0.010 \\
{[0.266]}\end{array}$ & $\begin{array}{c}-0.008 \\
{[-0.209]}\end{array}$ & $\begin{array}{c}-0.018 \\
{[-0.375]}\end{array}$ \\
\hline$\%$ Returned if Trustor Sent 80 SEK & $\begin{array}{c}0.410 \\
(0.228)\end{array}$ & $\begin{array}{c}0.406 \\
(0.189)\end{array}$ & $\begin{array}{c}0.411 \\
(0.260)\end{array}$ & $\begin{array}{c}0.003 \\
{[0.097]}\end{array}$ & $\begin{array}{c}-0.002 \\
{[-0.044]}\end{array}$ & $\begin{array}{c}-0.005 \\
{[-0.110]}\end{array}$ \\
\hline$\%$ Returned if Trustor Sent 100SEK & $\begin{array}{c}0.408 \\
(0.228)\end{array}$ & $\begin{array}{c}0.424 \\
(0.206)\end{array}$ & $\begin{array}{c}0.409 \\
(0.258)\end{array}$ & $\begin{array}{c}-0.016 \\
{[-0.438]}\end{array}$ & $\begin{array}{c}-0.001 \\
{[-0.017]}\end{array}$ & $\begin{array}{c}0.015 \\
{[0.316]}\end{array}$ \\
\hline \multicolumn{7}{|l|}{ Personality Traits: } \\
\hline Dark Triad: Narcissism & $\begin{array}{c}0.064 \\
(1.063)\end{array}$ & $\begin{array}{c}0.177 \\
(1.067)\end{array}$ & $\begin{array}{c}0.251 \\
(1.095)\end{array}$ & $\begin{array}{c}-0.113 \\
{[-0.663]}\end{array}$ & $\begin{array}{c}-0.188 \\
{[-1.084]}\end{array}$ & $\begin{array}{c}-0.074 \\
{[-0.335]}\end{array}$ \\
\hline Dark Triad: Machiavellianism & $\begin{array}{c}0.078 \\
(1.077)\end{array}$ & $\begin{array}{c}0.010 \\
(0.955)\end{array}$ & $\begin{array}{c}0.482 \\
(1.159)\end{array}$ & $\begin{array}{c}0.068 \\
{[0.399]}\end{array}$ & $\begin{array}{c}-0.404^{*} \\
{[-2.286]}\end{array}$ & $\begin{array}{c}-0.472^{*} \\
{[-2.168]}\end{array}$ \\
\hline Dark Triad: Psychopathy & $\begin{array}{c}0.147 \\
(1.047)\end{array}$ & $\begin{array}{c}0.360 \\
(0.976)\end{array}$ & $\begin{array}{c}0.401 \\
(1.080)\end{array}$ & $\begin{array}{c}-0.213 \\
{[-1.282]}\end{array}$ & $\begin{array}{c}-0.254 \\
{[-1.491]}\end{array}$ & $\begin{array}{c}-0.041 \\
{[-0.196]}\end{array}$ \\
\hline Competitiveness (WOFO) & $\begin{array}{c}0.149 \\
(1.029)\end{array}$ & $\begin{array}{c}0.266 \\
(1.051)\end{array}$ & $\begin{array}{c}0.525 \\
(1.009)\end{array}$ & $\begin{array}{c}-0.117 \\
{[-0.707]}\end{array}$ & $\begin{array}{c}-0.376^{*} \\
{[-2.265]}\end{array}$ & $\begin{array}{c}-0.259 \\
{[-1.223]}\end{array}$ \\
\hline Big-5: Extroversion & $\begin{array}{c}0.072 \\
(0.973)\end{array}$ & $\begin{array}{c}-0.023 \\
(1.028)\end{array}$ & $\begin{array}{c}-0.134 \\
(1.054)\end{array}$ & $\begin{array}{c}0.095 \\
{[0.603]}\end{array}$ & $\begin{array}{c}0.206 \\
{[1.288]}\end{array}$ & $\begin{array}{c}0.111 \\
{[0.519]}\end{array}$ \\
\hline Big-5: Agreeableness & $\begin{array}{c}-0.003 \\
(1.014)\end{array}$ & $\begin{array}{c}-0.108 \\
(0.833)\end{array}$ & $\begin{array}{c}-0.275 \\
(1.150)\end{array}$ & $\begin{array}{c}0.105 \\
{[0.667]}\end{array}$ & $\begin{array}{c}0.272 \\
{[1.615]}\end{array}$ & $\begin{array}{c}0.167 \\
{[0.811]}\end{array}$ \\
\hline Big-5: Conscientiousness & $\begin{array}{c}0.059 \\
(0.962)\end{array}$ & $\begin{array}{c}-0.236 \\
(0.990)\end{array}$ & $\begin{array}{l}0.048 \\
(0.960)\end{array}$ & $\begin{array}{l}0.295 \\
{[1.899]}\end{array}$ & $\begin{array}{c}0.010 \\
{[0.067]}\end{array}$ & $\begin{array}{c}-0.284 \\
{[-1.421]}\end{array}$ \\
\hline Big-5: Neuroticism & $\begin{array}{c}-0.146 \\
(0.965)\end{array}$ & $\begin{array}{c}-0.153 \\
(0.839)\end{array}$ & $\begin{array}{c}0.082 \\
(1.044)\end{array}$ & $\begin{array}{c}0.007 \\
{[0.044]}\end{array}$ & $\begin{array}{c}-0.228 \\
{[-1.437]}\end{array}$ & $\begin{array}{c}-0.235 \\
{[-1.209]}\end{array}$ \\
\hline Big-5: Openness & $\begin{array}{c}0.029 \\
(0.978)\end{array}$ & $\begin{array}{c}-0.264 \\
(1.017)\end{array}$ & $\begin{array}{c}-0.108 \\
(1.020)\end{array}$ & $\begin{array}{c}0.293 \\
{[1.850]}\end{array}$ & $\begin{array}{c}0.137 \\
{[0.860]}\end{array}$ & $\begin{array}{c}-0.155 \\
{[-0.743]}\end{array}$ \\
\hline
\end{tabular}

Notes: Attitudes towards risk: $S_{i}$ and $L_{i}$ are indicator functions for skewness and losses, respectively; e.g., $S_{1} L_{0}$ indicates the task with skewed lottery outcomes in the gain domain. Accordingly, risk tolerance, skewness tolerance, and loss tolerance are proxied by $S_{0} L_{0}, S_{1} L_{0}-S_{0} L_{0}$, and $S_{0} L_{1}-S_{0} L_{0}$, respectively. Distributional preferences: WTP indicates the midpoint of the interval of participants' willingness-to-pay to increase the other player's material payoff by one unit. Since the interval bounds may can take a value of positive or negative infinity, the midpoint is not defined for all participants. For the domain of disadvantageous inequality, sample sizes are 157 ("2413"), 38 ("2414"), and 38 ("3311"); for the domain of advantageous inequality, sample size are 91 ("2413"), 21 ("2414"), and 24 ("3311"), respectively. Trustworthiness: means and standard deviations refer to the percentage of the available amount (i.e., the tripled amount sent by the trustor) returned by the trustee. Personality traits: all personality traits are standardized scores (i.e., have a mean of
0 and a standard deviation of 1 in the overall sample). 


\section{G. Correlational Analysis}

As an exploratory analysis, we present correlations between the various preferences and traits elicited in the experiment, separated for the two subject pools, in Table G1. In particular, each cell in the lower triangular matrix in Table G1 shows Pearson correlation coefficients between the respective variables for the finance professionals sample in the top row, and those for the general population sample in the bottom row. The upper triangular matrix reports the (absolute) $z$-statistics corresponding to the differences between correlations coefficients between subject pools. To test the null hypothesis that the correlation between variable $x$ and $y$ for the sample of finance professionals $(F P), r_{x y}^{F P}$, does not differ from the correlation between variable $x$ and $y$ for the general population sample $(G P), r_{x y}^{G P}$, we resort to the Fisher $z^{\prime}$ transformation (see, e.g., Cohen et al., 2003). In particular, the $z^{\prime}$ transformation of a correlation coefficient $r$ is given by $z^{\prime}=1 / 2 \cdot[\ln (1+r)-\ln (1-r)]$, with the corresponding standard error $s e_{z^{\prime}}=(n-3)^{-0.5}$. To examine whether the correlation coefficients of the two sample systematically differ, we test the equivalent $H_{0}: z_{F P}^{\prime}-z_{G P}^{\prime}=0$ by determining the normal curve deviate

$$
z=\frac{z_{F P}^{\prime}-z_{G P}^{\prime}}{\sqrt{\left.\left(n_{F P}-3\right)^{-1}+\left(n_{G P}-3\right)^{-1}\right)}} .
$$

We find similar correlation patterns in both subject pools. For instance, risk tolerance and loss tolerance are significantly positively correlated in both subject pools (lower triangular matrix) and these correlation coefficients do not differ between subject pools (upper triangular matrix). As another example, we find similar correlation coefficients across the Big-5 personality traits dimensions in both subject pools. ${ }^{28}$ Again, these correlation coefficients do not differ across subject pools. We consider these findings in the correlation matrix exploratory in nature and the vast number of tests implies the possibility of false positives. Therefore, we refrain from discussing individual significant differences between the subject pools.

\footnotetext{
${ }^{28}$ In line with Becker et al. (2012) we find little evidence for association between economic preferences and personality traits.
} 


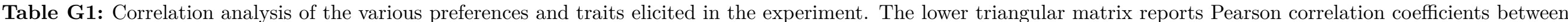

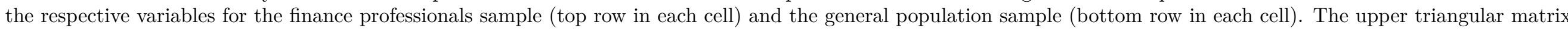

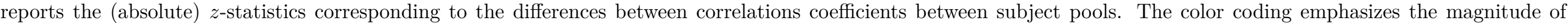

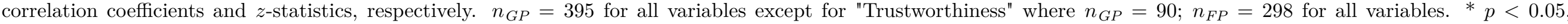
** $p<0.005$.

\begin{tabular}{|c|c|c|c|c|c|c|c|c|c|c|c|c|c|c|c|}
\hline $\begin{array}{l}\text { Risk } \\
\text { Tolerance }\end{array}$ & 0.155 & 0.215 & 0.186 & 0.624 & 1.215 & 0.233 & 1.930 & 0.647 & 0.090 & 0.231 & 0.316 & 0.768 & 0.603 & 1.059 & 1.160 \\
\hline $\begin{array}{l}0.538^{* *} \\
0.530^{* \star *}\end{array}$ & $\begin{array}{c}\text { Loss } \\
\text { Tolerance }\end{array}$ & 0.850 & 0.774 & 0.836 & 0.558 & 0.646 & 1.260 & 0.142 & 0.948 & 0.140 & 1.102 & 1.615 & 0.670 & 0.294 & $2.204^{*}$ \\
\hline $\begin{array}{l}0.511^{* *} \\
0.499^{* *}\end{array}$ & $\begin{array}{l}0.365^{* *} \\
0.420^{* *}\end{array}$ & $\begin{array}{l}\text { Skewness } \\
\text { Tolerance }\end{array}$ & 0.510 & 1.082 & 0.304 & 0.290 & 0.994 & 0.418 & 0.193 & 1.212 & 1.581 & 1.612 & 1.623 & 1.671 & 0.082 \\
\hline $\begin{array}{l}0.099 \\
0.113^{*}\end{array}$ & $\begin{array}{l}-0.084 \\
-0.025\end{array}$ & $\begin{array}{l}-0.011 \\
-0.051\end{array}$ & $x$-Score & $2.101^{*}$ & 0.223 & 1.211 & 0.942 & 0.011 & 0.886 & 1.840 & 0.544 & 0.524 & 0.056 & 1.063 & 1.128 \\
\hline-0.028 & 0.023 & $\begin{array}{l}0.045 \\
-0.039\end{array}$ & $\begin{array}{l}0.037 \\
-0.125^{*}\end{array}$ & $y$-Score & 1.304 & 1.438 & 1.088 & 0.971 & 0.439 & 0.296 & 0.041 & 1.411 & 0.962 & 0.941 & 0.908 \\
\hline-0.086 & 0.036 & -0.074 & 0.052 & $0.139^{*}$ & & & & & & & & & & & \\
\hline 0.062 & -0.032 & -0.037 & 0.079 & -0.019 & Trustworthiness & 0.239 & 1.504 & 1.787 & $3.103^{* *}$ & 0.059 & 1.585 & 1.046 & 1.685 & 0.124 & 1.900 \\
\hline 0.022 & -0.046 & -0.044 & 0.067 & -0.056 & 0.013 & Dishonesty & $2.905^{* *}$ & $2.540^{*}$ & 1.727 & 1.933 & 0.270 & 1.239 & 0.687 & 0.255 & 1.919 \\
\hline 0.004 & -0.095 & -0.021 & -0.026 & 0.055 & 0.042 & Lishonesty & & & & & & & & & \\
\hline $0.161^{*}$ & 0.019 & 0.025 & 0.073 & $-0.116^{*}$ & $-0.134^{*}$ & $0.170^{\star * *}$ & Dark Triad: & 0,483 & 0.571 & 1398 & 0.688 & 1053 & 0.102 & 1719 & 1115 \\
\hline 0.014 & -0.078 & -0.051 & $0.145^{* *}$ & -0.033 & 0.049 & -0.052 & Narcissism & & & & & & & 1.719 & \\
\hline 0.096 & -0.010 & -0.047 & $0.134^{*}$ & -0.100 & -0.108 & $0.222^{* *}$ & $0.510^{* *}$ & Dark Triad: & 0.009 & 0.782 & 0371 & $2224^{*}$ & 0735 & 0181 & $2526 *$ \\
\hline 0.047 & 0.001 & -0.079 & $0.134^{*}$ & -0.026 & 0.109 & 0.030 & $0.537^{* *}$ & Machiavellianism & 0.009 & 0.102 & - & $2.224^{\prime}$ & 0.105 & 0.101 & $2.520^{\circ}$ \\
\hline 0.085 & -0.066 & 0.008 & $0.197^{* *}$ & -0.066 & $-0.184^{* *}$ & $0.117^{*}$ & $0.329^{* *}$ & $0.443^{* *}$ & Dark Triad: & 0160 & 1281 & 0288 & (2) & 120 & 1058 \\
\hline 0.078 & 0.007 & -0.007 & $0.131^{*}$ & $-0.100^{*}$ & 0.190 & -0.016 & $0.289 * *$ & $0.443^{* *}$ & Psychopathy & 0.109 & 1.281 & 0.288 & 0.740 & 1.264 & 1.958 \\
\hline-0.041 & -0.004 & $-0.119^{*}$ & $-0.130^{*}$ & -0.039 & -0.036 & $0.127^{*}$ & $0.219^{* *}$ & 0.085 & $-0.138^{*}$ & Big Five: & rer & 0720 & nes & (25) & 0.567 \\
\hline-0.023 & -0.015 & -0.026 & 0.011 & -0.016 & -0.029 & -0.021 & $0.114^{*}$ & 0.025 & $-0.125^{*}$ & Extroversion & 0.595 & 0.169 & 0.445 & 0.519 & 0.557 \\
\hline 0.007 & 0.047 & 0.094 & 0.015 & $0.127^{*}$ & 0.069 & -0.026 & $-0.204^{* *}$ & $-0.264^{* * *}$ & $-0.278^{* \star}$ & $0.237^{* \star}$ & Big Five: & $2655 \mathrm{k}$ & 1178 & 0.509 & $2888^{\star *}$ \\
\hline-0.017 & -0.038 & -0.028 & -0.027 & $0.130^{*}$ & -0.123 & -0.005 & $-0.152^{\star \star}$ & $-0.238^{* *}$ & $-0.366^{* *}$ & $0.279^{* \star}$ & Agreeableness & 2.055 & 1.118 & .000 & 2.000 \\
\hline-0.026 & 0.067 & -0.074 & -0.093 & -0.103 & -0.032 & 0.076 & -0.078 & $-0.162^{* *}$ & $-0.216^{* *}$ & 0.016 & -0.053 & Big Five: & 000 & 1486 & 0 \\
\hline-0.085 & -0.057 & 0.050 & -0.053 & 0.005 & -0.158 & -0.019 & $-0.158^{* \star}$ & $-0.323^{* *}$ & $-0.237^{* *}$ & 0.075 & $0.150^{* *}$ & ascientioust & 0.000 & 1.486 & 0.300 \\
\hline-0.038 & -0.002 & -0.057 & -0.030 & -0.005 & $0.120^{*}$ & 0.043 & $0.120^{*}$ & 0.053 & -0.112 & $-0.207^{* *}$ & $-0.242^{* *}$ & $-0.114^{*}$ & Big Five: & 1038 & 0746 \\
\hline 0.008 & 0.050 & 0.068 & -0.025 & 0.069 & -0.085 & -0.010 & $0.128^{*}$ & $0.109^{*}$ & -0.056 & $-0.174^{* *}$ & $-0.155^{* *}$ & $-0.114^{*}$ & Neuroficism & 1.038 & 0.146 \\
\hline-0.067 & -0.022 & $-0.134^{*}$ & -0.039 & 0.033 & 0.058 & -0.001 & 0.032 & 0.070 & $-0.159^{*}$ & $0.114^{*}$ & -0.057 & 0.040 & 0.073 & Big Five: & \\
\hline 0.014 & 0.001 & -0.006 & 0.043 & $0.105^{*}$ & 0.042 & 0.019 & $0.163^{* *}$ & 0.056 & -0.063 & 0.075 & -0.018 & -0.075 & $0.152^{* x}$ & Openness & 0.628 \\
\hline $0.140^{*}$ & 0.097 & -0.012 & 0.085 & $-0.179 * *$ & $-0.160^{*}$ & 0.104 & $0.513^{* *}$ & $0.411^{* *}$ & $0.295^{* *}$ & 0.042 & $-0.324^{* *}$ & 0.034 & 0.016 & 0.033 & nestitive \\
\hline 0.051 & -0.073 & -0.006 & $0.170^{* *}$ & $-0.110^{*}$ & 0.070 & -0.044 & $0.447^{* *}$ & $0.237^{* *}$ & $0.152^{* *}$ & 0.085 & $-0.113^{*}$ & 0.058 & -0.042 & -0.015 & , \\
\hline
\end{tabular}

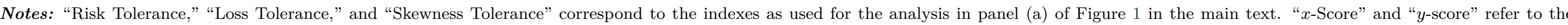

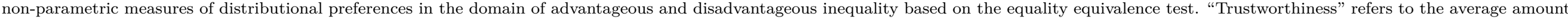

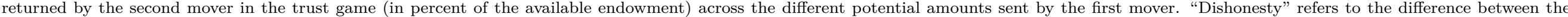
reported number of pips and the actual number of pips. Variables indicated with "Dark Triad," "Big Five," and "Competitiveness" are $z$-standardized scores of the respective traits. 
University of Innsbruck - Working Papers in Economics and Statistics

Recent Papers can be accessed on the following webpage:

https://www.uibk.ac.at/eeecon/wopec/

2021-03 Martin Holmen, Felix Holzmeister, Michael Kirchler, Matthias Stefan, Erik Wengström: Economic Preferences and Personality Traits Among Finance Professionals and the General Population

2021-02 Christian König-Kersting: On the Robustness of Social Norm Elicitation

2021-01 Laura Hueber, Rene Schwaiger: Debiasing Through Experience Sampling: The Case of Myopic Loss Aversion. 


\title{
University of Innsbruck
}

\section{Working Papers in Economics and Statistics}

2021-03

Martin Holmen, Felix Holzmeister, Michael Kirchler, Matthias Stefan, Erik Wengström

Economic Preferences and Personality Traits Among Finance Professionals and the General Population

\begin{abstract}
Given their relevance for the financial well-being of many private investors and the economy as a whole, the behavior and personality traits of finance professionals have come under scrutiny. To better understand characteristics of the main protagonists of the finance industry, we run artefactual field experiments with finance professionals and a sample of the working population to investigate differences across industry-relevant economic preferences and personality traits. We report that finance professionals differ along several economic preferences and personality traits. However, we show that after adjusting for socio-economic characteristics many differences disappear and finance professionals only remain slightly more risk tolerant, less trustworthy, show a slightly increased level of psychopathy, and are more competitive than comparable participants. To shed light on the question why finance professionals differ from employees in other industries, we run an survey on experts with hiring experience to investigate whether they consider industry selection, self-selection, and imprinting by industry norms as explanatory for the observed subject pool differences. We find that experts conceive all three channels to be relevant, which is consistent with the assumption that the three channels are mutually correlated.
\end{abstract}

ISSN 1993-4378 (Print)

ISSN 1993-6885 (Online) 